\title{
Upper Pleistocene Human Remains From Vindija Cave, Croatia, Yugoslavia
}

\author{
MILFORD H. WOLPOFF, FRED H. SMITH, MIRKO MALEZ, JAKOV \\ RADOVČÍ, AND DARKO RUKAVINA \\ Department of Anthropology, University of Michigan, Ann Arbor, Michigan \\ 48109 (M.H.W.), Department of Anthropology, University of Tennessee, \\ Knoxville, Tennessee 37916 (F.H.S.), and Institute for Paleontology and \\ Quaternary Geology, Yugoslav Academy of Sciences and Arts, 41000 Zagreb, \\ Yugoslavia (M.M., J.R., D.R.)
}

\author{
KEY WORDS Vindija, Neandertal, South Central Europe, \\ Modern Homo sapiens origin, Evolution
}

\begin{abstract}
Human remains excavated from Vindija cave include a large although fragmentary sample of late Mousterian-associated specimens and a few additional individuals from the overlying early Upper Paleolithic levels. The Mousterian-associated sample is similar to European Neandertals from other regions. Compared with earlier Neandertals from south central Europe, this sample evinces evolutionary trends in the direction of Upper Paleolithic Europeans. Compared with the western European Neandertals, the same trends can be demonstrated, although the magnitude of difference is less, and there is a potential for confusing temporal with regional sources of variation. The early Upper Paleolithic-associated sample cannot be distinguished from the Mousterian-associated hominids. We believe that this site provides support for Hrdlička's "Neandertal phase" of human evolution, as it was originally applied in Europe.
\end{abstract}

The Pannonian Basin and surrounding valleys of south central Europe have yielded a large and significant series of Upper Pleistocene fossil hominids (e.g. Jelínek, 1969) as well as extensive evidence of their cultural behavior (e.g. Valoch, 1968). One of the most informative sub-regions in this area is the semi-mountainous Hrvatsko Zagorje in northwestern Croatia (Yugoslavia), where several localities (caves, rockshelters, and open sites) have already yielded important information concerning the evolution of Upper Pleistocene hominids and their culture, in addition to patterns of faunal and climatic change (Malez, 1978b,c,d). The sites of Krapina, Velika Pećina, and Veternica are especially significant because each has produced remains of Upper Pleistocene fossil hominids. The hominids from Krapina are unquestionably archaic European Homo sapiens (Neandertals) and have contributed greatly to our conception of the morphology, variation, and population structure of European Neandertals (Gorjanović-Kramberger, 1906; Smith, $1976 \mathrm{~b}$; Wolpoff, 1979). The specimens from Velika Pećina and Veternica are clearly modern Homo sapiens, with the former specimen being the earliest chronometrically dated Upper Paleolithic-associated hominid in Europe (Smith, 1976a).

This report presents a detailed comparative description of a sample of fossil hominids recently excavated at the cave of Vindija, (Malez et al., 1980; Wolpoff, 1980), as well as a brief discussion of the stratigraphy and chronology of the site.

\section{THE VINDIJA SITE}

Vindija cave is located approximately $55 \mathrm{~km}$ NNE of Zagreb, $20 \mathrm{~km} \mathrm{~W}$ of Varaždin, and not far from the regional administrative center of Ivanec. It is situated in what is best termed semi-mountainous terrain, within a $50 \mathrm{~km}$ radius of all three previously mentioned hominid-bearing sites. The cave is formed in Tortonian conglomerated limestone and consists of a single large chamber measuring some $50 \mathrm{~m}$ in length, $28 \mathrm{~m}$ in maximum breadth, and over $10 \mathrm{~m}$ in height. Its mouth opens at an elevation

\footnotetext{
Address reprint requests to Dr. M.H. Wolpoff, Department of Anthropology, University of Michigan, Ann Arbor, Michigan 48109

Received January 30, 1980; accepted September 24, 1980
} 
of $275 \mathrm{~m}$ above sea level on the southwestern side of Križnjak peak and commands an excellent view of a small valley below. An average of approximately $8 \mathrm{~m}$ of stratified Pleistocene deposit was originally present in the cave, in addition to approximately $2 \mathrm{~m}$ of post-Pleistocene deposits. Most of the post-Pleistocene deposits were investigated and removed during earlier excavations by Vuković (see bibliography in Malez, 1978a,b). Renewed excavation began at Vindija in 1974 (Malez, 1975) and has concentrated on the Upper Pleistocene sediments.

\section{STRATIGRAPHY}

Detailed discussion of the Vindija stratigraphy is neither possible nor appropriate here. The most detailed stratigraphic consideration is found in Malez and Rukavina (1979), but additional analyses are presented in Malez and Rukavina (1975), Rukavina (1978), and Malez (1978c).

The Vindija deposits (Fig. 1) are divided into 13 primary stratigraphic units. The lower 10 , $\mathrm{D}-\mathrm{M}$ ( $\mathrm{M}$ is not shown in Fig. 1), are Pleistocene, while the upper 3 are post-Pleistocene and will not be described. Three of the primary Pleistocene units $(F, G, K)$ require further subdivision and are referred to here as complexes.

Level $\mathrm{D}$, the youngest of the Pleistocene deposits, is a yellowish-brown, fine sandy sediment with a loess-like habitus. It ranges from 50 to $150 \mathrm{~cm}$ in thickness and probably is aeolian in origin. Level $\mathrm{E}$ is a grayish sandy sediment with numerous small $(<2 \mathrm{~cm})$, often corroded pieces of limestone. Complex $F$ is further divided into 5 subunits and varies between approximately 30 and $150 \mathrm{~cm}$ in thickness. The complex is basically characterized by the presence of angular pieces of limestone of various sizes ranging from blocks to small particles in a sandy sediment. One distinct level, $\mathrm{Fd} / \mathrm{s}$, consists of a pasty loam with no rock fragments. It should be noted that the precise composition of the $F$ complex varies in different parts of the cave, due to varying sedimentological patterning.

Complex $\mathrm{G}$ is made up of generally sandy sediment, containing only rather small (often corroded) stone fragments, but in some places larger, angular fragments are present as well. However, there are markedly fewer stone fragments than in levels $E, F$, and $H$. Thickness varies between approximately 60 and $150 \mathrm{~cm}$, and near the mouth of the cave the units of complex $\mathrm{G}$ are disturbed by cryoturbation (Malez and Rukavina, 1975), Five distinct

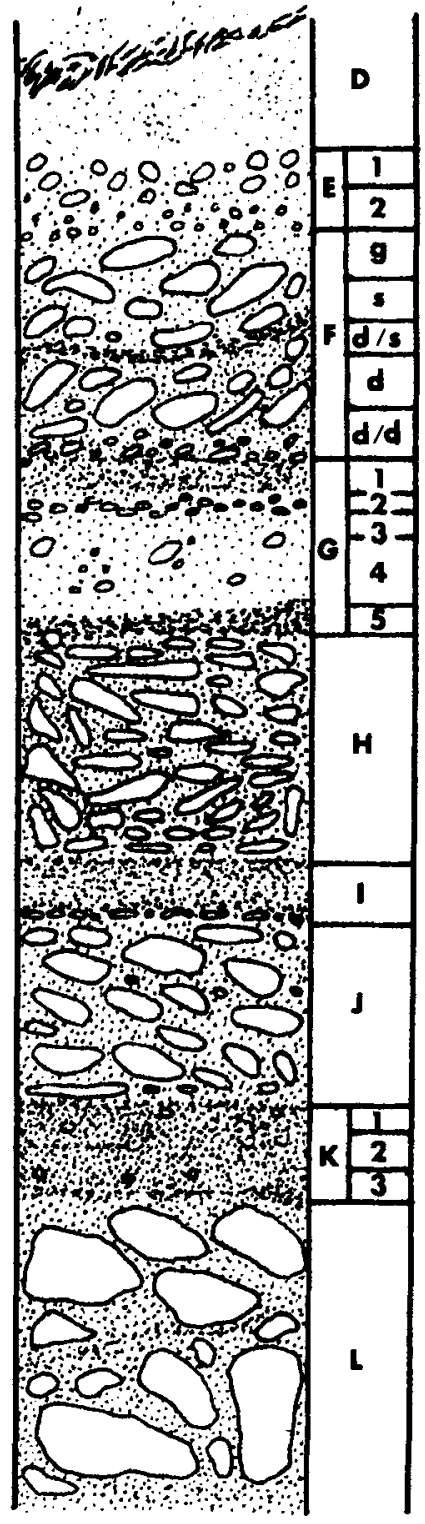

Fig. 1. Schematic profile of the Pleistocene deposits of Vindija. Thickness and descriptions of individual strata are given in the text, but relative thickness of the strata is accurate. Revised from Malez and Rukavina (1979).

units are recognized within complex G. Level $\mathrm{G}_{1}$, the superior-most of these, is a very distinctive, reddish-colored clay or loam. It contains very few stone fragments, and those that are present are rounded, markedly corroded, and colored by manganese. Level $\mathrm{G}_{1}$ is from 8 to $20 \mathrm{~cm}$ thick and is present throughout the cave. 
Level $\mathrm{G}_{2}$ is a grayish clay measuring 1 to $30 \mathrm{~cm}$ in thickness. It contains numerous small stones and is present only in certain portions of the cave. Level $\mathrm{G}_{3}$ is sandy sediment, loess-like in habitus, and varies between approximately 10 to $30 \mathrm{~cm}$ in thickness. It is quite distinctive in color (light green) and contains relatively few rocks, which are usually rounded and corroded. Level $\mathrm{G}_{4}$ is a darker green deposit, again of loess-like habitus, but containing more rock fragments. Level $G_{5}$ is a sandy deposit in which rocks are rare and, if present, corroded.

Level $\mathrm{H}$ is a thick $(100-200 \mathrm{~cm})$ layer of sandy deposits containing numerous large, angular rocks exhibiting no evidence of corrosion. When freshly exposed, these sediments are olive to grayish-yellow in color. Level $I$ is a sandy deposit, reddish-brown in color, and ranging from 30 to $100 \mathrm{~cm}$ in thickness. Few rocks are present, and these tend to be corroded. Level $J$ is a sandy deposit containing a considerable density of large rock fragments. This layer is olive-gray when the sediment is fresh and varies between 100 and $200 \mathrm{~m}$ in thickness. Complex $\mathrm{K}$ is divisible into 3 subunits. Level $\mathrm{K}_{1}$ is sandy, dark brown in color with many small corroded limestone fragments. $K_{2}$ is similar but contains virtually no rock fragments, while $\mathrm{K}_{3}$ is sandy and dark yellow to brown in color. Cryoturbation processes are observable in both $K_{2}$ and $K_{3}$. Level $L$ is characterized by the presence of very large blocks of limestone as well as smaller fragments. There is a bone breccia approximately $50 \mathrm{~cm}$ below contact with level $\mathrm{K}$. Below this, the sediments are compacted and hard. Level $L$ (and also $M$ ) is still largely unexcavated.

\section{ARCHAEOLOGY, CORRELATION, AND DATING}

The Pleistocene strata at Vindija contained rich Paleolithic assemblages (approximately 1,000 pieces in level $\mathrm{G}$ alone), which are still under study. Preliminary analysis of the lithic artifacts reveals that levels $\mathrm{G}_{2}$ through $\mathrm{K}$ contain remains of the Mousterian. Some of the upper Mousterian levels (e.g. $\mathrm{G}_{3}$ ) do contain elements most commonly associated with early Upper Paleolithic, but this phenomenon is common in the late Mousterian of central Europe (Valoch, 1968) and does not alter the basic Mousterian character of the assemblage. A single split-based bone point is the only diagnostic artifact from the early Upper Paleolithic level $G_{1}$, and it is from the top of the stratum. This indicates, though not conclusively, that level $G_{1}$ is Aurignacian. According to Valoch (personal communication), the lithic material in $G_{1}$ is neither Szeletian nor Mousterian. Above $G_{1}$, the remaining Pleistocene strata $(D$, E, F) contain only Upper Paleolithic assemblages. Level $D$ is characterized by a Gravettian assemblage, while the artifacts from $\mathbf{E}$ and $\mathbf{F}$ appear to represent the Aurignacian.

Based on the nature of the deposits described above, levels G, H, J, and complex $F$ (and also L) represent long periods of cold. This is suggested chiefly by the presence of large angular blocks resulting from deterioration of cave walls by frost action. So-called paleosoils, which are most likely the result of mild or warm climates and therefore of chemical decomposition, are seen in levels $G_{1}, G_{5}$, I, and the $K$ complex. The habitus of the $K$ complex sediment is very similar to the Riss-Würm levels at Krapina (Gorganovic-Kramberger, 1913), and the fauna are similar (particularly the presence of Merck's rhinocerous). Based on these factors, its stratigraphic location, and archeological content, it appears reasonable to correlate the $\mathrm{K}$ complex to the Riss-Würm interglacial. The strata below the $K$ complex ( $L$ and $M$ ) are tentatively correlated to the Riss.

Although charcoal is preserved in several levels from the cave, only one radiocarbon date has been obtained thus far. This date, associated with the Aurignacian at Vindija, is from a charcoal sample taken at the $F_{d}$ and $F_{d} / d$ interface and approximates 26,970 years B.P. (Malez, 1978c; 349). It is comparable to other Aurignacian dates from south central Europe (Frayer, 1978; Movius, 1960), and thus helps secure the upper end of the Vindija Pleistocene sequence.

Level $G_{1}$, which is tentatively considered an early Aurignacian level, appears to represent a warm period and is quite similar (Valoch, personal communication) to the layers representing the Podhradem interstadial in the Moravian Karst (Musil and Valoch, 1966). This would make sense relative to its position between a definitely Mousterian level $\left(\mathrm{G}_{2}\right)$ and a definitely Aurignacian one $\left(F_{d} / d\right)$ and the date of ca. 34,000 B.P. for probably early Aurignacian at Velika Pećina (Malez, 1978d; Smith, 1976a).

If one then compares the entire Vindija Upper Plesitocene sequence to that determined for the not-too-distant Moravian Karst (Musil and Valoch, 1966; Valoch, 1968), also on the Pannionian Basin rim, there appears to be a reasonably acceptable correlation. We believe that the data strongly support this correlation, based independently on both quaternary geology and archaeology. 


\section{THE HOMINIDS}

The hominid remains from Vindija fall into three stratigraphic samples. The most recent consists of some 34 specimens excavated from level D. These specimens exhibit a modern Homo sapiens morphology in every relevant respect and are not described here. Their morphology is consistent with their date of younger than 27,000 B.P. The second sample consists of four specimens from $G_{1}$ and three isolated teeth from the $\mathrm{F}$ complex. These are discussed here as Aurignacian-associated hominids. The remainder of the hominids (except for a few without certain provenience) are derived from level $G_{3}$. These hominids are clearly representatives of archaic European Homo sapiens (Neandertals) and are the stratigraphically earliest hominid sample yet excavated at Vindija. Based on the correlations discussed above, level $\mathrm{G}_{3}$ would be encompassed within the Lower Würm stadial, which dates between approximately 40,000 and 59,000 years B.P. according to Valoch (1968). It is not possible to ascertain a more precise radiometric date for the Vindija $\mathrm{G}_{3}$ hominids at present. Valoch, who examined some of the archeological and faunal materials from $\mathrm{G}_{3}$, believes this level to represent the latest portion of the Lower Würm stadial.

Regardless of their exact position within the Lower Würm stadial, it is quite certain that they date later than the Riss-Würm interglacial and are therefore chronologically more recent than the remains from the "Homo" zone at Krapina, if not more recent than virtually all of the Krapina specimens.

In the following sections the hominids are described by morphological area and by numeric order within each area. Beside each specimen number are references to the appropriate figure(s) and the level designation $\left(G_{3}\right.$, $\mathrm{G}_{1}, \mathrm{~F}_{\mathrm{d}}$ ). Absence of a level designation means that provenience is not conclusively known. These specimens are most likely from level $\mathrm{G}_{3}$. Summary sections conclude the descriptions of each skeletal region represented, and general comparisons and conclusions are presented at the end of the report.

\section{Maxillas}

\section{Vi 225 Right maxilla (Fig. 2): $\mathrm{G}_{3}$}

This edentulous specimen is broken at the midline and posteriorly at the middle of the $\mathrm{M}^{2}$ socket. It includes the lower portion of the lateral nasal aperture border and the base of the maxillary sinus. The base of a prominent nasal spine is also present, but the spine itself is bro- ken away. The nasal margin is sharply defined. A double line forms the margin resulting in what appears to be an inner and outer lower nasal border (the same morphology as in the $\mathrm{Vi}$ 259 maxilla but less distinctly expressed). The lines are separated by a shallow groove, but there is a transverse ridge connecting them beginning on the lower line at the midline and extending superiorly and laterally to the upper line. Nasal breadth is determined by doubling the distance from the right lateral nasal margin to the midline. It is narrow compared with Neandertals from Krapina and western Europe. Compared with the later sample, the nasal breadth is 3.2 standard deviations below the mean (Table 1). It is smaller than the single nasal breadth known for Krapina.

The maxillary sinus is in a low position relative to the molar roots. Because of the break in this region exposing the sinus, there is not enough of the maxilla left to determine whether there was a canine fossa. A slight buttress surrounds the canine root. Unfortunately, the size of the canine socket cannot be accurately measured because the labial wall is broken away. At $7.5 \mathrm{~mm}$ below the alveolar margin, the breadth of the socket is $11.3 \mathrm{~mm}$, and it is likely that the canine was quite large. The socket extends at least $20 \mathrm{~mm}$ superiorly from the alveolar margin. Length and breadth of the $\mathrm{I}^{1}$ and $\mathrm{I}^{2}$ sockets are, respectively, $8.2 \times 8.8 \mathrm{~mm}$ and $7.0 \times 9.5 \mathrm{~mm}$. The suggestion that the lateral incisor was broader than the central provides a similarity to the condition in some (although not all) western European Neandertals. While the anterior teeth were lost, dimensions incorporating the anterior tooth row (such as prosthion-post canine, Table 1) show no evidence of reduction from the Neandertal condition. In fact, this distance is greater than in any known Neandertal maxilla.

The subnasal area is uncurved, dropping straight downward from the nasal border. Alveolar height is quite small, lying 2.5 standard deviations below the western European Neandertal mean as well as below the range from Krapina (Table 1). Alveolar height is one of the features reflecting marked sexual dimorphism in the western European Neandertals. The Neandertal sex ratio for this feature $(\mathrm{M} / \mathrm{F})$ is $121 \%$. This would suggest that the $\mathrm{Vi} 225$ maxilla (as well as the Vi 259 maxilla, see below) is female. Even if so, the specimen is markedly smaller than western European Neandertal females like Gibraltar 1 and La Ferrassie 2.

The palate is shallow compared with Neandertals. Although variation in Neandertals is great enough for the difference not to attain 

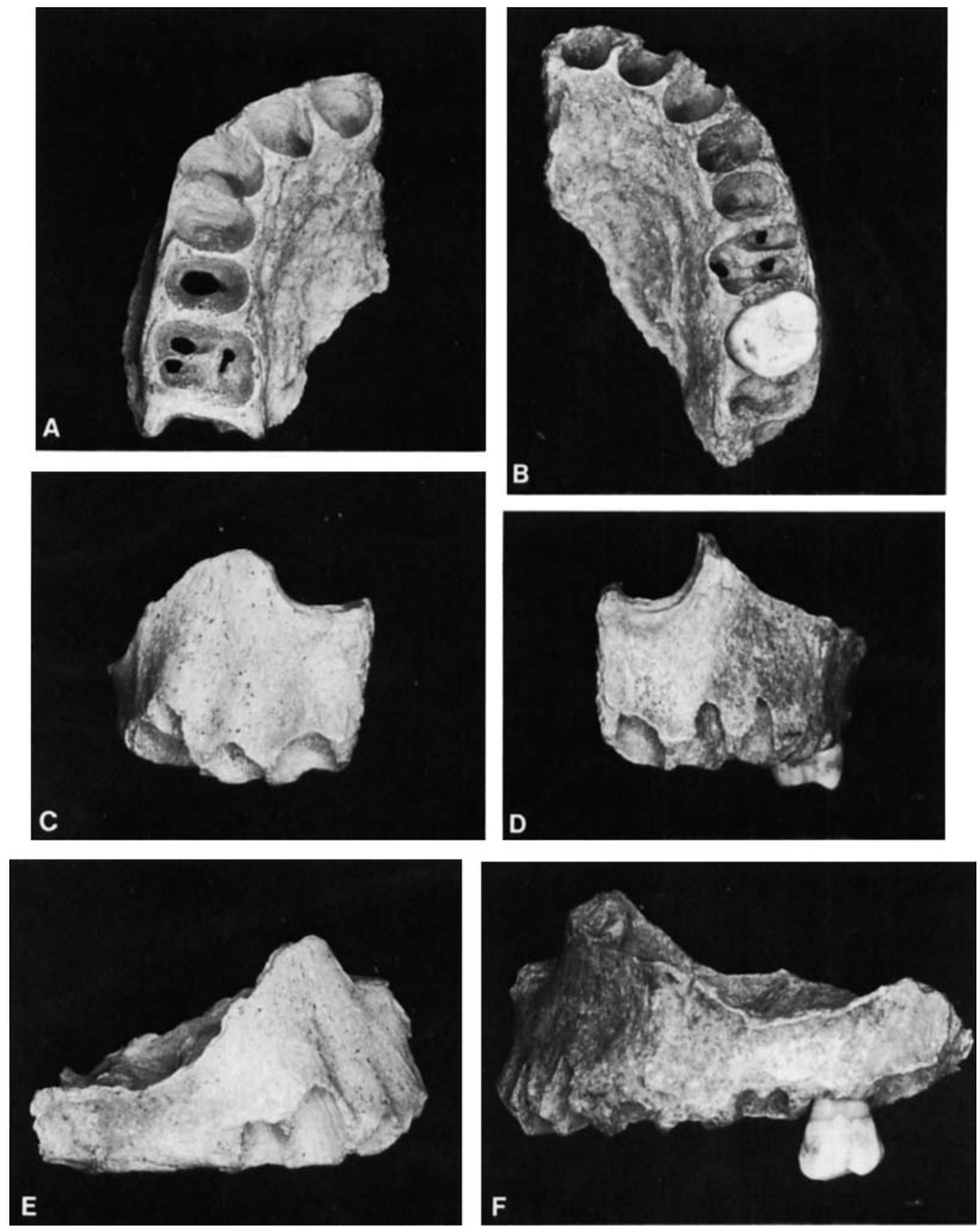

Fig. 2. Maxillae Vi 225 (left) and Vi 259 in inferior, frontal, and lateral views. Specimens are shown to the same approximate scale. Note the relative size of the incisor roots, the morphology of the lower nasal margin, and the low position of the maxillary sinus.

statistical significance, measurements of the palate wall height between $\mathrm{P}^{4}$ and $\mathrm{M}^{1}$, and $\mathrm{M}^{1}$ and $\mathrm{M}^{2}$ are well below the Neandertal mean and at the lower end or below the range (Table 1). There is no palatine torus.
Vi 259 Left maxilla (Fig. 2): $\mathrm{G}_{3}$

The fragment is broken almost identically to 225 , except for the fact that the entire alveolar margin and an $\mathbf{M}^{2}$ remain. Vindija 259 is the 
TABLE 1. Maxillary dimensions in millimeters for the Vindija, Krapina, and European Neandertal maxillae

\begin{tabular}{|c|c|c|c|c|c|}
\hline & \multirow{2}{*}{$\begin{array}{l}\text { Alveolar } \\
\text { height }\end{array}$} & \multirow{2}{*}{$\begin{array}{c}\text { Nasal } \\
\text { breadth }\end{array}$} & \multicolumn{2}{|c|}{$\begin{array}{c}\text { Internal } \\
\text { palate wall } \\
\text { height }\end{array}$} & \multirow{2}{*}{$\begin{array}{l}\text { Prosthion } \\
\text { to } \\
\text { post-canine }\end{array}$} \\
\hline & & & $\mathrm{P}^{4} / \mathrm{M}^{1}$ & $\mathbf{M}^{1} / \mathbf{M}^{2}$ & \\
\hline \multicolumn{6}{|l|}{ Vindija } \\
\hline 225 & 17.5 & 28.5 & 8.4 & 10.5 & 27.3 \\
\hline 259 & 16.3 & 26.2 & 9.6 & 9.6 & 24.3 \\
\hline \multicolumn{6}{|l|}{ Krapina } \\
\hline E & 22.5 & 30.5 & & & \\
\hline $\mathrm{F}$ & 24.2 & & & & \\
\hline \multicolumn{6}{|c|}{ Western European Neandertals } \\
\hline La Ferrassie 2 & 22.2 & & & & \\
\hline Gibraltar 1 & 22.5 & 34.1 & & 12.7 & 25.0 \\
\hline Saccopastore 1 & 23.0 & 32.9 & 23.9 & 20.9 & 25.8 \\
\hline La Quina 5 & 25.0 & & 12.0 & & \\
\hline Spy 1 & 25.3 & & & & 25.0 \\
\hline Monsempron 1 & & & 12.5 & 12.7 & \\
\hline La Chapelle & 26.5 & 33.1 & & & \\
\hline Saccopastore 2 & 27.9 & 33.7 & 18.7 & 17.1 & 26.2 \\
\hline Spy 2 & & & 11.1 & 10.1 & \\
\hline Arcy-sur-Cure 9 & 28.5 & 33.3 & 13.6 & 12.7 & 23.0 \\
\hline La Ferrassie 1 & 29.9 & 34.0 & 12.9 & 13.2 & 23.9 \\
\hline Kůlna & 30.4 & 30.0 & 12.5 & & 25.1 \\
\hline Mt Circeo 1 & & 35.1 & & 16.5 & \\
\hline \multicolumn{6}{|c|}{ Western European Neandertal } \\
\hline$\overline{\mathrm{x}}$ & 26.1 & 33.3 & 14.7 & 14.5 & 24.9 \\
\hline$\sigma$ & 3.0 & 1.5 & 4.4 & 3.4 & 1.1 \\
\hline \multicolumn{6}{|l|}{ Neandertal male } \\
\hline$\overline{\mathbf{x}}$ & 28.6 & 33.2 & 13.8 & 13.9 & 24.6 \\
\hline$\sigma$ & 1.6 & 1.7 & 2.9 & 2.9 & 1.4 \\
\hline \multicolumn{6}{|l|}{ Neandertal female } \\
\hline$\overline{\mathbf{x}}$ & 23.6 & 33.5 & 16.1 & 15.4 & 25.3 \\
\hline$\sigma$ & 1.4 & & 6.7 & 4.7 & 0.5 \\
\hline
\end{tabular}

'The Saccopastore crania are included in this Neandertal sample because of the likelihood that their temporal position corresponds to Würm I of France and Belgium, Kůlna, although published as a juvenile specimen, is actually adult since the $\mathrm{M}^{2}$ toothwear exceeds that of $\mathrm{Krapina}$ maxilla $E$ which has an erupted $\mathbf{M}^{3}$. Alveolar height is the nasospinale-alveolar point dimension, the postcanine position is the maximum distal point on the posterior surface of the root at the alveolar margin, and the internal palate wall heights were taken at the palate wall, perpendicular to the roof of the palate. All measurements were taken on the original specimens. In this and all other tables, measurements were taken by MHW unless otherwise indicated.

smaller of the two maxillas (Table 1) and is too small to fit any of the preserved mandibles. Also, none of the unassociated maxillary teeth fit this specimen. The maxillary sinus floor is in a low position. While the contour of the maxilla suggests the possibility of a shallow canine fossa, not enough of the bone is preserved to be sure this feature was present. Although broken, the remaining portion of the nasal spine is prominent. A marked ridge extends $14.7 \mathrm{~mm}$ posteriorly from it onto the floor of the nasal cavity, terminating at the opening for the incisive canal. The lower nasal margin is similar to that of $\mathrm{Vi} 225$ in that there are two distinct ridges separated by a deep groove with a transverse ridge connecting them. Below the nasal margin, the profile of the maxilla is somewhat concave. A moderate amount of alveolar prognathism is indicated.

The breadths of the central and lateral incisor sockets are 7.7 and $7.8 \mathrm{~mm}$, respectively. The canine was probably not large. The maximum breadth of the canine socket at the alveolar margin is $9 \mathrm{~mm}$ and the socket depth is $17.7 \mathrm{~mm}$. No canine buttress extends onto the lateral maxillary face.

The $\mathrm{M}^{2}$ is markedly smaller than the isolated Vi $229 \mathrm{M}^{2}$ (see Table 6). It is moderately worn and the roots are fused. The wear slope is lingual over the major portion of the crown; a second more distinctly angled facet covers the lingual $1 / 5$. There is a moderate area of dentin 
exposed by this facet, and the grooves have been obliterated over the entire lingual occlusal surface. On the buccal side, about ${ }^{1 / 2}$ of the original crown height remains. There is little interproximal attrition mesially. The facet measures $4.3 \mathrm{~mm}$ in breadth. The presence of a faint distal interproximal facet indicates that the $\mathrm{M}^{3}$ had erupted.

Alveolar height, nasal breadth, and the measures of palate depth are uniformly smaller than any western European Neandertal (Table 1), probably indicating that Vi 259 is female. However, relative anterior tooth expansion is suggested by the fact that the prosthion-postcanine distance is about the size of the La Ferrassie female (it was probably somewhat smaller, but the mesial migration of the anterior teeth of the much older La Ferrassie female has obscured the difference). The general size difference expressed by the other comparable dimensions is significant. Nasal breadth (determined also by doubling the measurement from the left lateral nasal border to the midline) lies 4.7 standard deviations below the western European Neandertal mean, and alveolar height is 2.8 standard deviations below this mean. Even when the comparison is limited to females, these dimensions are extraordinarily small.

Summary. The unusual morphology of the lower nasal border, as well as the more general similarities found in other features, suggest that these two individuals from level $\mathrm{G}_{3}$ may have been related, at least in a populational sense.

These maxillas seem to combine both Neandertal-like and more modern features. Their small size underlies many of the contrasts with western European Neandertals. Yet, size itself is an important feature, since facial reduction is one of the most dramatic differences between Neandertal populations and more modern populations that followed them in time. The most archaic-appearing features reflect the size and proportions of the anterior teeth. Both have a $I^{2}$ root that is broader than the $I^{1}$ root. The marked prosthion-postcanine distance is even more distinctive when the generally small size of the maxillas is taken into account. If the maxillas were drawn from the same sample as the postcranial remains, their small size might partially reflect a small average body size. However, even taking this into account, the fact remains that these specimens are much smaller than the most diminutive Neandertal female, and the size difference involves features that are taxonomically distinctive of $\mathrm{Ne}$ - andertals; facial height, palate depth, and nasal breadth. Since facial size reduction is one of the major morphological alterations associated with the transition from Neandertals to anatomically modern Homo sapiens (Brace, 1979; Howells, 1975; Brose and Wolpoff, 1971; Smith, 1976b), the fact that the Vindija $G_{3}$ hominids tend to approach the early modern condition is indeed significant. Also, though it is not possible to be certain because of the specimen's fragmentary condition, the possible presence of a shallow canine fossa in Vi 259 could be another feature indicating a reduced face relative to other Neandertals.

\section{Mandibles}

Vi 206 Right mandibular corpus with symphysis (Fig. 3,4): $\mathrm{G}_{3}$

This specimen extends from the middle of the left canine socket to the approximate horizontal midpoint of the right ramus and includes the right canine and molar series. The general appearance of the corpus is similar to many of the late Neandertals from western Europe. There is a distinct, although not prominent, mental eminence and a rather vertical symphysis. A single mental foramen lies directly under the center of the first molar; the anterior ramus border crosses the alveolar margin some $3 \mathrm{~mm}$ behind the distal face of $\mathrm{M}_{3}$, and the corpus is fairly uniform in height (Table 2).

There is a gentle concavity on the external face of the symphysis, beginning just below the incisor sockets and extending inferiorly about halfway down the bone. Here, the contour becomes convex and forms a moderately developed mental eminence. Oriented in the basal plane the eminence is more anterior than the incisor sockets at their superior margin, and in the occlusal plane orientation these are equally anterior. Laterally the concavity extends to the canine roots. The symphyseal angle for $\mathrm{Vi} 206$, measured from the basal margin (c.f. Olivier 1969) is $87^{\circ}$, considerably below the overall western European Neandertal and Krapina means of $95^{\circ}$ and $99.6^{\circ}$, respectively (Table 3). This value underscores the presence of a mental eminence and vertical symphysis for Vi 206. The symphyseal region of $\mathrm{Vi} 206$ is extraordinarily similar to Neandertal specimens such as Circeo 3 and Spy 1.

The right digastric fossa is extremely well excavated and is angled in the sagittal plane at about $45^{\circ}$ to the corpus base. The excavated portion is $18.2 \mathrm{~mm}$ long and $10 \mathrm{~mm}$ in breadth. The position of gnathion lies some $3 \mathrm{~mm}$ above the fossa. On the internal symphyseal surface 

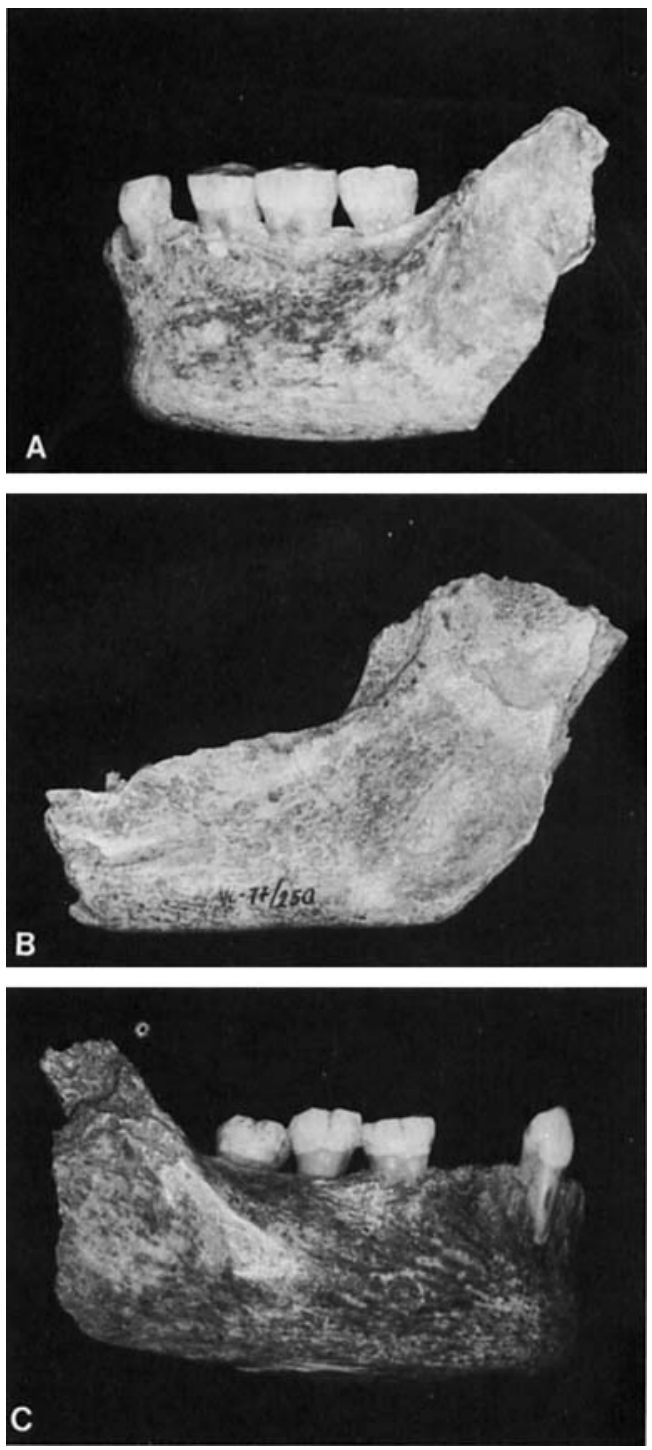

Fig. 3. Lateral views of three Vindija mandibles. Vi 231 (top), Vi 250 (middle internal view), and Vi 206 (bottom). The specimens are shown to the same approximate scale.

the plane posterior to the incisors drops steeply for some $13.5 \mathrm{~mm}$, where it forms a superior transverse torus contiguous with, but higher than, the lower border of the sublingual fossa. Below this is a deep $(0.8 \mathrm{~mm})$ genial fossa with a lower border that forms an inferior transverse torus. This torus extends laterally to form the division between the digastric and sublingual fossae. The genial fossa is vertically divided into two equal sections.

The external face of the corpus is smooth, curving posteriorly at the position of the canine. The oblique line begins $11 \mathrm{~mm}$ below the alveolar margin, at the rear of $\mathrm{M}_{2}$. The posterior face of the ramus is broken vertically about $20 \mathrm{~mm}$ posterior to the position where it crosses the alveolar margin and extends no more than $17 \mathrm{~mm}$ superior to the margin. Medially, the extramolar sulcus measures approximately 5 $\mathrm{mm}$ in breadth (taken from the buccal $\mathrm{M}_{3}$ face). The ramus is broken just above the division between the condylar and coronoid buttresses. Only the base of the mylohyoid groove is preserved.

On the internal corpus face the sublingual fossa extends to the position of $M_{z}$, and an irregular submaxillary fossa begins at the genial fossa border.

The canine is worn at an approximately $30^{\circ}$ angle to the long axis of the root; the occlusal surface is some $5.5 \mathrm{~mm}$ long, and its maximum breadth is $2.9 \mathrm{~mm}$. Wear on the crown is moderate. Crown height, measured from the mesial cemento-enamel junction is $9.5 \mathrm{~mm}$ mesially and $8.2 \mathrm{~mm}$ distally. A series of fine chips are spread over the lingual border of the occlusal surface, while the labial border is chip free and evenly rounded. Microscopic examination reveals that the chip borders are rounded, suggesting that the chips resulted from antemortem activities. On the mesial side of the crown, an elongated interproximal facet begins some $1.5 \mathrm{~mm}$ inferior to the occlusal surface and extends $3.6 \mathrm{~mm}$ directly downward. Breadth of the facet is $2.75 \mathrm{~mm}$. On the distal side, a round interproximal facet is displaced to the lingual corner and is some $1.6 \mathrm{~mm}$ below the distal edge of the occlusal surface. This facet is $2 \mathrm{~mm}$ in height. On the lingual crown surface, the mesial marginal ridge is very weakly developed. Prominence of the distal marginal ridge is much stronger, but the ridge terminates only some $3.5 \mathrm{~mm}$ above its base. A central groove, offset distally, divides the labial surface into two distinct portions. At the neck, the length and breadth of the root are 5.6 and $7.4 \mathrm{~mm}$, respectively.

A Y fissure pattern occurs on the occlusal surface of the first two molars while the 3rd molar has an X pattern. Wear has made it impossible to determine whether there were more than five cusps on the two anterior molars. However, there is a moderate 7th cusp on the 3rd molar. The 5th cusp is smaller than the 7 th, and there is no 6th cusp. This tooth has a 

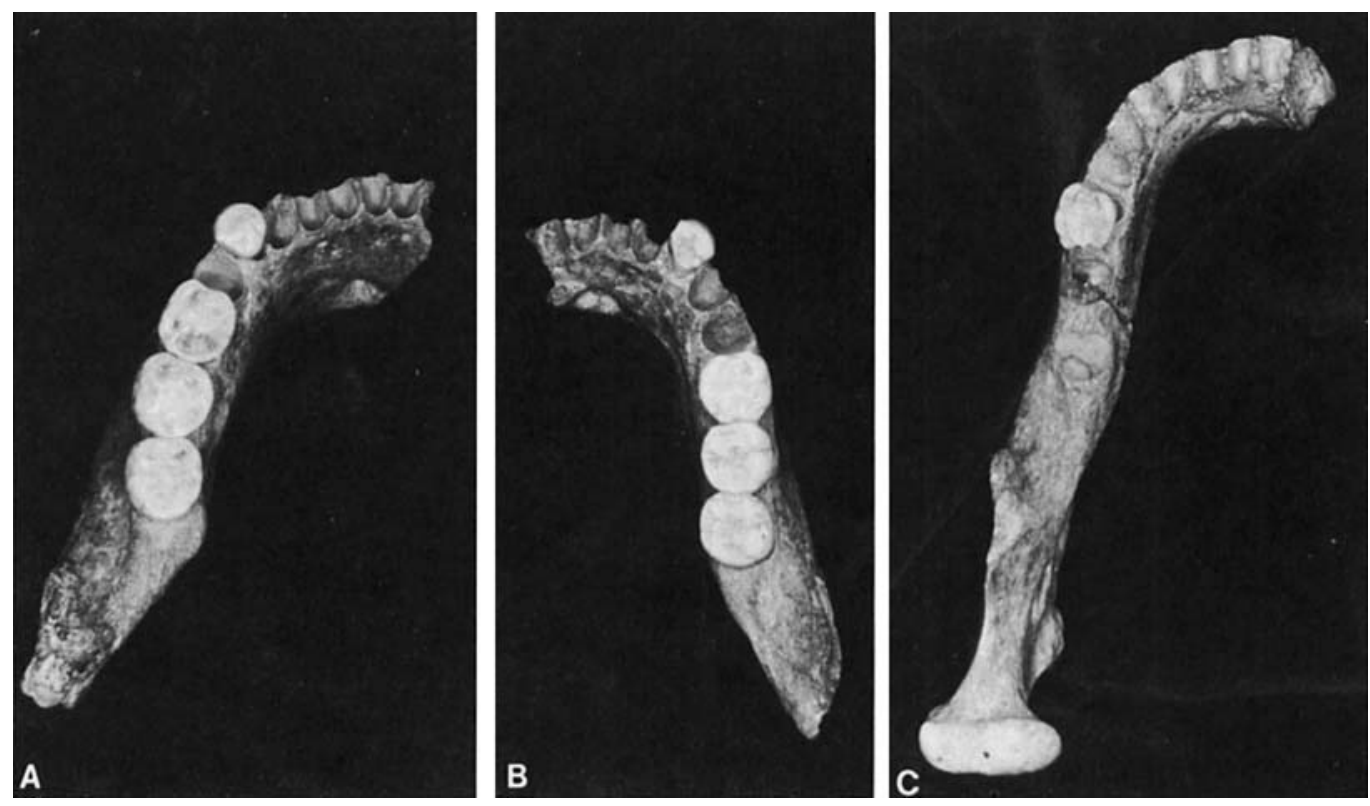

Fig. 4. Occlusal views of Vi 231 (left), Vi 206 (center), and Vi 226 (right), shown to the same approximate scale. Note the variation in toothrow shape.

large Carabelli's pit just below the occlusal level at the center of the buccal crown surface. Additional small Carabelli's pits appear on the buccal distal corners of the 3rd as well as the 1st molars, at the same position just below the occlusal surface. There is marked hypoplasia on the buccal $M_{3}$ face where at least seven distinct pits appear.

The mesial interproximal facet on $M_{1}$ is quite large, measuring $3.3 \mathrm{~mm}$ in height and $5.3 \mathrm{~mm}$ in breadth. Contact between $M_{1}$ and $M_{2}$ extends for $5.75 \mathrm{~mm}$, and the $\mathrm{M}_{2} / \mathrm{M}_{3}$ contact is $4.0 \mathrm{~mm}$ broad.

The pattern of wear is similar on the three molars. Reduction of the mesiobuccal cusp (protoconid) is strongest, followed by the distobuccal cusp (hypoconid). Wear on the distolingual cusp (entoconid) is only slightly less, and on all three the distolingual cusp sustains the least wear. Differential wear is moderate; wear on the buccal side of $\mathbf{M}_{2}$ approximates the lingual side of $M_{1}$, and the buccal side of $M_{3}$ approximates the lingual side of $M_{2}$. Dentin patches are exposed on the four main $M_{1}$ cusps, with the largest exposure on the mesiobuccal cusp. At the other extreme, the lingual side of the $\mathbf{M}_{3}$ is barely worn. A small dentin spot is exposed on the mesiobuccal $\mathrm{M}_{2}$ cusp.
Canine size in this mandible shows reduction compared with the Krapina dentitions (see Table 6). Its dimensions closely approach the average for the two canines from Hortus. In contrast, the molars are large compared with those from this late western European site. In fact, molar breadths are near the Krapina average $\left(\mathrm{M}_{3}\right.$ for Vi 206 is actually broader). Lengths, however, are less than the Krapina values, and this difference is greater than the difference that could be due to interproximal wear. The fact that Vi 206 is older than the average age of individuals with molars at Krapina (see below) could account for some of the length difference. However, it is likely that the Vi 206 molars show some relative length reduction holding age constant. This reduction is almost certainly associated with the shortening of the Vi 206 mandibular corpus.

Dental age was estimated for the specimen by comparison with the aged Krapina remains (Wolpoff, 1979). The specimen closest in wear is Krapina G. Vi 206 shows slightly more mesial wear on the $M_{1}$, while on $M_{2}$ the buccal and distal portions are slightly more worn (especially on the hypoconulid which, unlike Krapina G, shows slight dentin exposure). The Vindija mandible is probably not older than 19 


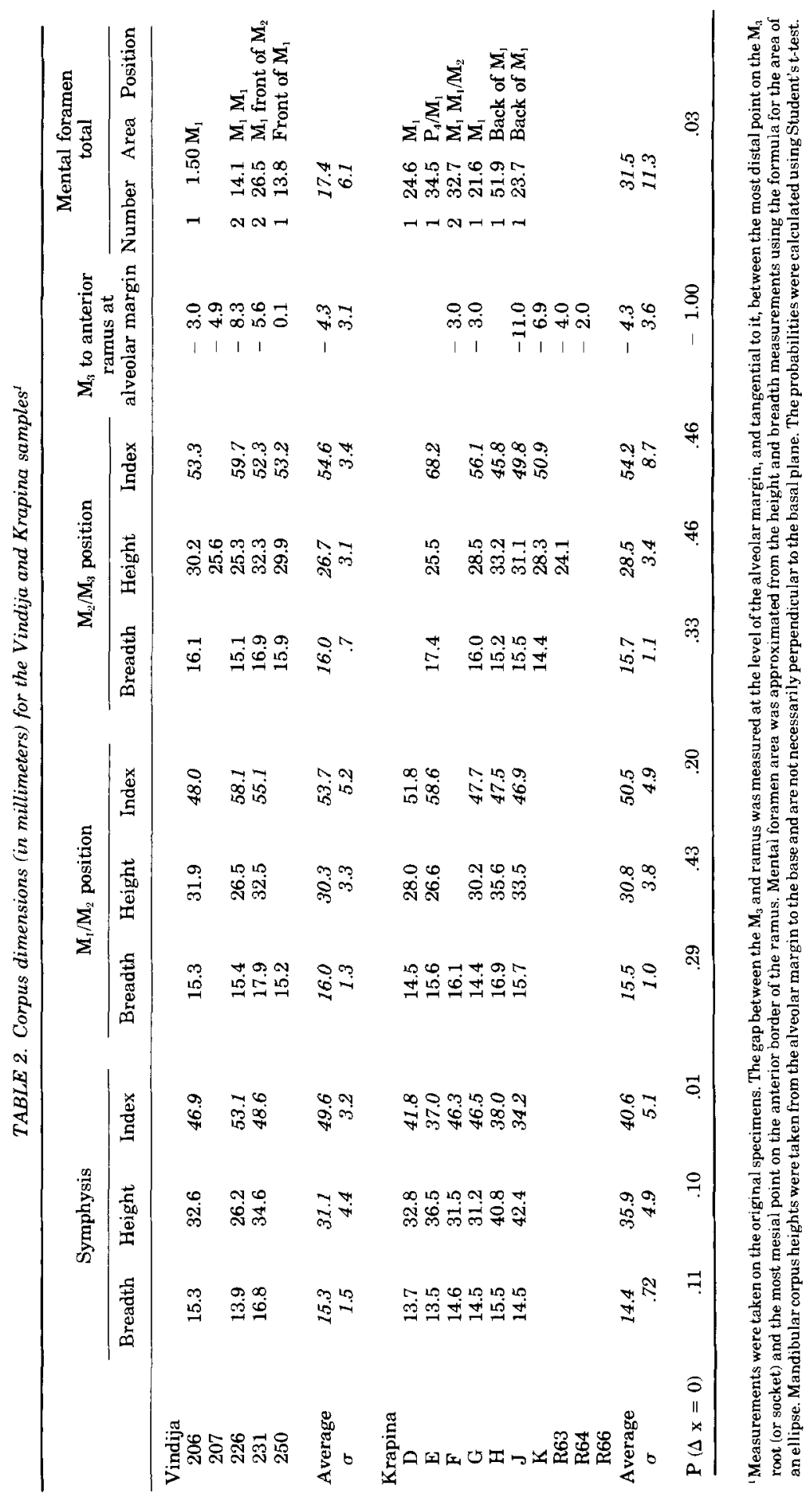


TABLE 3. Symphyseal angles for Vindija, Krapina, and western E'uropean Neandertal mandibles

\begin{tabular}{|c|c|c|}
\hline Specimen & $\begin{array}{c}\text { Symphyseal } \\
\text { angle }^{2}\end{array}$ & Source $^{3}$ \\
\hline Vindija 206 & $87^{\circ}$ & 1 \\
\hline Vindija 231 & $89^{\circ}$ & 1 \\
\hline Vindija $226 / 265$ & $85^{\circ}$ & 1 \\
\hline Vindija average $(\sigma)$ & $87^{\circ} \quad(1.6)$ & \\
\hline Krapina D & $98^{\circ}$ & 1 \\
\hline Krapina $\mathrm{E}$ & $98^{\circ}$ & 1 \\
\hline Krapina G & $102^{\circ}$ & 1 \\
\hline Krapina $\mathrm{H}$ & $101^{\circ}$ & 1 \\
\hline Krapina J & $99^{\circ}$ & 1 \\
\hline Krapina average $(\sigma)$ & $99.6^{\circ}(1.8)$ & \\
\hline La Ferrassie 1 & $85^{\circ}$ & 2 \\
\hline La Chapelle-aux-Saints & $95^{\circ}$ & 2 \\
\hline La Naulette & $95^{\circ}$ & 2 \\
\hline Regourdou & $103^{\circ}$ & 2 \\
\hline Spy 1 & $106^{\circ}$ & 2 \\
\hline La Quina H9 & $93^{\circ}$ & 2 \\
\hline Banōlas & (cast) & 2 \\
\hline Hortus 5 & $95^{\circ}$ & 3 \\
\hline \multicolumn{3}{|l|}{ Western European } \\
\hline Neandertal average $(\sigma)$ & $95.5^{\circ}(6.5)$ & \\
\hline \multicolumn{3}{|l|}{$\mathrm{P}(\Delta \overline{\mathrm{x}}=0)$} \\
\hline $\mathrm{V} / \mathrm{K} \quad .000$ & & \\
\hline V/EN $\quad .015$ & & \\
\hline K/EN .101 & & \\
\hline
\end{tabular}

'Although Hortus 5 has been regarded as a juvenile, the $\mathbf{M}_{3}$ had just come into occlusion at the time of death. Means are compared using Student's t-test.

2The symphyseal angle is taken after the method described by Olivier ('69).

1 = measurements by FHS; $2=$ Heim (76); $3=$ de Lumley ('73).

(Krapina G was aged at 18). The amount of wear on the $M_{3}$ is equal to molars with 3-4 years of wear at Krapina (for instance, the $M_{2}$ of Krapina E). Thus, early $\mathrm{M}_{3}$ eruption (i.e. approximately 15 years) is indicated for this Vindija mandible.

Vi 207 Right ramus and posterior mandibular corpus (Figs. 3,5): $\mathrm{G}_{1}$

This edentulous specimen consists of a complete ramus, broken only at the tip of the coronoid, and a corpus extending to the mid $\mathrm{M}_{1}$ position buccally but only to the mid $\mathrm{M}_{3}$ lingually.

The corpus is low (Table 2) and relatively thick. The oblique line begins at the position of the $\mathrm{M}_{3}$ socket center. Judging from the condition of the socket, the tooth was erupted.

The root of the ramus appears at about the mid $\mathbf{M}_{2}$ position, and the anterior border of the ramus does not cross the alveolar margin until some $4.9 \mathrm{~mm}$ posterior to the distal border of the $M_{3}$ socket. The ramus is small (Table 4 ) and
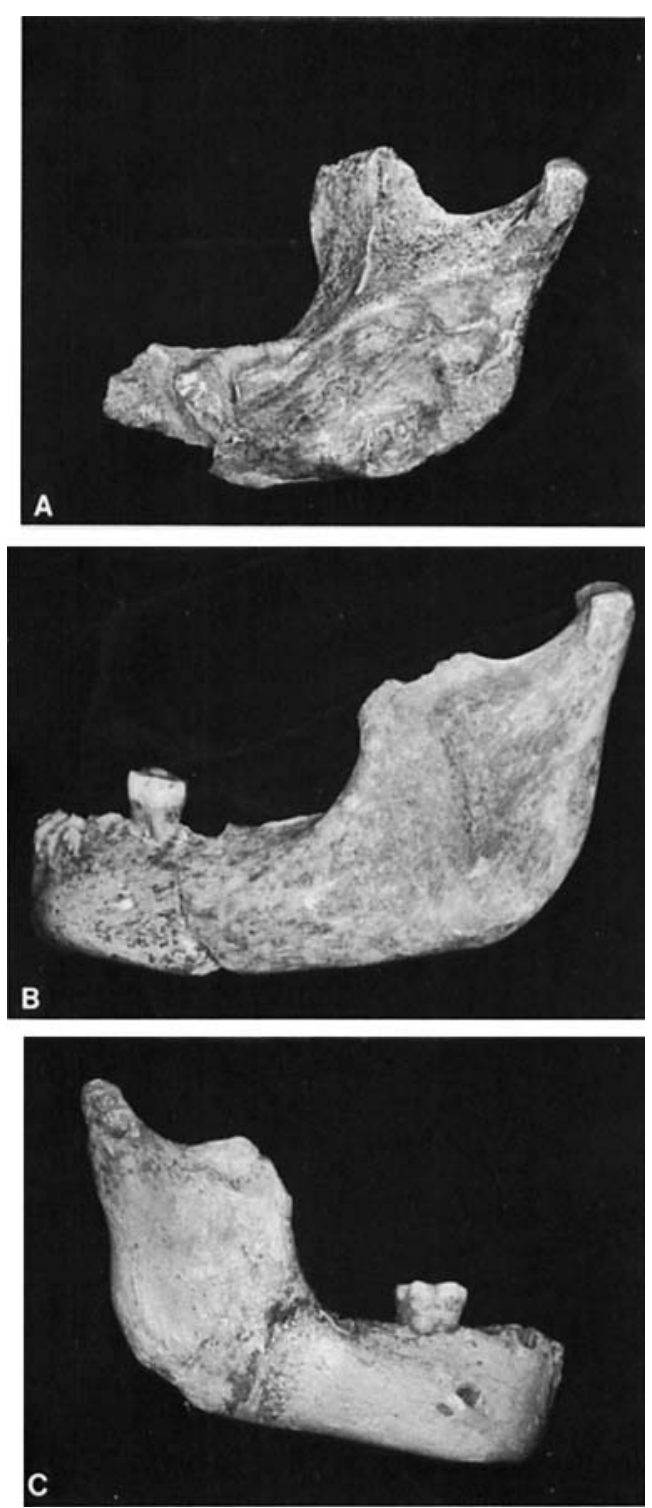

Fig. 5. Lateral internal view of $\mathrm{Vi} 207$ (top) and external views of Vi 226 (middle) and Malarnaud (bottom) to the same approximate scale.

distinctly angled posteriorly. The angle between the back of the ramus and the (preserved) inferior margin of the corpus is $113^{\circ}$. The gonial region is very weakly angled and slightly inverted. The anterior flare of the anterior coronoid surface results in a maximum ramus breadth that is much greater than the minimum, and the wide distance between the 


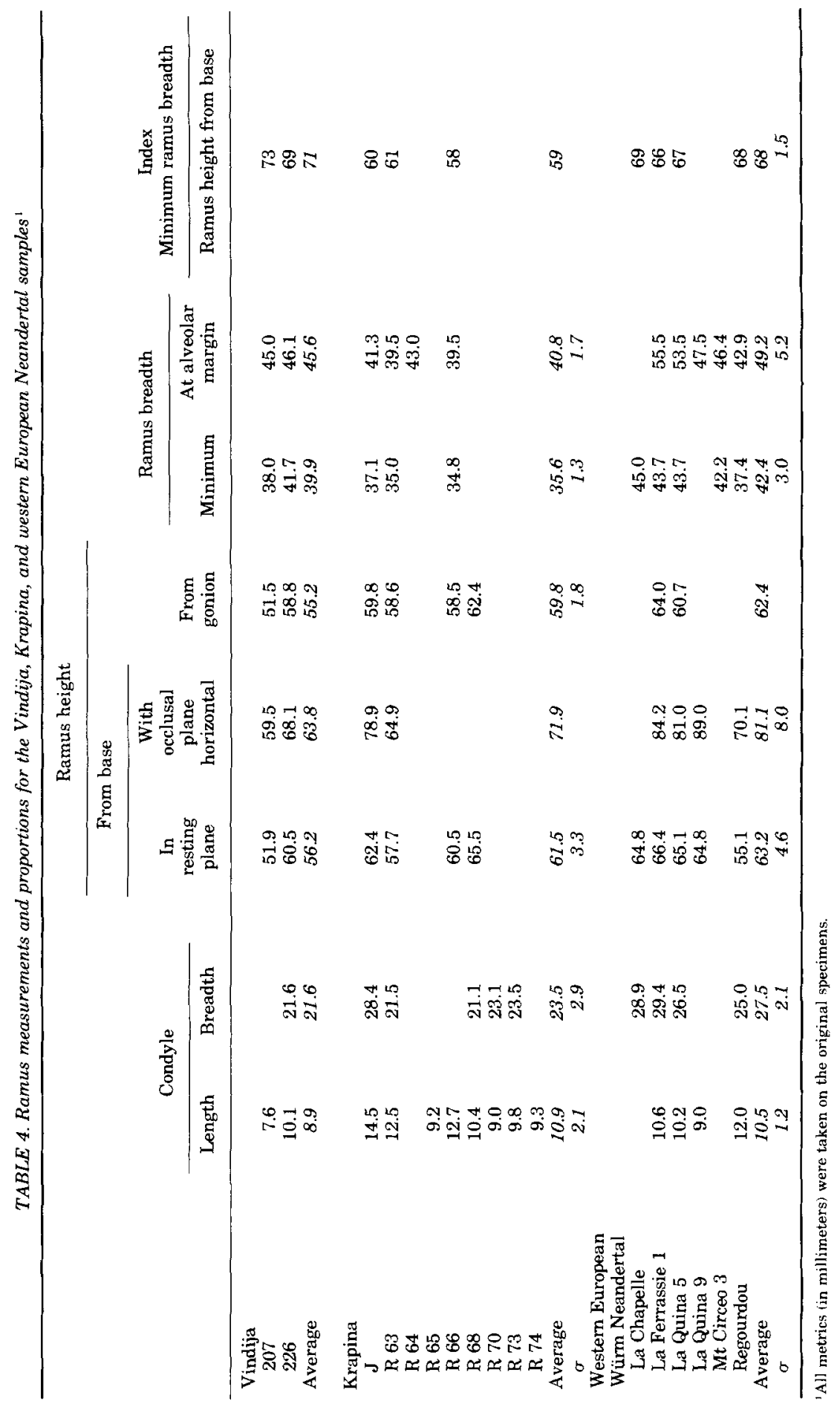


coronoid process and the condyle defines a deep, broad mandibular notch. From the coronoid buttress to the anterior face of the condyle measures $30.5 \mathrm{~mm}$, and the depth of the existing notch (without the coronoid tip) is $10.8 \mathrm{~mm}$. The mylohyoid sulcus/mandibular foramen is of the horizontal-oval form (c.f. Kallay, 1970; Smith, 1978), with the sulcus beginning some $2.7 \mathrm{~mm}$ below the inferior border of the foramen.

The dimensions of the corpus and the height of the ramus indicate that $\mathrm{Vi} 207$ is a small specimen compared with Neandertals. The ramus height is lower than the four adult Krapina specimens preserving this region. It lies 2.9 standard deviations below their mean value of $61.5 \mathrm{~mm}$ for ramus height measured from the base (Table 4). The ramus is the approximate size of the Tabun female.

Another measure of the small size of Vi 207 is in the length of the condyle, which is 1.9 standard deviations below the mean of 10.9 for eight Krapina specimens. However, minimum ramus breadth is larger than the three measurable Krapina rami (Table 4). In expansion of minimum breadth, $\mathrm{Vi} 207$ is similar to the western Neandertals (Fig. 5). The $3.7 \mathrm{~mm}$ breadth of the extramolar sulcus (measured from the buccal $\mathrm{M}_{3}$ root position) is quite small.

\section{Vi $226 \quad$ Left half-mandible and symphysis (Figs. 4,5): $\mathrm{G}_{3}$}

The two fragments constituting this specimen were found in successive years and combine to form a virtually complete left corpus (lacking only the coronoid process tip) extending across the symphysis to the center of the right canine socket. The only damage to the corpus is some deterioration on the buccal edge of the anterior alveolar margin, extending posteriorly to the $P_{3}$ position. The specimen is edentulous except for a surviving $M_{1}$, the smallest of the Vindija first molars (see Table $6)$.

The symphysis is low (Table 2) but relatively thick. Its orientation is close to or thogonal relative to the parallel alveolar margin and corpus base. There is no mental eminence on its face, which is vertical from infradentale to pogonion and then smoothly curved to gnathion. Internally, both a superior and inferior transverse torus are present; the inferior torus is the larger of the two structures and has the more marked posterior projection. The genial fossae are well excavated and broad $(6.4 \mathrm{~mm})$. As in the other specimens, there is an indistinct vertical ridge below it rather than a mental spine.
The mylohyoid ridge is not continuous with the superior torus. Although very pronounced, it ends under the $M_{t}$. The anterior region is not modern, but it is also unlike Neandertals of similar size such as La Naulette and Malarnaud (Fig. 5). The Vi 226 symphysis is more vertical than either of these (Table 3), but it represents the position of the lowest corpus height, whereas in La Naulette and Malarnaud the corpus is tallest anteriorly and the inferior corpus border and alveolar margin converge posteriorly. Moreover, the superior transverse torus is more prominent in these two western European mandibles. The digastric fossae are deeply excavated and bordered by a distinct anterior ridge in Vi 226 . They are markedly angled relative to the inferior border of the corpus.

The corpus is fairly low but is relatively the thickest of the Vindija mandibles (Table 2). Two small mental foramina lie below the $M_{1}$ position. The larger of these opens directly laterally. The ramus is the most posteriorly positioned of any at Vindija. Its anterior edge crosses the alveolar margin $8.3 \mathrm{~mm}$ posterior to the distal border of the $\mathrm{M}_{3}$ socket. The anterior ramus border appears to be swinging markedly anteriorly (similar to Vi 207) at the point where the coronid process is broken away. The posterior border is straighter and less sculpted than the Vi 207 condition (Fig. 5). Interiorly, the gonial region is perpendicular anteriorly, but at the gonial angle and superior to it there is inversion of the border. The mylohyoid sulcus/mandibular foramen is of the horizontaloval form with the sulcus beginning $8.3 \mathrm{~mm}$ below the medial edge of the sulcus. The mandibular notch appears to be shallower than Vi 207 . The breadth of the extramolar sulcus $(4.0$ $\mathrm{mm}$ ) is one of the smallest at the site.

The ramus appears to be very broad, for instance exceeding the three measurable Krapina rami (Table 4) in absolute ramus breadth and in breadth proportional to height. In fact, Vi 207 is relatively even broader (the Malarnaud relative breadth is greater yet). The absolute breadth of Vi 226 falls just at the western Neandertal mean. What makes it appear broad is the comparison of the ramus with the low corpus height. The ramus is moderate in height, and oriented fairly perpendicularly to the corpus. Relative to corpus length, ramus height does not differ substantially from Krapina J, La Ferrassie 1, and La Chapelle (Table 5). Regourdou and Malarnaud are somewhat smaller in this regard. In absolute terms, the ramus is about $20 \%$ taller than $\mathrm{Vi}$ 207. While it is smaller than the male speci- 
M.H. WOLPOFF ET AL.

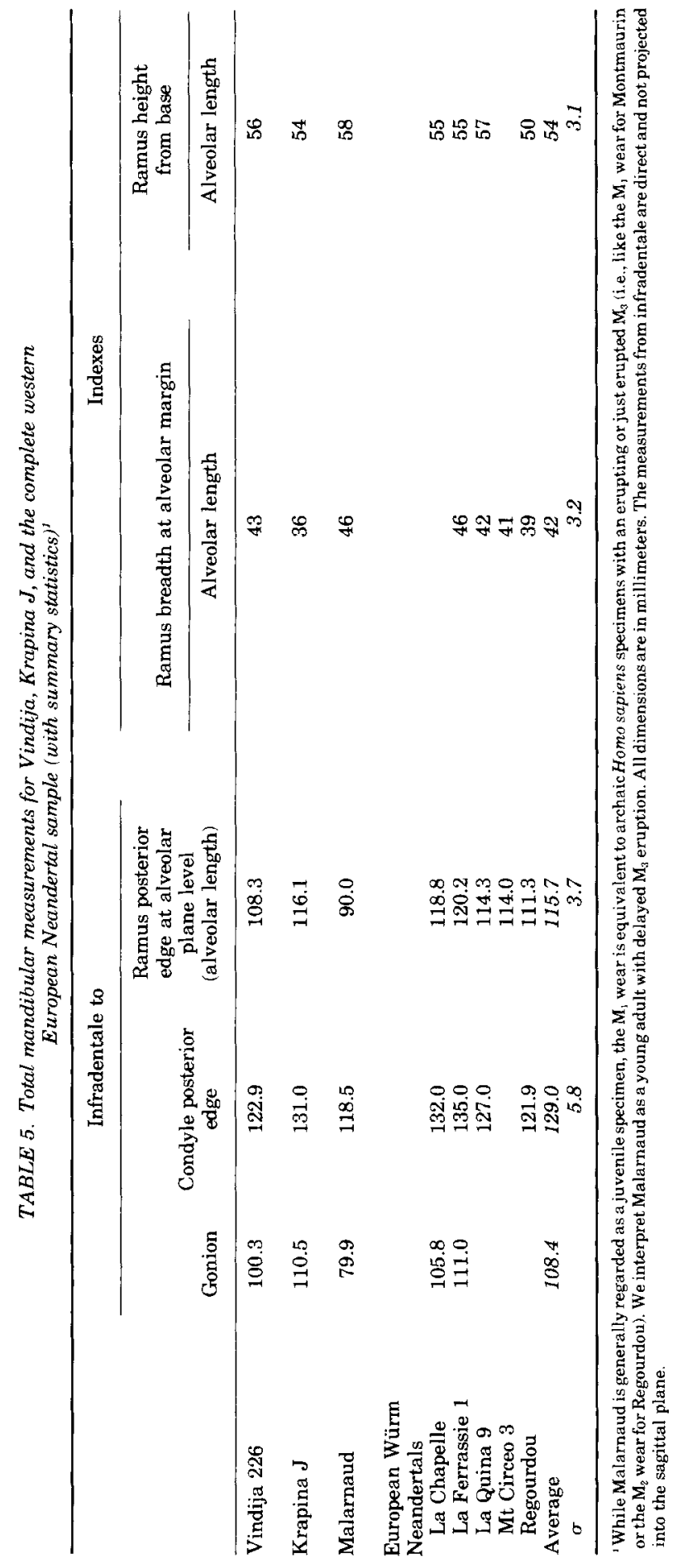


mens La Chapelle, La Ferrassie 1, and Krapina $\mathrm{J}$, it is substantially taller than Malarnaud (Fig. 5).

The condyle is moderate in size; its dimensions lie just below the Krapina average, although the divergence from the western Neandertal average is somewhat greater. Compared with these specimens, the greatest difference is in breadth. The Vi 226 condyle is relatively narrower.

Generally, the dimensions of the total mandible are short compared with either Krapina or the western Neandertals. The total proportions, however, differ little from these samples, and there is no combination of features that suggests the specimen be regarded as anything but Neandertal in its affinities. Sex determination for the specimen is somewhat more equivocal. While ramus height and symphysis height are generally accurate sex-distinguishing criteria in the Neandertals, only symphysis height seems to indicate clearly that the individual was a female. Ramus height is intermediate between the male and female Neandertal distributions. Even at Vindija these proportions stand out; the ramus is taller than that of Vi 207, while the symphysis is the shortest of the three preserved. We regard the bulk of the features as indicating the specimen was female, although this is not suggested with great certainty.

The first molar is worn quite flatly, except for the slight prominence of the mesiolingual cusp. Dentin is exposed at the positions of the five main cusps, which form a Y pattern as indicated by the remaining central fissures. Dentin exposure on the two mesial cusps is about three times greater than on the other three. Interproximal facets are quite large; mesial and distal facet breadths are 4.6 and $5.1 \mathrm{~mm}$, respectively. There are distinct buccal pits near the occlusal surface under the positions of the buccal and distobuccal grooves. The wear is greater than in the Vi $206 \mathrm{M}_{1}$ and most closely matches the $\mathrm{M}_{2}$ of $\mathrm{Vi} 231$. An approximate age of 20 years is suggested. The tooth is smaller than the other Vindija first molars. It is slightly under the Hortus average.

Vi 231 Left mandibular corpus and symphysis (Figs. 3,4): $\mathrm{G}_{3}$

This fragment is broken almost identically to Vi 206, except it is the opposite side. The specimen extends from right canine socket to a vertical break at about the middle of the left ramus and preserves the left $P_{3}$ and $M_{1}-M_{3}$ as well as the sockets for the other (missing) teeth. Cor- pus dimensions for $\mathrm{Vi} 231$ are about $10 \%$ larger than for Vi 206 (Table 2), and the indexes of robustness are slightly greater. The dental dimensions for Vi 231 and Vi 206 are virtually identical (Table 6), except for the broader Vi $231 \mathrm{M}_{2}$. The molars and $\mathrm{P}_{4}$ are relatively shortened compared with Krapina.

The symphyseal areas of the Vi 231 and 206 mandibles are also remarkably similar. A centrally placed low ridge extends inferiorly on the symphyseal surface, bordered by shallow depressions under the incisor roots. In profile, the concavity separating the incisor-bearing superior portion and the mental eminence in $\mathrm{Vi} 231$ is somewhat more marked, al though the projection of the eminence relative to the alveolar margin is about the same. The most anterior projection of the eminence in Vi 231 is near the base. Measured from the basal margin, the Vi 231 symphyseal angle is $89^{\circ}$ (Table 3 ). Internally, the superior transverse torus is somewhat better delineated. The symphysis is relatively thicker. The genial fossa is much smaller (a breadth of $5 \mathrm{~mm}$ compared with $7.8 \mathrm{~mm}$ ) and shallower. However, there is a similar expression of the inferior transverse torus. Another difference from Vi 206 is in the submaxillary fossa, which does not extend to the border of the genial fossa but instead ends under $\mathbf{M}_{1}$. The digastric fossa is wider in $\mathrm{Vi} 231$, but otherwise the basal regions are virtually identical. The sublingual fossa is more poorly excavated in 231 . On the internal face of the ramus, much of the mylohyoid line is preserved, separated from a small tuber just posterior to $M_{3}$. There are two mental foramina, located under the $M_{1}$ and under the medial portion of the $\mathbf{M}_{2}$. The larger of these opens directly laterally as in Vi 206. The separation of the anterior ramus border from the distal $\mathrm{M}_{3}$ face is $5.9 \mathrm{~mm}$, about twice as great as the separation in Vi 206. The breadth of the extramolar sulcus is also greater in $\mathrm{Vi}$ $231(9.0 \mathrm{~mm}$ compared with $6.1 \mathrm{~mm}$ ).

The greatest contrast between these mandibles is in the apparent shape of the dental arcade. Vindija 231 seems to have been a much broader mandible (Fig. 4) with a more pronounced parabolic shape of its tooth row.

The groove pattern for $M_{2}$ is $Y$, but an $X$ pattern for $M_{3}$ suggests another similarity to the Vi 206 mandible. Too much occlusal wear is present to determine whether any of the molars had more than five cusps. The worn $\mathrm{M}_{1}$ and $\mathrm{M}_{2}$ have a buccal slope. There is a slight wear depression between these teeth, with the distal third of $M_{1}$ and the mesial third of $M_{2}$ sustaining the heaviest wear on each tooth. No grooves 


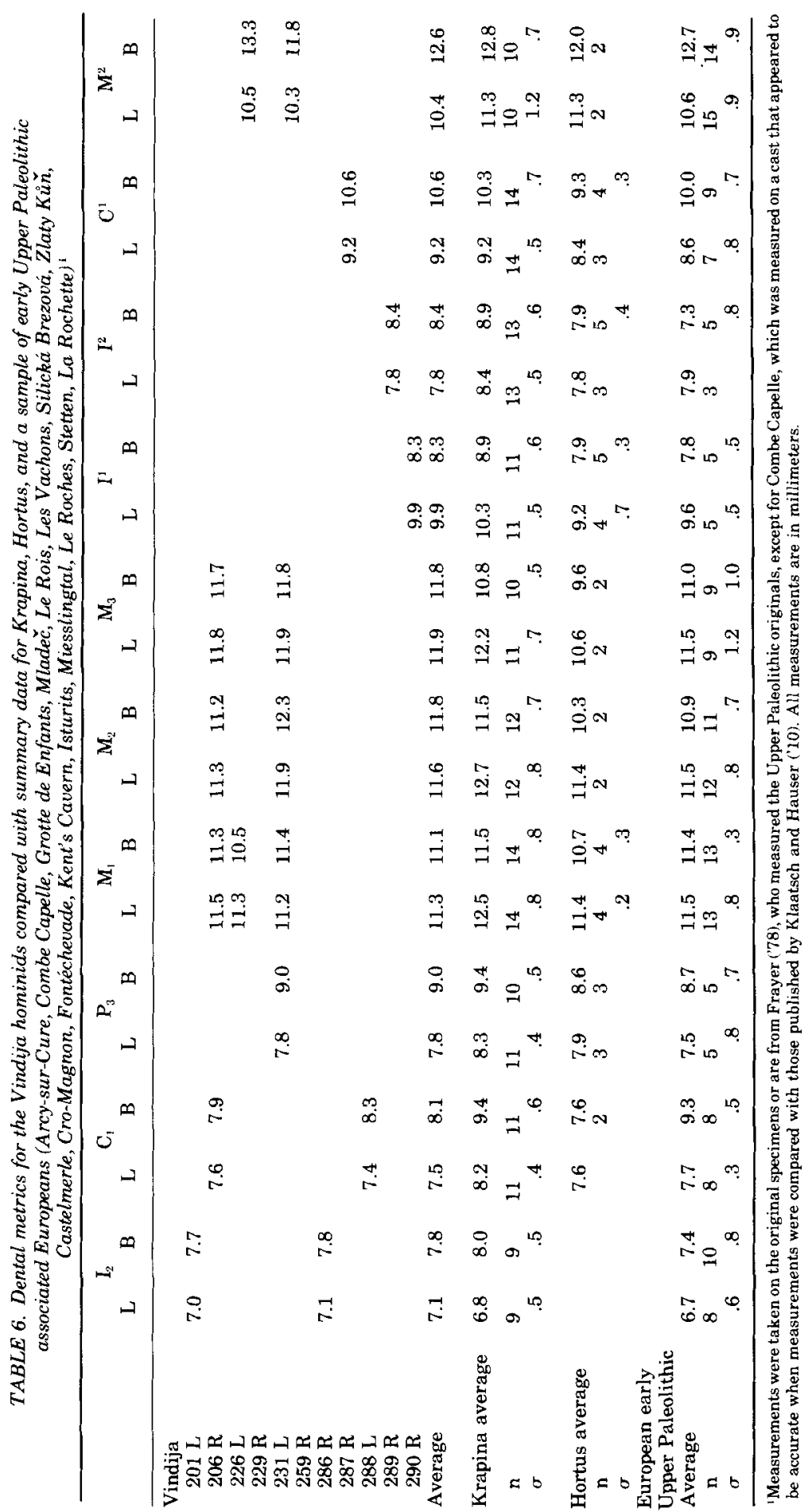


remain on the $M_{1}$ occlusal surface, and the distal portion is cupped in a predominantly transverse but partially mesiolingual direction. There is also a large dentin exposure on the mesiobuccal quadrant. Enamel perforation occurs on the five main cusps of $\mathrm{M}_{2}$ (more mesially). Third molar wear, however, is fairly flat. Dentin is exposed only on the mesial cusps, and the exposure is greater lingually. Wear on $P_{3}$ is entirely buccal. There is a large dentin exposure on this side, which is flat and slightly angled buccally. In contrast, there is only slight polishing on the lingual portion of the occlusal surface. The buccal cusp was probably quite high, and the buccal face of the crown was fairly well curved.

Interproximal wear is marked on $\mathrm{M}_{1}$ and $\mathrm{M}_{2}$, with mesial facet breadths of 6.0 and $5.0 \mathrm{~mm}$. There is a smaller $(3.3 \mathrm{~mm})$ facet on $\mathbf{M}_{3}$, and a very small, centrally located facet on the mesial $\mathrm{P}_{3}$ face. The teeth show neither hypoplasia nor the presence of any Carabelli's features.

Finally, the specimen is somewhat older than Vi 206. The $M_{3}$ is slightly more worn than the $M_{1}$ on the Vi 206 mandible. Assuming a 15 year date for the $M_{3}$ eruption, the estimated age is greater than 26 years. The molars are not much more worn than those of Krapina $\mathrm{H}$, aged to 23 years (Wolpoff, 1979), and it is likely that Vi 231 is not much older than the 26-year minimum estimate.

\section{Vi 250 Right portion of posterior corpus} and ramus (Fig. 3): $\mathrm{G}_{3}$

This edentulous specimen extends from the distal border of the $\mathrm{P}_{3}$ root to the ramus, posterior to the mandibular foramen. This posterior break is approximately vertical up to the position of the mandibular foramen. A small segment of the most inferior border of the notch also remains. The alveolar margin is intact buccally from the $\mathrm{M}_{1}$ root and lingually from the $\mathrm{M}_{2}$ root, although the alveoli up to the distal $\mathrm{P}_{3}$ border remain. There are a number of similarities to $\mathrm{Vi} 207$ and $\mathrm{Vi} 226$, although the corpus appears slightly taller where comparable (Table 2). The base of the gonial region is slightly inverted, the mylohyoid sulcus is separated from the mandibular foramen (of horizontal-oval form) by $12.3 \mathrm{~mm}$, and the internal fossae are not well excavated. While the region is imperfectly preserved, the ramus seems to have a distinct posterior orientation (perhaps as much as Vi 207). Unlike the other Vindija mandibles, however, the anterior border of the ramus crosses the alveolar margin at about the back of the $\mathrm{M}_{3}$ socket. A small lateral flange beginning at the $M_{1}$ position on the buccal corner of the corpus base is broken away anteriorly.

The small mental foramen opens almost exactly laterally. Breadth of the extramolar sulcus $(4.6 \mathrm{~mm})$ is also small. In contrast, ramus dimensions are generally large.

The corpus is narrower than Vindija 226 at the $M_{1} / M_{2}$ position, and only slightly taller and broader behind $\mathrm{M}_{2}$.

Summary. The mandibular sample consists of four Mousterian-associated specimens and a 5 th from the early Aurignacian level. The latter differs in no significant way from the former, but for its generally smaller size.

Considering the sample as a whole, specimens range in completeness from $\mathrm{Vi} 226$ to $\mathrm{Vi}$ 250. The Vi 226 mandible is short when compared with Krapina $J$ or the fairly complete Würm Neandertals from western Europe (Table 5). However, the Riss/Würm specimen from Malarnaud is even smaller. Measures of its mandibular body length are similar to Regourdou.

Dimensions of the ramus of $\mathrm{Vi} 226$ are also diminished, again only approached by Regourdou (Table 4). Vi 226 resembles the (approximately contemporary) western Neandertals and differs from the Krapina specimens in the breadth of the ramus relative to its height. The difference is mainly the result of relative broadening in the later Vindija specimens. When ramus breadth at the alveolar margin and ramus height are compared with alveolar length (Table 5), the breadth ratio for Krapina $\mathrm{J}$ is the smallest of all the mandibles compared, while the height ratio differs little. The Aurignacian-associated mandible, Vi 207, has the relatively broadest ramus of any of these specimens. Its ramus height, however, is the smallest, as is the length of its condyle. The two Vindija rami have the semi-sculpted appearance of the western European Neandertals. Where the ramus base can be observed, it is consistently inverted.

Corpus dimensions of the Vindija mandibles do not differ significantly from the Krapina average (Table 2 ). However, at the symphysis the average breadth for Vindija is greater and the average height is less, resulting in a significant difference for the breadth/height index. The indices for the three Vindija specimens preserving the symphysis lie above the Krapina range. The thickness is enhanced by the development of both superior and inferior transverse tori on the internal symphyseal 
faces of these three specimens, as well as a mental eminence on two of the three (see below).

There are certain aspects of the symphyseal region in the three Vindija specimens preserving it (Vi 206, Vi 226, and Vi 231) which approach the early modern sapiens condition more closely than the majority of other $\mathrm{Ne}$ andertals do. Basically the Vindija $G_{3}$ mandibular symphyses exhibit relatively more for ward projection of the base than the alveolar region, and in two (Vi 206 and Vi 231) there are slight concave depressions separating the two regions. This results in a weakly pronounced but distinct mental eminence and infers that the alveolus was somewhat less prognathic than most Neandertals. Typically, the alveolus of Neandertal mandibles projects anteriorly more than the base, and the contour between the areas is essentially linear (Wolpoff, 1975; Howells, 1975; Weidenreich, 1936; Smith, 1976b). A few western European Neandertal mandibles (Spy 1, La Ferrassie 1, and Circeo 3), however, exhibit external symphyseal morphologies similar to the Vindija $\mathrm{G}_{3}$ specimens.

The relative reduction in the projection of the alveolus relative to the base in the Vindija mandibles can also be illustrated by examination of their symphyseal angles (Table 3). The Vindija $\mathrm{G}_{3}$ mean of $85^{\circ}$ lies 1.2 and 6.7 standard deviations below the western European Neandertal and Krapina means, respectively. At Vindija, all symphyseal angles are below $90^{\circ}$. Thus, as a group, the Vindija $\mathrm{G}_{3}$ hominids are closer to the modern European pattern in symphyseal morphology than the western $\mathrm{Ne}$ andertal sample in general, and the late sites, such as Hortus, in specific.

Interestingly, the reduction of the alveolar projection relative to the mandibular base at Vindija does not seem to reflect a general posterior repositioning of the tooth row. This can be seen at the corpus posterior where, except for $\mathrm{Vi}$ 250 , the anterior border of the Vindija rami generally crosses the alveolar margin posterior to the last molar. In fact, the average distance between the crossing and the back of the tooth is identical to the Krapina average, and the distance for $\mathrm{Vi} 207$ is near the average for both samples. A related feature, the position of the mental foramen (or foramina) also does not differ between these two samples.

Similarly, both samples include specimens with multiple foramina. However, there is a marked difference in foramen size. The average foramen (or foramina) area for the Vindija sample is only $55 \%$ that of Krapina.
In considering the Vindija mandibular sample as a whole (including the Aurignacian-associated Vi 207), we believe that there are a number of important similarities to the western European Neandertal mandibles. However, while we do not wish to overemphasize the differences, the fact remains that they are present. Some, we believe, are due to the late date of the sample. These provide the basis for similarity to the latest of the western European sample. Other differences, however, may be idiosyncratic or perhaps geographic, and it may not be possible at present to fully distinguish these from the temporal component of variation. For instance, what is the meaning of the fact that the Vindija specimens tend to have a corpus that is shallower anteriorly and slightly deeper posteriorly while on the western European sample the opposite is the case? The fact that central European mandibles from Ochoz and Subalyuk tend to be more similar to the Krapina sample while the late Sipka juvenile more closely approximates the Vindija specimens might help provide evidence for temporal trends in central Europe. However, accurate dates for all of the sites concerned would present a firmer basis for this contention.

\section{Isolated teeth \\ Vi 290 Right $I^{1}$ (Fig. 6): $G_{1}$}

Except for a slight chip from the apex of its root, this tooth is a perfectly preserved maxillary central incisor with a total height of 30.6 $\mathrm{mm}$. Vi 290 is not the same individual as Vi 289 though both exhibit strong shoveling (see below), due to the latter's much more extensive occlusal wear. Root height for Vi 290 is $19.1 \mathrm{~mm}$ and crown height is $12.6 \mathrm{~mm}$, measured from the center of the cemento-enamel junction. Crown dimensions (Table 6) are large and approach the Krapina mean values. Length and breadth of the crown lie respectively 0.7 and 1.1 standard deviations below the Krapina means. The root measures $7.7 \mathrm{~mm}$ in length and 6.7 $\mathrm{mm}$ in breadth.

Occlusal wear is slight to moderate, with only very slight dentin exposure along the occlusal surface. Wear on the occlusal surface is flat in the labiolingual direction but convex mesiodistally. The wear surface is sharply inclined lingually and continues about halfway down the marginal ridges of the tooth. Both interproximal facets are centrally located on their respective margins and begin at the occlusal surface. They are only slightly developed, with breadths of $1.9 \mathrm{~mm}$ for the mesial facet and $2.4 \mathrm{~mm}$ for the distal facet. 

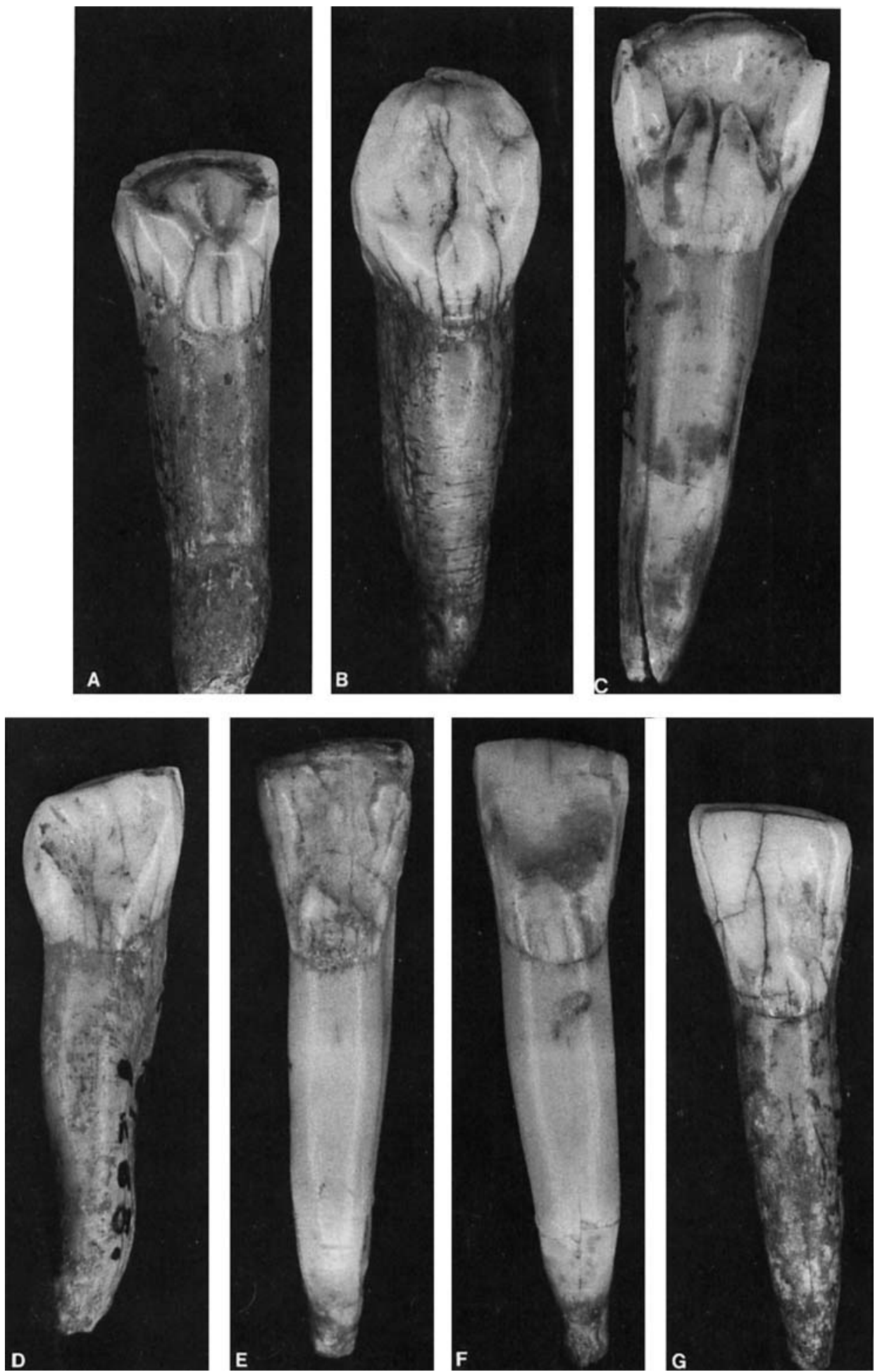

Fig. 6. The isolated Vindija anterior teeth, shown to the same approximate scale. Above are Vi 289 (left, I²), Vi 287 (middle, maxillary canine), and Vi $290\left(\mathrm{I}^{1}\right)$, all in lingual view. Below is $\mathrm{Vi} 288$ to the left, a mandibular canine in lingual view. In the center are lingual and labial views of the $\mathrm{Vi} 201 \mathrm{I}_{2}$ (note the chipping surrounding the occlusal surface on both sides). The right lower specimen is Vi $286\left(I_{2}\right)$. We believe that each tooth represents a different individual 
A number of chips occur on the occlusal surface and the scar for a large step flake occurs on the labiodistal corner. For three of the chips, the edges are worn and rather rounded, suggesting that they represent antemortem damage.

Like most Neandertal maxillary incisors, $\mathrm{Vi}$ 290 is markedly shoveled. The basal tubercle is doubled, with the mesial tubercle measuring $1.8 \mathrm{~mm}$ in breadth at its base and the distal tubercle measuring $2.3 \mathrm{~mm}$. Finger-like extensions of both extend up the lingual face. The marginal ridges are very well developed and measure over $2 \mathrm{~mm}$ in breadth each. The distal ridge is separated from the labial surface by a distinct groove, but the internal margin for the mesial ridge is less distinet.

\section{Vi $289 \quad$ Right $\mathrm{I}^{2}$ (Fig. 6): $\mathrm{F}_{\mathrm{d}}$}

This lateral maxillary incisor is very heavily shoveled and markedly worn. Maximum tooth height and height of the center of the crown are $25.6 \mathrm{~mm}$ and $9.3 \mathrm{~mm}$, respectively, but at least half the original crown height is lost due to the extensive occlusal attrition. Root height is $\mathbf{1 7 . 5}$ $\mathrm{mm}$, and the root measures $8.2 \mathrm{~mm}$ in labiolingual diameter by $5.3 \mathrm{~mm}$ in mesiodistal diameter. Crown dimensions are moderate by Krapina standards, although well within the observed range (Table 6). Crown breadth is about one standard deviation below the Krapina mean.

Occlusal wear is very heavy for this specimen, as well as slightly concave labiolingually and lingual in slope. The angle of the occlusal surface is about $30^{\circ}$ to the horizontal defined by the long axis of the tooth. Dentin is exposed along the entire occlusal surface, including the marginal ridges, forming a continuous " $U$ " or horseshoe pattern. A large chip occurs at the distolabial corner, with step flaking continuing down the labial face. The rounded edges suggest that this occurred antemortem. The interproximal facets are about $2 \mathrm{~mm}$ in breadth and are both centrally located on the labiolingual plane. Interproximal wear is moderate in degree for this specimen.

Morphologically, Vi 289 is very similar to several lateral maxillary incisors at Krapina. The basal tubercle and marginal ridges are all very strongly developed on the lingual aspect of this specimen, resulting in a marked degree of shoveling. The tubercle is $3.5 \mathrm{~mm}$ high and exhibits a well-excavated lingual pit superiorly. The mesial and distal marginal ridges, only remaining for $2.5 \mathrm{~mm}$ above their base due to the extensive occlusal attrition, are $2.5 \mathrm{~mm}$ and $3.4 \mathrm{~mm}$ in breadth, respectively. The root is stout and oval in shape, with a moderate mesial groove. There is a distinct distal curve to its lower half.

\section{Vi 201 Left $\mathrm{I}_{2}$ (Fig. 6)}

This lateral mandibular incisor was the first hominid specimen found at Vindija. It is a perfectly preserved tooth measuring $27.3 \mathrm{~mm}$ in height. Root height is $17.8 \mathrm{~mm}$, and crown height is $10.5 \mathrm{~mm}$ from the labial aspect of the cemento-enamel junction. The crown size of this tooth is very close to the western Neandertal mean. Using breadth for comparison, since it is unaffected by interproximal attrition, the $7.7 \mathrm{~mm}$ value for this specimen lies at the mean of $7.8 \mathrm{~mm}$ calculated for 15 western Neandertals $(\sigma=0.69)$. Breadth for this specimen is 1.4 standard deviations below the mean of $8.4 \mathrm{~mm}$ for the three western specimens dated to Würm 1 (2 from Arcy-sur-Cure and 1 from Regourdou) and is also less than the $8.0 \mathrm{~mm}$ mean value for nine measurable individuals from Krapina (Table 6). Crown length is $7.0 \mathrm{~mm}$ and exceeds the Krapina mean. The maximum labiolingual and mesiodistal diameters of the root are 8.4 $\mathrm{mm}$ and $4.6 \mathrm{~mm}$, respectively.

Occlusal wear is moderately flattened and slightly convex in both the mesiodistal and labiolingual planes. The occlusal facet measures $7.0 \mathrm{~mm}$ in length and $2.4 \mathrm{~mm}$ in maximum breadth. Only a slight exposure of dentin is present along this plane. The borders of the incisal surface are rounded, and there is extensive chipping on both the labial and lingual faces. (Fig. 6). Microscopic examination indicates only some small chips with rounded borders, indicating they were clearly antemortem.

Interproximal wear is slight. The mesial interproximal facet measures some $4.5 \mathrm{~mm}$ in length and drops vertically from the occlusal plane. The distal facet is placed to the labial edge of the distal surface. It begins some $2 \mathrm{~mm}$ below the occlusal surface and extends inferiorally and slightly labially for $3 \mathrm{~mm}$.

Morphologically, the tooth is weakly shoveled with a broad basal tubercle, and a pattern of slight horizontal bands covering the labial crown surface. The root is mesiodistally compressed with strong labial and lingual pillars.

\section{Vi $286 \quad$ Right $I_{2}$ (Fig. 6): $F_{d}$}

This tooth is remarkably similar to Vi 201 in size (Table 6), morphology, and wear, except for the absence of chipping and crown damage. Total tooth height is $26.1 \mathrm{~mm}$, root height is 
$17.2 \mathrm{~mm}$, and crown height is $10.6 \mathrm{~mm}$. Crown breadth is $7.8 \mathrm{~mm}$, and the length and maximum breadth of the occlusal surface (incisal plane) are 7.1 and $2.7 \mathrm{~mm}$, respectively. The labiolingual diameter of the root is $8.6 \mathrm{~mm}$, and the mesiodistal diameter is $4.6 \mathrm{~mm}$.

Occlusal wear is moderate and flat, with a distinct distal slope. Dentin is exposed along almost the entire surface length, but breadth of the exposure is never greater than $0.6 \mathrm{~mm}$.

Interproximal wear is slight. The mesial contact facet (breadth $=2.2 \mathrm{~mm}$ ) lies at the occlusal margin, while the distal facet (breadth $=2.2 \mathrm{~mm}$ ) is somewhat lower. Its superior edge is $2 \mathrm{~mm}$ below the occlusal margin. Both facets are centrally located on a labiolingual plane.

Like Vi 201, Vi 286 is weakly shoveled with very weak marginal ridges on its lingual crown surface. The basal tubercle is quite well developed and extends about $1 / 3$ of the way up the crown. A distally positioned vertical groove lies between the tubercle and the weak marginal ridge. The root is strongly compressed mesiodistally, with well-developed mesial root concavities and pillars.

\section{Vi $287 \quad$ Right $\mathrm{C}^{1}$ (Fig. 6): $\mathrm{G}_{1}$}

This canine shows only slight occlusal wear, but in two distinctly separate planes. An occlusal facet occurs at the tip, resulting in a worn surface $3.4 \mathrm{~mm}$ in length and $3.6 \mathrm{~mm}$ broad. This facet is interrupted mesially by a large chip extending down the labial face with sharp edges that do not allow a determination of whether it occurred post- or ante-mortem. The central facet is convex in both labiolingual and mesiodistal directions and has a marked lingual slope. There is a very slight area of dentin exposure at its center. The second facet is contiguous with the first, extending halfway down the distal marginal edge of the lingual side. It is flat and only slightly angled relative to the length axis of the crown, resulting in a sharpened distal edge.

Total tooth height for this specimen is 33.0 $\mathrm{mm}$ and is probably only slightly reduced by occlusal wear. Root height and crown height are $21.8 \mathrm{~mm}$ and $12.5 \mathrm{~mm}$. Crown dimensions are virtually identical to the Krapina means (Table 6). Maximum root dimensions are 6.7 $\mathrm{mm}$ (mesiodistal) and $10.1 \mathrm{~mm}$ (labiolingual).

Occlusal wear is moderate on this specimen, while there is but a trace of interproximal wear. A small mesial interproximal facet (breadth $=1.7 \mathrm{~mm}$ ) is found about halfway up from the crown base and is displaced lingually viewed from the mesial aspect. An identically sized distal facet is located somewhat lower on the crown but more centrally positioned in labiolingual aspect.

The basal tubercle continues on the mesial surfaces as a weak marginal ridge, marked by a distinct groove distal to it. The mesial pit is well developed and is connected to a second pit just mesial to the tubercle by a very weak groove. Additional small pits are found near the mesial and distal margins.

Vi 288 Left $\mathrm{C}_{\mathrm{1}}$ (Fig. 6): $\mathrm{F}_{\mathrm{d}}$

This canine exhibits more occlusal wear and a different interproximal wear facet size than either Vi 201 or Vi 286, suggesting that it represents a different individual than either of the unassociated mandibular incisors in the sample. Total tooth height for this specimen is 25.4 $\mathrm{mm}$. The root height is $16.5 \mathrm{~mm}$, and the mesial and distal heights of the crown are $11.0 \mathrm{~mm}$ and $9.8 \mathrm{~mm}$, reflecting the marked distal slope of the flat occlusal surface. Crown length lies 2.2 standard deviations below the Krapina mean, and the breadth difference is about the same (Table 6). The occlusal surface does not extend to the distal edge of the tooth and its maximum length and breadth diameters are 6.2 and 3.0 $\mathrm{mm}$, respectively. Exposed dentin occupies approximately $1 / 3$ of the occlusal surface breadth. Maximum root diameters are $8.8 \mathrm{~mm}$ (labiolingual) and $5.0 \mathrm{~mm}$ (mesiodistal).

The lingual surface of the tooth is moderately shoveled, with the distal marginal ridge being the more pronounced and exhibiting a more distinct groove following its edge. The marginal ridges extend to within $2.1 \mathrm{~mm}$ of the cemento-enamel junction. There are some weak hypoplastic features near the base on the labial side. The root is robust and slightly compressed mesiodistally.

Interproximal wear is slight. The mesial interproximal facet measures $1.7 \mathrm{~mm}$ in breadth and is centrally located. A very weakly developed distal facet parallels the distal marginal ridge.

\section{Vi 229 Right $\mathbf{M}^{2}$}

This upper molar exhibits a distal interproximal facet (breadth $=4.1 \mathrm{~mm}$ ) indicating that it is not a third molar. It is suggested to be a second molar on the basis of the marked angulation of the roots and their lack of divergence. Adult status is indicated by the distal facet, fusion of the distal roots, and the amount of interproximal and occlusal wear.

Occlusal wear is moderate and fairly flat, with a mesiolingual slope. The most wear is on 
the mesiolingual cusp (protocone), where dentin exposure is advanced. The least degree of wear is on the distobuccal cusp (metacone), where no dentin is exposed, although the grooves are virtually obliterated. Occlusal wear on the other cusps are intermediate between the two. Hypocone development is moderate.

Dimensionally, the tooth is broad and mesiodistally short (Table 6). The mesial interproximal facet is large, measuring some $5.6 \mathrm{~mm}$ in breadth.

Summary. All of the isolated Vindija anterior teeth with known provenience are from the Aurignacian levels. These teeth are somewhat reduced compared with the Krapina averages. However, they are markedly larger than the late Neandertal anterior teeth from Hortus but also are larger than the early Upper Paleolithic sample, primarily representing western Europe (Table 6). While intermediate between Krapina and the early Upper Paleolithic sample, the specimens fall within both ranges. The fact that different individuals seem to be represented by these teeth suggests that this intermediate position may be regarded with more certainty than the small sample sizes might suggest. Since anterior dental reduction is one of the critical evolutionary trends associated with early modern Homo sapiens populations (Frayer, 1978), the large size of the Vindija Aurignacian-associated anteriors may be important.

Some morphological features resemble $\mathrm{Ne}$ andertals. These include the marked shoveling of the maxillary incisors and their lingual basal tubercle development. Even the $I_{2}$ specimens are slightly shoveled, and there are distinct marginal ridges on the mandibular canine. Yet, the ranges of variation overlap with more modern populations. Moreover, the pronounced lingual angulation of occlusal wear on the maxillary incisors is generally found in more modern populations.

The posterior teeth with provenience (including those in jaws) are Mousterian associated. However, like the anteriors discussed above, they are generally between the Krapina sample and the early Upper Paleolithic sample in size. They are larger than the Hortus teeth, paralleling the canine comparison. Compared with Krapina the main reduction is in length, and as a result the Vindija posterior teeth are squarer. Some of this difference is surely due to age; the Krapina average age at death is much lower than any estimate that could be made for
Vindija, and consequently there is less opportunity for length reduction due to interproximal attrition at Krapina. However, if the Krapina interproximal wear rate can be applied to both sites, it is too low to account for the differential reduction of posterior tooth length (Wolpoff, 1979).

\section{Frontals with supraorbitals}

As a preface to the discussion of the individual frontals from Vindija, it is necessary to consider some points pertinent to our analysis of supraorbital torus morphology. Two basic measures of torus size are used in this study. These are thickness and projection, taken at specific points along each torus (defined below). Thickness is defined as the cranial-caudal dimension of the torus, and measurements of thickness are taken as chords from the anterior, superior orbital wall (the inferior aspect of the torus) to the superior toral margin. Projection is defined as the anterior-posterior dimension of the torus. Measurements of projection are taken as minimum chords from the anterior internal margin of the frontal just above the orbital roof to the most anterior point on the torus at that level.

Depending on preservation of the specimen, thickness and projection are taken at up to three points above each orbit. The first, or medial, point is slightly lateral and superior to the medial orbital margin. In this sample, the dimension here was invariably the thickest point on the entire torus. The second, or lateral, point is defined as the thickest point on the supraorbital trigone portion of the torus. The third point, or mid-orbit, is positioned slightly lateral to the middle of the orbit. In this sample it is also the minimum thickness between the first two points. Projections were taken at each of these points as well. Very little asymmetry was noted for specimens possessing a complete torus. Therefore, when both right and left sides of a single torus were available for measurement, the values for corresponding measurements were averaged, and this value was used in computations.

A second point we believe to be relevant concerns the fact that there is a significant amount of age change in torus size in Neandertals (c.f. Vlček 1967; Smith 1976b). Infant and juvenile Neandertals exhibit very little torus development (Vlček 1970), and it is not until full adulthood is reached that the torus achieves its maximum size. Apparently, to judge from Le Moustier and the Krapina remains, a good deal of growth and remodeling of the torus occurs 
between adolescence and adulthood. Moreover, it is possible that continued changes characterize this region through adult life. Thus great care must be taken only to compare dimensions between adult specimens. Even older subadults must be treated with caution to insure equivalent samples.

Determining the age of isolated tori accurately is, of course, not possible. However, after careful studies of the tori from Krapina, Vindija, and other localities, it does seem possible to place tori in age "classes" (infant, adolescent, adult) based upon such factors as relative demarcation of the torus from the frontal squama, degree of fine cancellous bone deposition and primary bone deposition on the anterior sinus wall and on the superior and posterio-lateral aspects of the torus at the level of the temporal notch, and the development of the frontal sinus. Our current research suggests that thickening of the anterior sinus wall by the deposition of fine cancellous bone appears to be the crucial factor assuring adult status for a specimen, because this deposition apparently occurs during the later stages (i.e. adolescent to adult) of toral remodeling.

\section{Vi 202 Right supraorbital segment \\ (Figs. 7,8): $\mathrm{G}_{3}$}

This fragment consists of a well-developed supraorbital torus and some adjacent frontal squama extending from the fronto-malar suture medially for $45.9 \mathrm{~mm}$ to a point well past the mid-orbit but short of the glabellar region. At this point, the medial cross section of the torus reveals a well-excavated frontal sinus. The sinus extends laterally to the level of the supraorbital notch $(26.6 \mathrm{~mm}$ from the fmo position). A portion of the frontal squama extends slightly more medially than the torus but still does not reach the midline. The temporal ridge is prominent on the preserved squama just behind the orbit at the weakly developed temporal notch but quickly lowers to become an indistinct line. At the most posterior edge of the preserved squama, $33.8 \mathrm{~mm}$ behind the anterior face of the torus, the thickness of the squama at the temporal line is $4.8 \mathrm{~mm}$. The maximum preserved thickness of the frontal squama is $5.3 \mathrm{~mm}$ and lies just medial to tr is point.

Fig. 7. Lateral view of frontal fragments (beginning above) Vi 279, Vi 262, Vi 260, and Vi 202. Note differences in supraorbital projection, frontal form, and sulcus development. The specimens are shown to the same approximate scale.
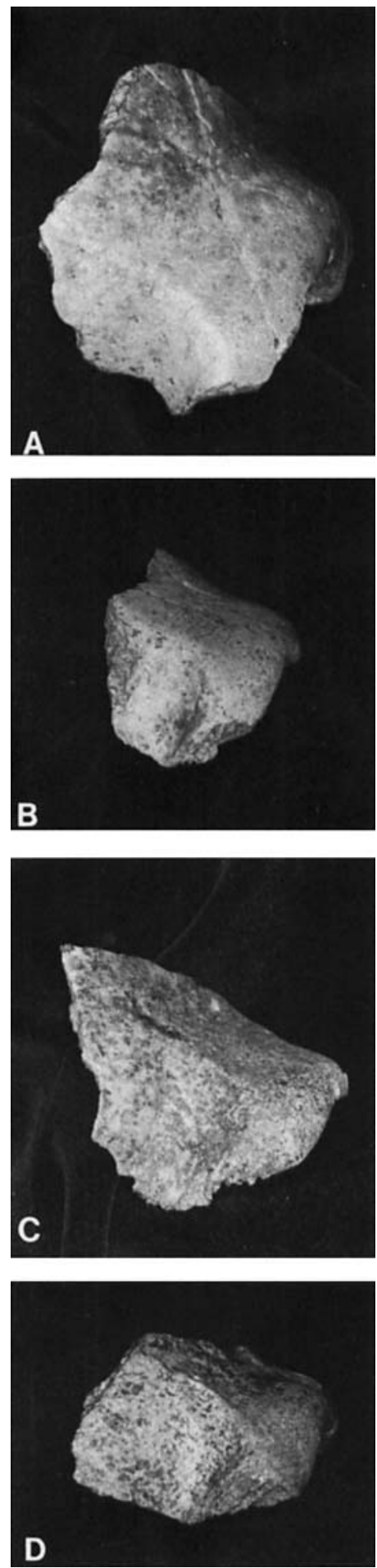

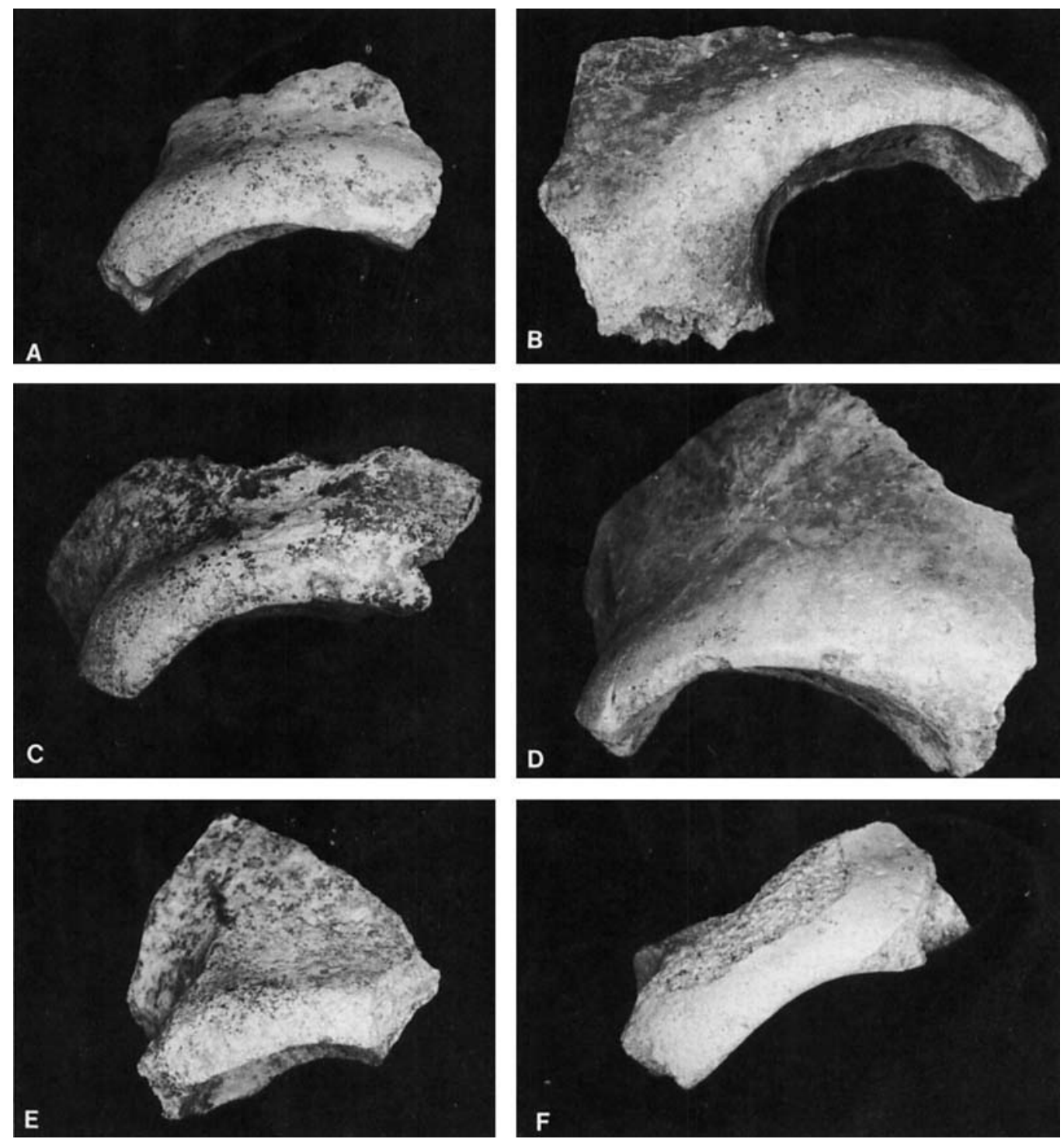

Fig. 8. Frontal view of Vindija supraorbital fragments, shown to the same approximate scale. Left to right, the top row shows Vi 262 and Vi 224, the middle row Vi 202 and Vi 279, and the bottom row Vi 260 and Vi 264 . Vi 224 and 279 may not be fully adult.

Vi 202 is unquestionably from an adult individual. In addition to the presence of a well-developed continuous supraorbital torus and an extensive frontal sinus (both of which indicate an adult) the anterior wall of the frontal sinus is considerably thickened by the deposition of fine cancellous bone. This later feature, as noted earlier, is a characteristic of adult Neandertals.
The supraorbital torus is one of the thickest of the Vindija tori at both the lateral and midorbital points and lies within one standard deviation below the Krapina mean for each (Table 7). However, Vi 202's projection is only average (mid-orbit) or below (lateral) for Vindija tori and more than three standard deviations below the Krapina mean (Table 7).

Morphologically, the torus is rather evenly 


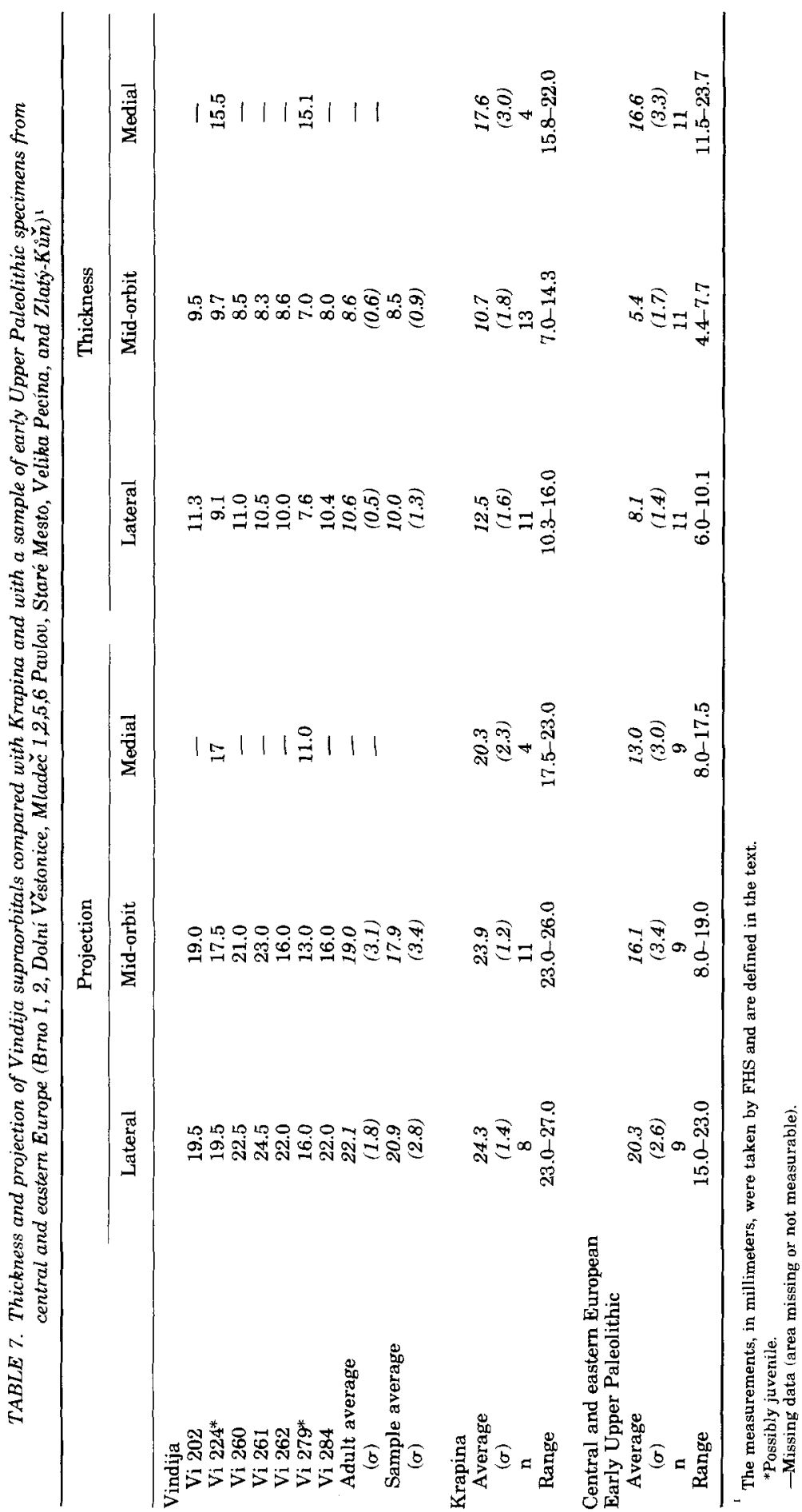


distributed over the orbit. In spite of the presence of a supraorbital notch (breadth $=4 \mathrm{~mm}$ ), there is no division of the torus into the distinct medial and lateral elements characteristic for modern Europeans (c.f. Cunningham, 1908). There is, however, a tendency toward more thinning of the mid-orbital segment of the torus relative to the lateral segment. This pattern is characteristic for all the Vindija adult tori. Surface bone characterized by the "vermiculate pattern" (c.f. Tappen, 1978; Oyen et al., 1979) is present on the anterior torus along its entire preserved length and on its superior aspect from the level of the supraorbital notch laterally. Finally, a shallow sulcus separates the torus from the frontal squama.

Vi 224 Supraorbital region (Figs. 8,9): $\mathrm{G}_{3}$

The specimen consists of an entire left supraorbital region preserved from the frontomalar suture past the midline and including a portion of the nasofrontal region. Virtually none of the frontal squama is preserved. Maximum preservation of the squama is at the midline, extending $33.1 \mathrm{~mm}$ behind glabella. Some damage was sustained by the lateral $2 / 3$ of the anterior torus face, which is reminiscent of Le Moustier, Krapina 23, and Vi 279 in form. Although evenly developed, it barely projects anterior to the frontal squama and is only separated from the squama by a shallow sulcus laterally. At the midline, there is no sulcus separating the frontal squama from the glabellar region. The anterior face of the torus is not vertical. Instead, it is evenly curved between the superior orbital margin and the frontal squama. While this morphology may reflect a young age for the specimen, the presence of a moderately marked temporal ridge and a fairly large frontal sinus extending laterally to within $27 \mathrm{~mm}$ of the fmo position argue against juvenile status. One further factor, however, suggests that Vi 224 may not be an adult. The anterior wall of the frontal sinus does not exhibit significant build-up of fine cancellous bone, which is found in all specimens from Krapina and Vindija that are unequivocally adult. Thus, since it cannot be definitely ascertained whether the torus of this specimen has reached its maximum growth level, it will not be included as an adult in the Vindija sample for purposes of metric comparisons. The specimen is probably older than Le Moustier (13 years).

Laterally, the torus of Vi 224 is one of the thinnest at Vindija, although at mid-orbit its thickness is the maximum at the site (Table 7).
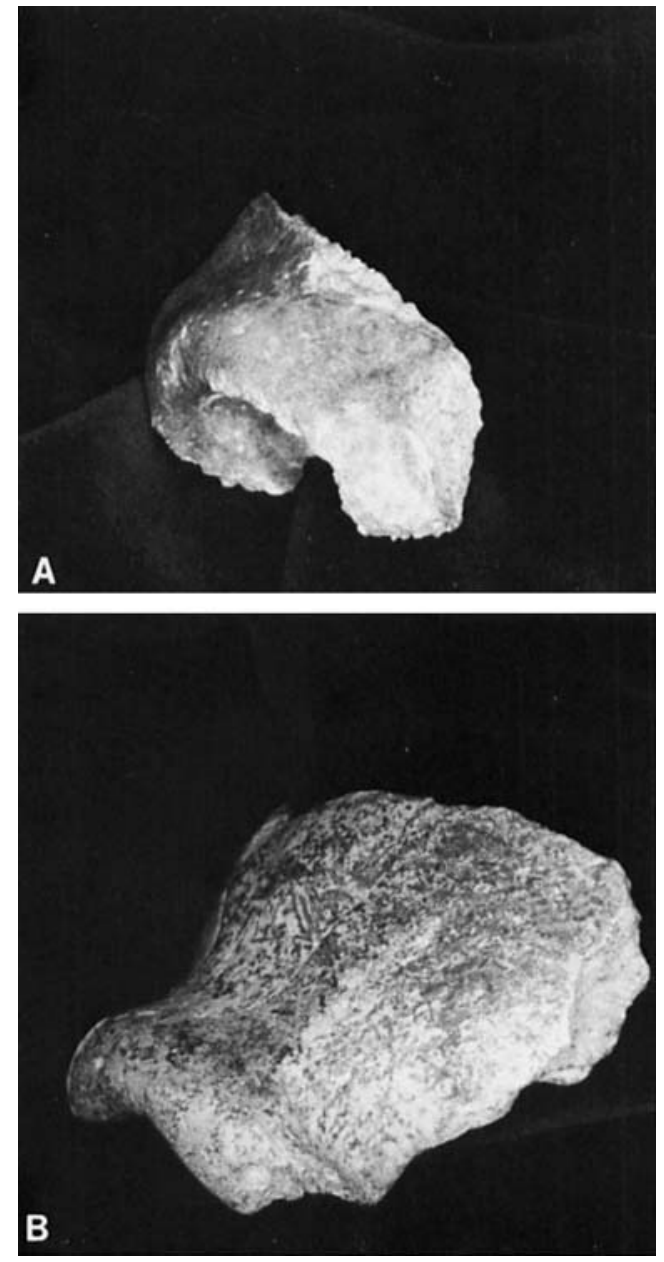

Fig. 9. Vi 224 (above) and Vi 261 in lateral view. Note the marked differences in supraorbital form and projection, and in the position of the frontal squama relative to the torus.

Projection at mid-orbit is moderate. The midorbit and lateral thicknesses are 0.4 and 2.1 standard deviations below the Krapina mean. Vi 224 is one of the two Vindija specimens preserving glabella and the most medial extent of the torus. Here the thickness of the Vindija specimen lies 0.7 standard deviations below the Krapina mean.

Measures of torus projection provide interesting results. Supraorbital length as defined by Weidenreich is one of the smallest at Vindija, reflecting the shallow supra-toral sulcus. Torus projection measured from the internal cranial surface is 0.5 standard deviations below 
TABLE 8. Projection of nasion anterior to the bi-fmt line for Vindija and all other available Neandertal specimens ${ }^{I}$

\begin{tabular}{lccc}
\hline & $\begin{array}{c}\text { bi-fmt } \\
\text { breadth }\end{array}$ & $\begin{array}{c}\text { Nasion } \\
\text { to } f m t\end{array}$ & $\begin{array}{c}\text { Nasion } \\
\text { projection }\end{array}$ \\
\hline Vindija 224 & 113.5 & 60.3 & 20.4 \\
Sala & 114.3 & 61.8 & 23.5 \\
Krapina E & 117.9 & 63.5 & 23.6 \\
Krapina C & 118.9 & 64.6 & 25.6 \\
Spy 1 & 121.8 & 66.4 & 26.5 \\
Le Moustier & 115.4 & 63.7 & 27.0 \\
Mt Circeo & 120.0 & 66.2 & 28.0 \\
Saccopastore 1 & 118.0 & 65.5 & 28.4 \\
La Chapelle & 121.0 & 67.1 & 29.0 \\
Neandertal & 118.4 & 66.1 & 29.4 \\
La Quina 5 & 106.5 & 61.2 & 30.2 \\
Gibraltar & 114.8 & 65.5 & 31.6 \\
La Ferrassie 1 & 121.4 & 69.4 & 33.6 \\
Saccopastore 2 & 124.3 & 71.7 & 34.5 \\
& & & \\
Western European & & & \\
Neandertal & & & \\
त & 117.9 & 65.5 & 28.5 \\
$\sigma$ & 4.5 & 2.9 & 3.4 \\
$\Delta$ Vindija & & & \\
$\sigma$ & 1.0 & 1.8 & 2.4 \\
\hline
\end{tabular}

'The projection is defined as the perpendicular height of a triangle with the base being the bi-fmt chord and the sides being the nasion-fmt chord. The measurements, in millimeters, were taken on the original specimens.

the Vindija mean at mid-orbit and 1.5 standard deviations below the Vindija mean laterally. We believe these data may reflect the incomplete frontal sinus development. Medial, mid-orbit, and lateral projections for Vi 224 are, respectively, 1.0, 5.5, and 3.5 standard deviations below the appropriate Krapina means. This contrasting development of supraorbital projection (i.e. relatively less lateral and midorbit than medial projection) may also reflect the juvenile status of Vi 224. Full remodeling and maximum torus development had not yet occurred in the lateral region.

One modern aspect of the torus lies in the relative projection of nasion as measured to a line drawn between the fmt points (Table 8). The normal Neandertal condition of mid-facial prognathism is reflected by a marked perpendicular projection of nasion anterior to this line. In $\mathrm{Vi} 224$, nasion is in a very high position, approaching glabella, which would tend to increase its projection. Yet, the projection of the Vi 224 frontal is below the Neandertal range and 2.3 standard deviations below the $\mathrm{Ne}$ andertal mean. This suggests a reduction in the extent of mid-facial prognathism for the Vindija specimen.
Aligning the superior orbital roof horizontally indicates a fairly high angle for the forehead. Squama thickness at the midline, $33 \mathrm{~mm}$ behind glabella, is $8.5 \mathrm{~mm}$. This is $13.6 \mathrm{~mm}$ behind the posterior wall of the frontal sinus.

The intraorbital region is fairly broad. Posterior intraorbital breadth is estimated at 30.5 $\mathrm{mm}$, and the length of the nasofrontal suture from nasion to the medial orbital margin is 21 $\mathrm{mm}$. Nasion is $19.6 \mathrm{~mm}$ anterior to the crista frontalis and $11.7 \mathrm{~mm}$ in front of the anterior sinus wall.

Vi 227 Frontal fragment with left portion of supraorbital: $\mathrm{G}_{3}$

This fragment unquestionably is from an infant. It extends from the left frontomalar suture to a point $15 \mathrm{~mm}$ to the right of the midline and sagitally no more than $39.5 \mathrm{~mm}$ posterior to the posterior border of the frontal sinus at the midline. While there is no actual torus development, a shallow sulcus extends posterior to the left orbital edge up to the somewhat elevated midline region. This creates a distinct "outline" of where the torus will develop later. Similar morphology is exhibited by several infant and young juvenile Neandertals (Vlček 1967, 1970; Smith 1976b). There is no development of the vermiculate pattern on the frontal of this specimen.

The vault bone is thin $(4.4 \mathrm{~mm}$ at the most posterior point on the midline and $3 \mathrm{~mm}$ at a point $26 \mathrm{~mm}$ behind the midorbit), probably a reflection of the specimen's age. Yet, the posterior-superior portions of at least two distinct sinus cavities are preserved on the left, and there is a corresponding single cavity on the right which terminates at the broken edge of the fragment. The left cavities extend $15.6 \mathrm{~mm}$ from the midline. This suggests that the frontal sinuses begin to develop very early in these hominids. Midline curvature of the squama suggests a bulging (bossed) profile similar to some of the adults. Based on a horizontal orientation for the superior orbital roof, the forehead slope is moderate.

\section{Vi 260 Right supraorbital torus fragment (Figs. 7,8): $\mathrm{G}_{3}$}

This specimen extends some $32.5 \mathrm{~mm}$ along the torus from the frontomalar suture to a point just short of the mid-orbit. The frontal squama is preserved as far as $49.7 \mathrm{~mm}$ posterior to the superior orbital margin, and its thickness at this point is $3.6 \mathrm{~mm}$.

At its lateral border the torus is about average in thickness for Vindija (Table 7). Mid-orbit 
thickness lies 1.2 standard deviations below the Krapina mean. In contrast the torus projection is marked, and there is a deep sulcus separating it from the fairly straight preserved portion of the frontal squama. At the medial break, frontal sinus is exposed. The anterior sinus border is $12 \mathrm{~mm}$ behind the anterior torus edge, but laterally it extends to about $20 \mathrm{~mm}$ from the fmo position. The anterior wall exhibits significant thickening due to fine cancellous bone deposition. Also, the external bone table on the superior and anterior aspects of the torus exhibits the vermiculate pattern over the entire preserved segment. Thus, Vi 260 appears to be an adult specimen.

The temporal line is prominent, extending as a ridge for $25.5 \mathrm{~mm}$ behind the orbit. In contrast, however, the squama is very thin compared with other Vindija specimens (see Table $11)$ or with the Krapina sample.

\section{Vi $261 \quad$ Frontal (Figs. 9,10): $\mathrm{G}_{3}$}

The specimen consists of three pieces. Two of these (discovered in 1977 and 1978, respectively), combine to form a large fragment that extends from the border with the zygomatic on the lateral left side to a point $36.5 \mathrm{~mm}$ to the right of the midline. On its lateral left face, the frontal squama extends to the coronal suture, some $59.3 \mathrm{~mm}$ posterior to the supraorbital torus. The torus is preserved in its entirety for $36 \mathrm{~mm}$ medial to the frontozygomatic suture, and the top of the structure is preserved to the midline. The anterior and inferior portions of the torus are missing medial to mid-orbit. A frontal sinus is exposed by the broken orbital roof. On the left side the complete sinus is $29 \mathrm{~mm}$ in transverse breadth, and its superior surface extends $23 \mathrm{~mm}$ behind the anterior face of the torus. There is significant deposition of fine cancellous bone in the anterior wall of the sinus. The vermiculate pattern is present over the entire external surface of the anterior aspect of the torus but is limited on the superior aspect to the region lateral to the sinus.

This is the most archaic-appearing of the preserved tori, resembling the Ehringsdorf $\mathrm{H}$ frontal in its marked projection. It is the most projecting Vindija specimen both at mid-orbit and laterally, but it is still below the Krapina mean at mid-orbit and only slightly above it laterally (Table 7). The torus is continuous but unevenly developed, closely following the orbital contour and dipping significantly at glabella. While there is thickening at both the lateral position and the most medial extension, the torus is thinnest at a point about midway between these. In fact, laterally and at mid-orbit the thicknesses of Vi 261 are below the Vindija means and far below Krapina.

There is no supraorbital notch or groove. As seen from the top, there is a significant posterior-lateral angulation to the torus.

The extension of the torus anterior to the frontal squama is marked. The squama has a fairly high angle to the orbital roof and is distinctly rounded in lateral view. There is a very deep sulcus between the squama and the supraorbital (Fig. 9), which is accentuated by the marked boss immediately above it. This sulcus is shallowest at the midline but deepens significantly laterally. Measured at the position of the lateral eminence, the squama is the thickest of the Vindija specimens (Table 11) and is slightly above the Krapina average. At this position, just behind the sinus and $29 \mathrm{~mm}$ from the midline, the thickness attains $8.7 \mathrm{~mm}$. The temporal line forms a prominent ridge, extending for most of the preserved length of the squama. Finally, the temporal notch is deep. Combined, these features suggest the likelihood that the specimen was a male. It is unquestionably adult.

A third piece is Vindija 278, a centrally located posterior fragment of frontal squama with a $6.7 \mathrm{~mm}$ length of coronal suture. This is almost certainly the same individual. Unfortunately, the badly eroded posterior border of the larger supraorbital-bearing fragment makes a clear contact impossible to establish. Vi 278 is maximally $64.8 \mathrm{~mm}$ in length (approximately parallel to midline) and $44.8 \mathrm{~mm}$ transversely. A marked endocranial groove, almost certainly representing the posterior extension of the sagittal sulcus, occurs along the long edge of the fragment. This edge is the approximate midline and consequently the bregma position is preserved on the coronal suture. Along the midline, thickness expands from $5.9 \mathrm{~mm}$ at bregma to $8.2 \mathrm{~mm}$ at the most anteriorally preserved point. Combining the two pieces in their approximate relationship indicates a glabella-bregma distance of $113-116 \mathrm{~mm}$. In midline profile the complete squama is markedly curved.

\section{Vi 262 Right supraorbital torus fragment (Figs. 7,8): $\mathrm{G}_{3}$}

The lateral and central portions of the right side are present in this specimen and extend from the frontomalar suture to a position just medial to the mid-orbit. The frontal squama is preserved to a maximum of $30.8 \mathrm{~mm}$ posterior to the superior orbital margin. The torus is only 

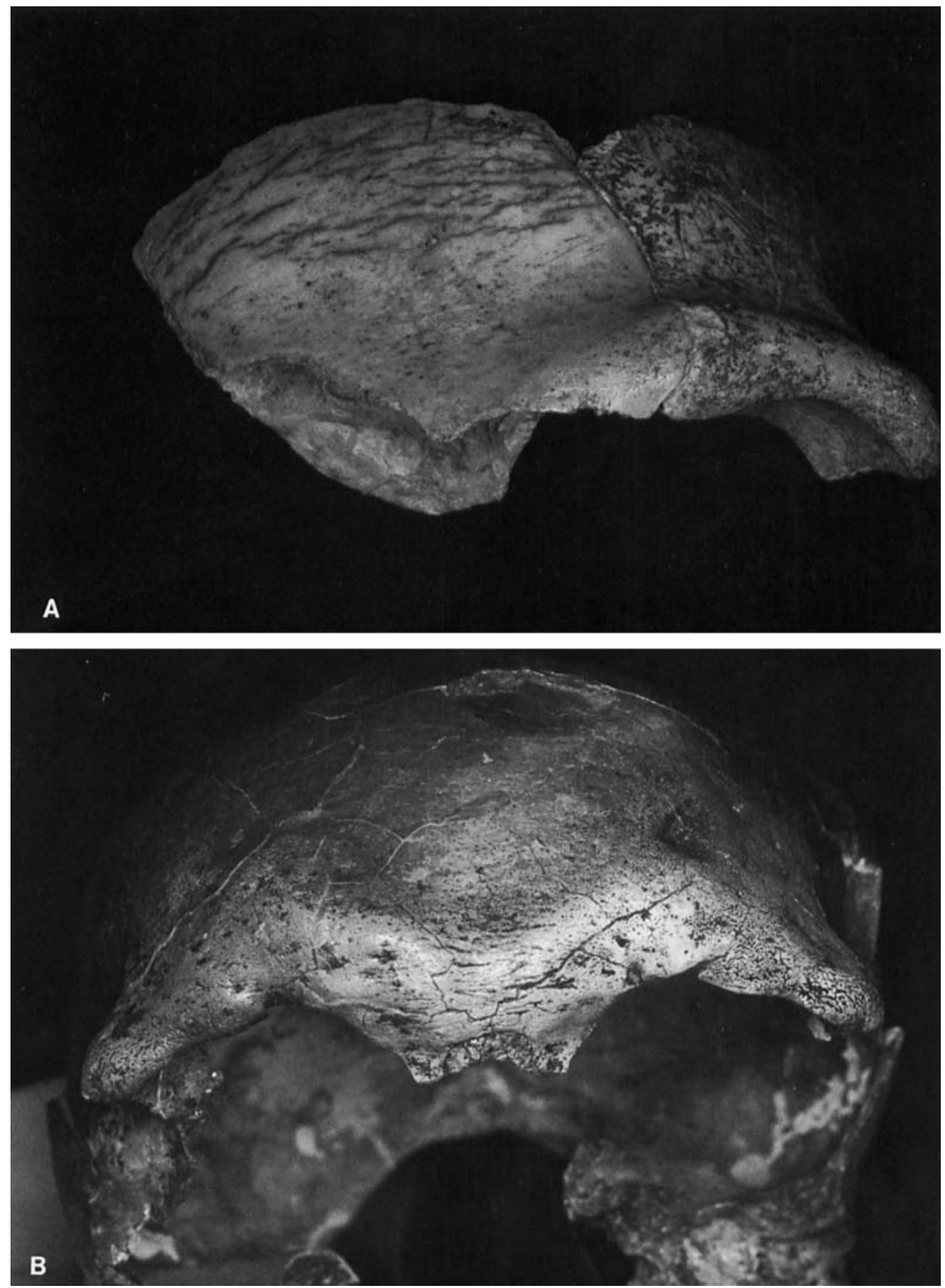

Fig. 10. Comparison of the Vi 261 supraorbital torus (top) with Mladec 5 (bottom). The specimens are shown to the same approximate scale. The lateral and lateral-central thinning of the Vindija torus reflects its intermediate position between the European Neandertal form and the early Upper Paleolithic associated morphology. The differences between these specimens do not suggest a radical change. 
moderately developed, curving smoothly backwards from the superior orbital margin and presenting no steep anterior face. There is a great similarity to Vi 224 in this region. A shallow sulcus separates the torus from the squama. The torus itself is continuous and seems to thicken medially. The vermiculate pattern is present both on the superior and anterior aspect of the torus. No frontal sinus is exposed at the medial break. The overall form of the torus suggests an adult or older juvenile.

The temporal line is weakly developed, swinging directly posteriorly from the poorly excavated temporal notch. The frontal seems moderately angled relative to a horizontal plane defined by the orbital roof.

\section{Vi 279 Right supraorbital fragment (Figs. 7,8): $\mathrm{G}_{3}$}

This fragment extends from the frontozygomatic suture, over the entire superior orbital margin, to a point that cannot be more than several millimeters short of the midline. Maximum frontal squama preservation is at about the mid-orbit position and extends 41.7 $\mathrm{mm}$ behind the superior orbital margin. The very weakly developed torus does not present a vertical face above this margin. Actually, there is virtually no torus up to the position of the distinct supraorbital notch (breadth $=2.6 \mathrm{~mm}$ ), located $34.9 \mathrm{~mm}$ medial to the fmt position. There is no groove extending from this notch, while moderate torus development appears medial to it. A well-developed frontal sinus, measuring $16.2 \mathrm{~mm}$ in height and $8.4 \mathrm{~mm}$ in length, is visible at the medial break. The exposed sinus extends to the supraorbital notch, $26 \mathrm{~mm}$ from the fmo position, and has very thin walls with virtually no anterior thickening. As was the case for Vi 224, this feature, along with the generally weak torus development, identifies Vi 279 as a juvenile, perhaps of the approximate age of Le Moustier.

In both thickness and projection anterior to the internal surface, the torus is the most poorly developed of any specimen from Vindija, excepting Vi 227 (Table 7). Medial thickness is only 0.8 standard deviations below the Krapina mean; however, the virtual absence of torus development at the mid-orbital and lateral regions contrasts markedly with the Krapina condition. Mid-orbit projection from the internal surface is more than 9 standard deviations below the Krapina mean, and lateral projection is 6 standard deviations below the Krapina mean.
Behind the torus there is a broad groove separating it from the frontal squama. The squama thickness is $5.3 \mathrm{~mm}$ at its most posterior preserved portion. Although one of the steepest foreheads from the site, horizontal angulation of the superior orbital border indicates that the forehead was far from vertical.

The temporal notch is not deep, and the weak temporal line has virtually disappeared by some $36 \mathrm{~mm}$ behind the superior orbital margin.

The similarity of this specimen to Vindija 224 is marked. At first glance, it appears that the two fragments almost meet and could represent a single individual. However, a number of factors convince us that two individuals are involved. The fragments do not actually contact. Moreover, there is marked asymmetry in the development of supraorbital torus thickness (especially centrally) and the projection of the torus at this position (Table 7). Also, there is the presence of a supraorbital notch on $\mathrm{Vi}$ 279 , whereas only a small foramen on the supraorbital surface just medial to the anteriormedial orbital corner appears on Vi 224 . Finally, the temporal notch differs between these specimens insofar as its medial face is more vertical below the temporal line in Vi 224 .

\section{Vi 284 Right supraorbital (Fig. 8): $\mathrm{G}_{3}$}

This fragment extends from the frontomalar suture to approximately the mid-orbit position, $40.4 \mathrm{~mm}$ medial to fmt. The most posterior extent is at the temporal notch, where the fragment is $26 \mathrm{~mm}$ behind the anterior supraorbital border. Beginning at the temporal notch and extending $22 \mathrm{~mm}$ medially, there is extensive damage to the superior supraorbital region and frontal squama.

A frontal sinus is exposed by the medial break, extending to within $28.5 \mathrm{~mm}$ from $f m o$. At its lateral wall, the sinus is $11 \mathrm{~mm}$ in its anterior-posterior dimension and $7.8 \mathrm{~mm}$ in height. The anterior sinus wall is thickened by fine cancellous bone deposition. At the mid-orbit, there is virtually no sulcus between the frontal squama and the supraorbital.

Mid-orbital and lateral supraorbital thicknesses (Table 7) are moderate to small compared to the other Vindija and Krapina specimens. Mid-orbit projection from the internal surface is very small, lying 6.8 standard deviations below the Krapina mean. Both the temporal ridge and notch are moderately pronounced. 
TABLE 9. Indexes of relative supraorbital torus thickness and projection, based on the data and samples shown in Table 7

\begin{tabular}{|c|c|c|c|c|}
\hline & \multicolumn{2}{|c|}{ Thickness } & \multicolumn{2}{|c|}{ Projection } \\
\hline & Mid-orbit/lateral & Mid-orbit/medial & Mid-orbit/lateral & Mid-orbit/medial \\
\hline \multicolumn{5}{|l|}{ Krapina average $(\sigma)$} \\
\hline & $\begin{array}{c}0.85 \\
(0.08)\end{array}$ & $\begin{array}{c}0.62 \\
(0.07)\end{array}$ & $\begin{array}{c}1.00 \\
(0.07)\end{array}$ & $\begin{array}{c}1.20 \\
(0.11)\end{array}$ \\
\hline \multicolumn{5}{|l|}{ Vindija average $(\sigma)$} \\
\hline & $\begin{array}{c}0.81 \\
(0.04)\end{array}$ & - & $\begin{array}{c}0.86 \\
(0.12)\end{array}$ & - \\
\hline \multicolumn{5}{|l|}{$\begin{array}{l}\text { Central and eastern } \\
\text { European Early Upper } \\
\text { Paleolithic average }(\sigma)\end{array}$} \\
\hline & $\begin{array}{c}0.70 \\
(0.05)\end{array}$ & $\begin{array}{c}0.34 \\
(0.06)\end{array}$ & $\begin{array}{c}0.79 \\
(0.10)\end{array}$ & $\begin{array}{c}1.25 \\
(0.16)\end{array}$ \\
\hline
\end{tabular}

Summary. The average differences between the supraorbital regions of Neandertals and early modern Europeans are distinctive. The Neandertal torus tends to be a rather uniformly thick bar, projecting in a shelf-like fashion over each orbit. In early modern Europeans (early Upper Paleolithic), the torus is less projecting and considerably reduced in thickness laterally and at mid-orbit (Table 7). Particularly evident in the early moderns is the pronounced thinning of the torus at mid-orbit. This thinning, reflected both in absolute dimensions at midorbit and mid-orbit dimensions relative to other thicknesses, is noted in descriptions of several early Upper Paleolithic specimens from central Europe (Szombathy, 1925; Matiegka, 1934; Smith, 1976a) such as the Mladeč and Predmostí crania, and Velika Pećina. The torus is only slightly thinner, however, at the medial position in early moderns. The ensuing supraorbital morphology thus reflects the separation of the supraorbital torus into the two distinct regions discussed by Cunningham ('08): the arcus superciliaris medially and the trigonum superorbitale laterally. Though the development of these regions continues to reduce from the early Upper Paleolithic to the present, this morphological pattern is essentially typical for the supraorbital region of modern European and European-derived populations.

Although the adult tori of the Vindija $G_{3}$ hominids would certainly be considered $\mathrm{Ne}$ andertal-like, they appear to approach the early modern condition more than earlier $\mathrm{Ne}$ andertals from Europe do. This is seen in their intermediate metric position, both in thickness and in projection, between the Krapina $\mathrm{Ne}$ andertals and a series of early Upper Paleo- lithic crania from south central Europe (Table 7). The results of $t$-tests for comparison of small and unequal samples (Sokal and Rolf, 1969) confirm this intermediate position for the Vindija $\mathrm{G}_{3}$ hominids as a group (Table 9).

It might be suggested that some of the reduction of toral thickness and projection relative to the Krapina tori is a function of smaller overall body size in the Vindija $\mathrm{G}_{3}$ hominids. There are some data, however, which strongly suggest that the reduction in the torus of the Vindija $\mathrm{G}_{3}$ hominids does in fact represent an evolutionary trend toward the early modern pattern and not simply smaller body size. For example, if one compares reductions in thickness and projection of the three points on the torus, the early Upper Paleolithic morphology exhibits reduction in the thickness of the torus at midorbit relative to either the lateral or medial point (Table 10). Projection at mid-orbit also decreases relative to the lateral point but increases slightly relative to the medial (Table 10 ). When the Vindija $G_{3}$ hominids are compared as a group to Krapina and early moderns, they exhibit an intermediate degree of relative toral thinness. The mid-orbit is reduced relatively more than the lateral segment, exactly what you would expect as a morphological intermediate between the earlier Neandertal (Krapina) and early modern supraorbital morphology (see Fig. 10). This relative reduction at mid-orbit is also observable upon visual examination of the adult Vindija $\mathrm{G}_{3}$ tori.

Comparison of supraorbital projection to thickness reveals a similar pattern. For instance, at the mid-orbit position the early modern European tori shows more reduction in thickness than in projection. A linear regres- 


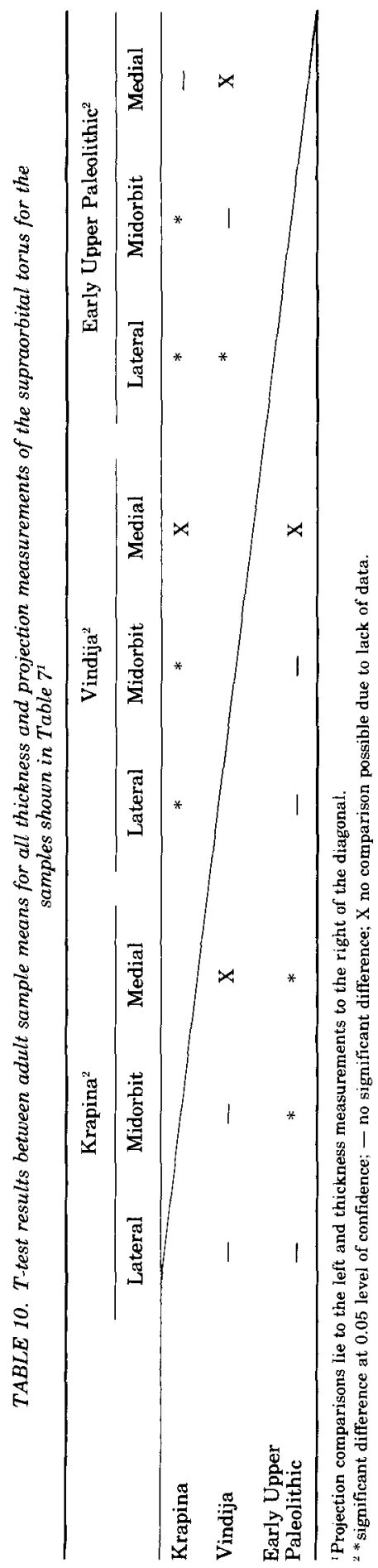

sion fit for thickness and projection has a lower slope in the early modern sample when compared with Krapina. A corresponding slope calculated for the Vindija specimens is intermediate, although closely approaching the early modern European value.

Interestingly, other aspects of the Vindija $G_{3}$ hominid total morphological pattern suggest that reduced supraorbital tori might be expected. Vi 224, for example, indicates that midfacial prognathism may be reduced at Vindija relative to other Neandertals. Furthermore, at least two adult ( $\mathrm{Vi} 261$ and $\mathrm{Vi} 262$ ) and two possibly juvenile (Vi 224 and Vi 279) frontals appear to possess more vertical frontal squamae than most Neandertals. Thus, based on either Endo's (1966) or Moss and Young's (1960) hypothesis to explain the presence and degree of development of a supraorbital torus, the Vindija $G_{3}$ hominids might well be expected to exhibit reduced tori relative to other Neandertals, no matter what their body size.

Vindija is the only European site besides Krapina to preserve a large enough sample of Neandertal supraorbitals to estimate variability. In almost every case, the Vindija coefficients of variation exceed those at Krapina for browridge projections but are somewhat less for thicknesses. The same pattern appears in a comparison of Vindija for the averages of the 11 adult western Neandertals with supraorbitals. Vindija is more variable in projections and less so in thicknesses. This pattern of variability change represents another area in which the Vindija sample is intermediate between earlier Neandertals and the early modern European specimens. This more recent sample is even more variable than Vindija in supraorbital projections and less variable in thicknesses.

Finally, the Vindija tori represent the latest Neandertal supraorbital sample from anywhere in Europe. We believe it is significant that there is evidence for evolutionary change (contra Trinkaus and Howells, '79), and that the evolutionary trends they reveal, when compared with the earlier Neandertal sample from the same region, suggests change in the direction of early modern European populations. The fact that the Săla frontal exhibits a parallel pattern of supraorbital thinning may not be coincidental, although it is unclear whether this better supports a grade or regional clade interpretation of the variation. Yet, we believe it is necessary to restate the fact that these data suggest an evolutionary trend within a morphological complex that must be regarded as Neandertal. 

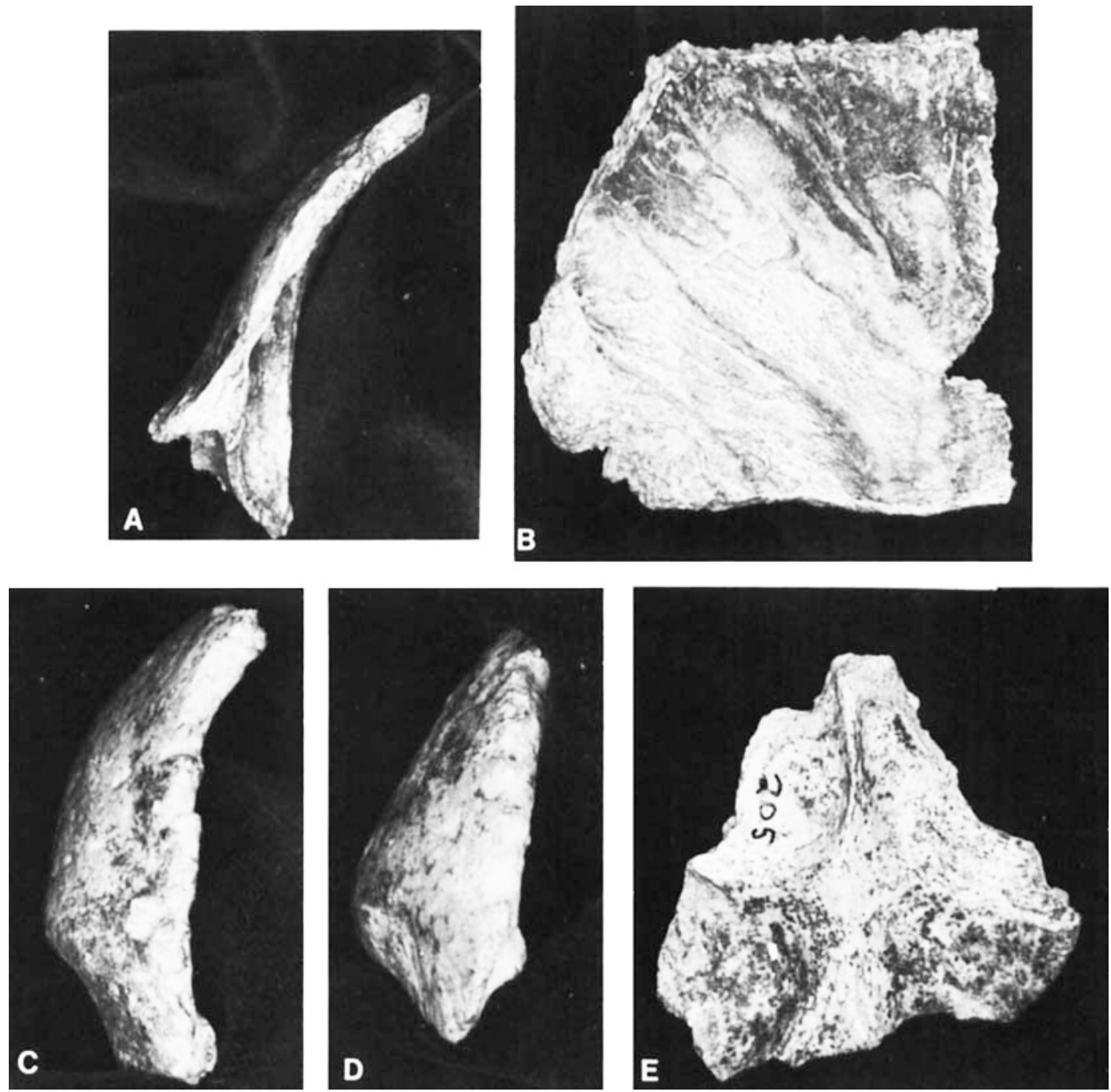

Fig. 11. Some Vindija vault fragments. Above right is an internal view of the Aurignacian-associated specimen Vi 208, and left is a lateral view of the Vi 255 frontal. Vindija occipital fragments are shown below; right is an internal view of Vi 205 ; and center and left are lateral views of Vi 258 and $\mathrm{Vi} 252$, respectively.

\section{Other vault fragments}

Vi 230, Vi 255, and Vi $256 \quad$ Frontal and parietal fragments (Fig. 11): $\mathrm{G}_{3}$

These three fragments constitute what the authors strongly believe (but cannot prove) is a single cranial vault. Vi 230 is a fragment of the anterior superior corner of a left parietal, preserving $29.1 \mathrm{~mm}$ of the sagittal suture (broken just posterior to bregma) and extending maximally some $69.5 \mathrm{~mm}$ downward from the su- ture. The more inferior aspect of the coronal suture is also preserved, although the edge is somewhat damaged. Vi 256 is a fragment of a left posterior portion of a frontal squama with $43.8 \mathrm{~mm}$ of coronal suture preserved. The fragment extends as much as $60 \mathrm{~mm}$ anterior to this suture. No temporal line can be found on the external surface. Maximum bone thickness is about $5.5 \mathrm{~mm}$ positioned along the mid-portion of the bone on an anterior-posterior axis. The minimum thickness of $4.3 \mathrm{~mm}$ is attained 
at the anterior-medial corner. The match with Vi 230 is possible along part of the coronal suture, although the damage on Vi 230 makes an exact fit impossible to establish. Finally, Vi 255 is a large diamond-shaped portion of centrally located frontal squama exposing the posterior wall of a large (breadth $=15.6 \mathrm{~mm}$ ) central lobe and several lateral lobes of frontal sinus on each side. Except for behind glabella, there is a moderately expressed supraorbital sulcus, and the forehead bulges visibly above it. The anterior-posterior length of the exposed sinus is at least $24.5 \mathrm{~mm}$ behind the broken anterior edge. The sinus appears to have been better developed on the left side.

The frontal is thin compared with the Krapina average (Table 11), although the difference is less than a standard deviation and the value lies within the Krapina range. Parietal thickness is virtually identical with the Krapina average. The condition of the sutures suggests that the individual was fairly young, almost certainly a young adult. A lack of marked coronal curvature in the preserved parietal indicates that the vault was probably fairly large. Internally, the parietal preserves impressions of the frontoparietal branch of the middle meningeal artery. There is no trace of either Breschet's sinus or Pacchioni's fossa.

\section{Vi 264 Frontal fragment}

This fragment preserves the anterior midportion of the frontal squama, extending laterally to about the mid-portion of the left side. No sutural borders remain. Anteriorly, the most posterior border of the frontal sinus is preserved. The sagittal sulcus remaining just superior to this is very shallow.

\section{Vi 280 Posterior fragment of frontal squama: $\mathrm{G}_{3}$}

This fragment preserves bregma and extends for $63.3 \mathrm{~mm}$ anterior to it without any trace of crista frontalis endocranially. The maximum transverse breadth is $45 \mathrm{~mm}$. On the posterior border $23.4 \mathrm{~mm}$ of coronal suture remain on the left side and $10 \mathrm{~mm}$ remain on the right. The bone is fairly thin; thickness varies from 3.6 $\mathrm{mm}$ at bregma to $6.8 \mathrm{~mm}$ at the most anterior point. While the fragment is curved over its full anterior-posterior length, the curvature increases over the anterior half. Condition of the coronal suture indicates that the specimen probably was not especially young.

\section{Vi 204 Posterior superior right parietal fragment}

This fragment is roughly rectangular in shape, with $63 \mathrm{~mm}$ of the sagittal suture and
$51.5 \mathrm{~mm}$ of the lambdoidal border preserved (the suture is broken away from the most inferior $15.5 \mathrm{~mm}$ of the border). The lambdoidal region bears no evidence of flattening, and the parietal is evenly curved in the sagittal plane. The suture itself appears to be unfused both internally and on the more complex external surface. The transverse curvature is also even but is rather marked, suggesting that the parietal breadth may not have been great. No parietal foramen is present.

The contour of the bone is not evenly rounded as seen from the rear; instead, the side is fairly gabled, with a pronounced angle between the superior and inferior portions. Rounding is the common, but not invariant, morphology for Neandertals.

No temporal line is visible on the external surface. On the posterior inferior corner there is an approximately $17 \mathrm{~mm}$ square area with outer bone table loss on the external surface (at the corner itself the bone thins to $4 \mathrm{~mm}$ ). Observed microscopically, the external bone surface in this region is irregular, giving the appearance of randomly distributed low swells. In cross section, all of the bone bordering this region is compact. The internal surface appears undisturbed. Terminal portions of the grooves formed by the middle meningeal artery are present.

Parietal thicknesses differ little from the Krapina mean values (Table 11). The central dimensions are slightly under the Krapina mean, and the posterior dimensions are slightly above it.

\section{Vi 208 Anterior superior fragment of} left parietal (Fig. 11): $\mathrm{G}_{1}$

This fragment is roughly pentagonal (the posterior surface has an angle), with $65.7 \mathrm{~mm}$ of the coronal suture and $44.7 \mathrm{~mm}$ of the sagittal suture preserved and intersecting at bregma. The sutures appear to have been unfused, and it is unlikely that the specimen was an adult. There is little sagittal or transverse curvature to the preserved fragment, which might suggest a rather broad vault. Vault thickness decreases markedly along the sagittal suture, varying from $6.8 \mathrm{~mm}$ at bregma to $5.0 \mathrm{~mm}$ at the most posterior preserved point. Generally the vault thicknesses are moderate compared with other Vindija specimens (Table 11), but they are not significantly below the Krapina mean values. No trace of the temporal line is visible.

Internally, the fronto-parietal branch of the middle meningeal artery shows a distinct stem just posterior $(10 \mathrm{~mm})$ to the coronal suture at the fragment's base. Breschet's sinus appears 
as a broad shallow sulcus ( $5.7 \mathrm{~mm}$ ), which proceeds vertically from this point, ending in a shallow pit (Pacchioni's fossa) $21.5 \mathrm{~mm}$ inferior to the sagittal suture. Bregmatic and obelionic branches extend superiorly and posteriorly from this sulcus, and a second larger branch of Breschet's sinus $8.3 \mathrm{~mm}$ in breadth also proceeds in this direction and terminates in an even larger fossa, which is centered $10.6 \mathrm{~mm}$ inferior to the sagittal suture and $34 \mathrm{~mm}$ posterior to the coronal suture.

\section{Vi 251 Left parietal}

The specimen is a small fragment $(40 \times 35$ $\mathrm{mm}$ ), which is difficult to identify with certainty. The presence of two shallow internal pits, the relative positions of minimum and maximum thickness, and the curvature suggest that it is a fragment of left parietal very near the anterior-superior corner. There is no sutural preservation on its edges. Thickness varies from $5 \mathrm{~mm}$ to $6.4 \mathrm{~mm}$.

\section{Vi 257 Left parietal fragment}

This fragment is mainly composed of the mastoid angle of a left parietal, preserving 35 $\mathrm{mm}$ of lambdoidal suture and $37.7 \mathrm{~mm}$ of the beveled squamosal border. The fragment distinctly thickens anteriorly, varying from 7.3 $\mathrm{mm}$ on the most superior point preserved on the lambdoidal suture to $8.1 \mathrm{~mm}$ on the most anterior point preserved, about $10.5 \mathrm{~mm}$ superior to the squamosal border. At the corner of the mastoid angle, the bone is thinner than the Krapina parietals, lying below the range and one standard deviation below the Krapina mean (Table 11). Although the temporal line should appear on this fragment, its position cannot be ascertained.

Internally, grooves representing sporadic terminal branches of the middle meningeal artery are preserved.

\section{Vi 263 Right parietal fragment}

The specimen consists of a $64.7 \mathrm{~mm}$ long portion of the right squamosal border of a parietal, extending to the anterior corner of the bone, where $16.7 \mathrm{~mm}$ of the squamosal suture is preserved. The maximum height above the squamosal suture is $41 \mathrm{~mm}$. The thickness along the squamosal border is almost identical to Vi 257, and it is possible that the same individual is represented. Parietal thickness at the approximate position of the middle eminence is the smallest at Vindija (Table 11) and is 2 standard deviations below the Krapina mean. The bevel for the temporal squama does not extend far up the parietal, reaching $10.8 \mathrm{~mm}$ above the inferior border at the maximum.
On the internal surface, a very marked expression of Breschet's sinus is centered $11 \mathrm{~mm}$ posterior to the coronal suture, paralleling it for the preserved extent of the bone. The sinus breadth is $6.8 \mathrm{~mm}$, and its maximum depth is $1.5 \mathrm{~mm}$. It is identical in form to the expressions noted for Vi 208 and Vi 293.

\section{Vi 285 Left parietal fragment: $\mathrm{G}_{3}$}

The fragment is roughly rectangular, preserving $38.9 \mathrm{~mm}$ of coronal suture from about the midpoint of its length, and extending posteriorly for a maximum of $41.3 \mathrm{~mm}$. Vault thickness ranges from $3.8 \mathrm{~mm}$ at the most superior point on the coronal suture to $5.7 \mathrm{~mm}$ at its most inferior point. The thinness of the vault and the condition of the coronal suture suggest the specimen is juvenile. Endocranially, at least three arterial impressions remain. There is a very shallow indistinct anterior sulcus paralleling the lower portion of the coronal suture. Its posterior edge is $8.7 \mathrm{~mm}$ behind the suture.

\section{Vi 293 Left parietal fragment}

This specimen is roughly triangular in shape and preserves the lower anterior corner of a thick parietal, broken anteriorly just short of the coronal suture. Basal length and height of the specimen are $68.3 \mathrm{~mm}$ and $69.7 \mathrm{~mm}$, respectively. The inferior border has a $29 \mathrm{~mm}$ length of beveled edge for the temporal. The height of this bevel is $12.3 \mathrm{~mm}$.

Externally a distinct temporal line is present $56 \mathrm{~mm}$ above the base of the temporal bevel. In the transverse plane, the curvature of this fragment is rounded evenly, lacking the more angled appearance of a modern parietal. Here there is no distinction between the top and sides of the vault. Thickness varies from $9.1 \mathrm{~mm}$ at the apex to $5.1 \mathrm{~mm}$ at the posterior inferior corner. The maximum breadth is at the approximate position of the anterior eminence. It is markedly greater than the other Vindija specimens, above the Krapina range, and 2.7 standard deviations above the mean (Table 11). Thick parietals are characteristic of much later hominids from Vindija. Two Gravettian-associated specimens from layer $\mathrm{D}, \mathrm{Vi} 210$ and $\mathrm{Vi}$ 220 , measure 7.5 and $9.6 \mathrm{~mm}$ in thickness at the anterior eminence.

Internally, the arterial impressions are indistinct. However, a broad $(6.8 \mathrm{~mm})$, deep (1.4 $\mathrm{mm}$ ) Breschet's sinus extends along the full length of the preserved anterior margin.

\section{Vi 205 Occipital fragment (Fig. 11)}

This fragment is centrally located and roughly triangular, reaching from about 18 mm superior to inion (the apex) to no more than 
M.H. WOLPOFF ET AL.

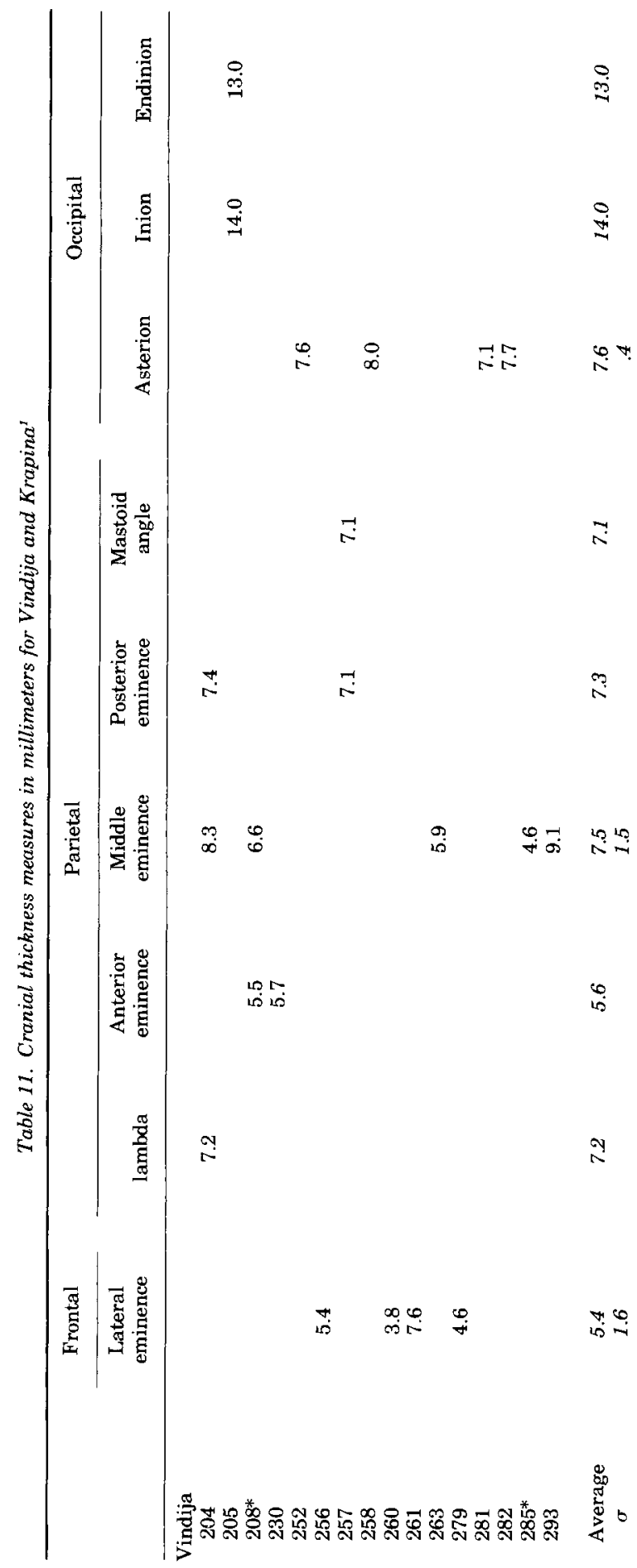




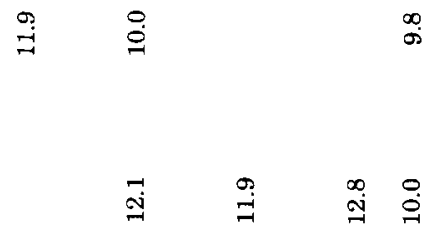

웅ำ

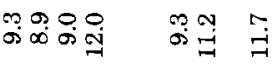

ำ

ตุำ

ซี

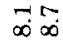

$\infty$

๙ุำ

$\stackrel{\circ}{\infty}$

$\stackrel{109}{\square}$

ํำ

$\infty \infty$

$\stackrel{\circ}{\circ}$

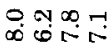

$\infty$

我员

5

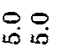

เุ่า ชุ

용

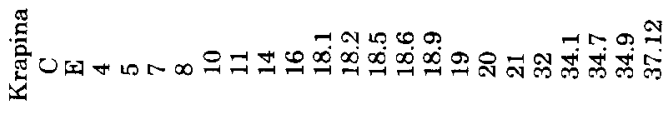

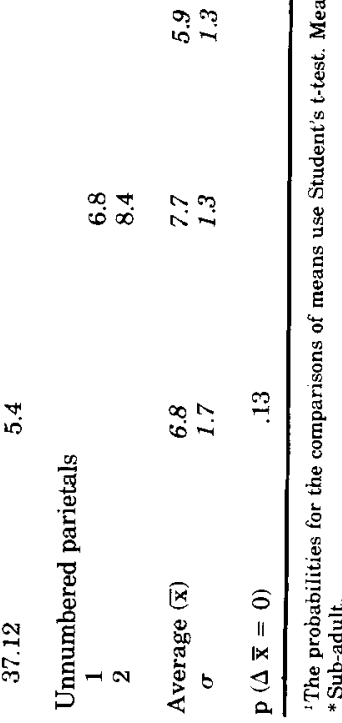


$41 \mathrm{~mm}$ inferior to it (the base). The maximum transverse breadth is $65.6 \mathrm{~mm}$. No distinct prominence marks the position of inion. The point was defined at the intersection of the midline with the low nuchal torus. The fragment has very little curvature, either sagitally or transversely. Above the torus appears a suprainiac depression, a small concavely depressed area that is characteristic of some Neandertal (and other) occiputs. The external bone table in this depression exhibits a surface pitting characteristic for similar depressions in the Krapina occipitals. There is a wide but very shallow sulcus below the low torus. In all, the region is quite similar to known Neandertal occiputs.

The inferior nuchal line is $22.5 \mathrm{~mm}$ below inion. The angle at inion formed by chords to this line and to the maximum superior extension of the fragment is $160^{\circ}$. While this is not analogous to the occipital angle, it can be duplicated on both Neandertal and more modern crania. Not enough of the occipital plane is preserved to determine whether the occipit was bunned. However, from the angulation and lack of marked curvature in the sagittal plane, it is clear that the position of inion lay well below opistocranion. Compared to Krapina specimens, the nuchal plane of Vi 205 exhibits moderate rugosity in the area for insertion of the nuchal musculature.

Internally, the sagittal and transverse crest intersection (endinion) forms a cross, and there is little apparent asymmetry of the cerebral fossae (the left may be slightly larger). The separate ridges of the inferior cruciate eminence are well divided by the base of the fragment (they are $14 \mathrm{~mm}$ apart at the break), suggesting that the break is not far short of the foramen magnum posterior border. If so, the nuchal plane of the specimen was short (probably no longer than $46 \mathrm{~mm}$ ). The superior branch of the cruciate eminence is very prominent. The position of endinion is some $12 \mathrm{~mm}$ inferior to inion.

Bone thickness at inion and endinion is marked (Table 11). In both cases the Vindija values fall above the Krapina range, about 2 standard deviations from the mean. However, the marked thickness is more a reflection of the prominence of the cruciate eminence than of an unusual cortical bone development. The minimum thickness of the occiput is $1.8 \mathrm{~mm}$.

\section{Vi 252 Right occipital fragment (Fig. 11)}

This fragment represents the superior right corner of an occiput, beginning at asterion and extending along the lambdoidal suture for 52.7 mm. Medially the fragment reaches the approximate midline position. Eroded remnants of the sagittal sinus are present, and the top of the transverse sinus is visible along the fragment's base. Externally, the nuchal line dips inferiorly as it extends medially from asterion. While there is no nuchal torus on the fragment, it shows a marked angulation at the nuchal ridge as seen in sagittal profile. Below the nuchal ridge, a marked sulcus parallels it and almost reaches asterion. Above the nuchal ridge is a roughened, shallow concave area (suprainiac depression) at least $23.7 \mathrm{~mm}$ in height and extending $22.5 \mathrm{~mm}$ laterally from the apparent midline. The nuchal ridge and transverse sinus reach the lambdoidal suture at the same point, which appears to represent asterion. If the break approximates the midline position, the occiput was rather narrow. Positioning the fragment on a cast of La Ferrassie 1 leaves the sagittal sulcus border far short of the cast's midline.

The orientation of the nuchal line and the fact that inion appears to be in a low position because of the marked inferior dip at the (approximate) midline suggests that the specimen is female. A feature supporting this suggestion is the lack of marked thickening at asterion (Table 11).

\section{Vi 258 Right occipital fragment (Fig. 11)}

The specimen, like Vi 252, also represents a right occiput in the vicinity of asterion, although less of the bone remains (the maximum height and breadth dimensions of the fragment are $38 \mathrm{~mm} \times 41 \mathrm{~mm}$ ). The morphological details preserved are similar to those of $\mathrm{Vi} 252$, but the individuals are far from identical.

The fragment is thicker (Table 11) at asterion, and the difference is even greater medially. The nuchal line is in a higher position, relative to the preserved comparable landmarks. For instance, no transverse sinus is preserved, showing that the nuchal line and the sinus do not reach the lambdoidal suture at the same position. Moreover, parallel orientation of the lambdoidal sutures of $\mathrm{Vi} 258$ and $\mathrm{Vi}$ 252 shows that, as it extends toward the midline, the nuchal line of Vi 258 curves superiorly prior to its less marked inferior curvature. The sulcus inferior to the nuchal line does not seem as pronounced in Vi 258. Enough remains to show that Vi 258 does not represent the same individual as Vi 205.

\section{Vi 281 Right occipital fragment: $\mathbf{G}_{3}$}

The specimen consist of a fairly flat nuchal plane fragment including asterion, $17.6 \mathrm{~mm}$ of 
lambdoidal suture, and $39.3 \mathrm{~mm}$ of occipitomastoid suture. It is roughly rectangular in shape (asterion is at one of the corners); in its approximate anatomical position, the anterior-posterior length (a diagonal of the rectangle) is $46.6 \mathrm{~mm}$ and the breadth is $56 \mathrm{~mm}$. The inferior nuchal line can be distinguished toward the bottom of the fragment, approximately $30 \mathrm{~mm}$ from asterion as measured along the occipitomastoid suture. Since the transverse sinus does not appear endocranially, it must reach the lambdoidal suture above asterion. The nuchal line is correspondingly in a high position since it does not appear on the fragment. Thickness at asterion is the smallest at Vindija (Table 11) and lies 2.2 standard deviations below the Krapina mean.

\section{Vi 282 Right occipital fragment: $\mathrm{G}_{3}$}

This specimen includes asterion and $32.5 \mathrm{~mm}$ of lambdoidal suture, extending $52.2 \mathrm{~mm}$ medially. Externally, the nuchal ridge is less pronounced than in Vi 252 and Vi 258, and the sulcus inferior to it is less distinct. Like these specimens, the nuchal ridge of $\mathrm{Vi} 282$ reaches the lambdoidal suture at asterion. In similar orientation there is the same superior curvature as in $\mathrm{Vi} 258$. In both of these inion was probably higher than its position in Vi 252. At $46.6 \mathrm{~mm}$ medial to asterion, the lateral portion of what appears to be a concave depressed area above the nuchal ridge begins. The suprainiac concavity is deeper than in either Vi 205 or Vi 252 and exhibits the same characteristic pitting. Another difference is in the shape of the lambdoidal suture above asterion. Instead of forming a fairly straight line, the suture path arcs over about one-quarter the circumference of a circle, beginning its direction laterally and ending (at the break) almost anteriorly.

Internally, the transverse cruciate eminence spans the breadth of the fragment, reaching the lambdoidal suture at asterion as in Vi 252. Thickness at asterion (Table 11) is intermediate at Vindija but below the Krapina range and well below the mean.

Summary. The fragmentary cranial vault remains provide some limited information about vault form in the Vindija hominids. No specimen reveals the pattern of occipital bunning and lambdoidal flattening that is common in the western European Neandertals. However, the occiputs with the relevant area preserved exhibit a suprainiac depression-a feature common in European Neandertals, but contra Santa Luca (1978), not unique to them (for instance, Weidenreich reported it in the
Solo sample (1951)). There is some evidence of reduced occipital breadth. Average vault thickness is reduced compared with the Krapina average. The parietal thickness reductions are more pronounced posteriorly, and the greatest reduction is at the asterionic region of the occipital. Finally, there is indication that the frontal squamae of some specimens ( $\mathrm{Vi}$ $224,261,262$, and 279) may be more vertical than in most western European Neandertals.

Generally, few morphological features clearly distinguish fragmentary remains of Neandertal vaults from early modern Europeans for the regions represented by these Vindija remains. Were these the only remains known from Vindija, their associations would be problematic. Interestingly, one feature said to be characteristic of Neandertals (including some of the Mousterian-associated Vindija remains) appears in the early Aurignacian-associated parietal, $\mathrm{Vi} 208$. This is the expression of Breschet's sinus paralleling the coronal border. Thus, like the mandibles, no important difference can be demonstrated between the Mousterian-associated and Aurignacian-associated fragments.

\section{Postcranial remains}

\section{Vi 203 Distal end of right fibula}

This fragment is $53 \mathrm{~mm}$ in length and preserves perfectly the distal epiphysis and inferior diaphysis. At the proximal break the cortical bone is very thin, varying from $1.7 \mathrm{~mm}$ on the medial wall to $2.5 \mathrm{~mm}$ on the posterior wall. The anterior-posterior and transverse dimensions of the shaft at this point are 13.5 and 10.1 $\mathrm{mm}$ respectively. The shaft exhibits no significant differences when compared with modern fibulae. The tendon groove is well excavated, lying $2 \mathrm{~mm}$ above the tip on the lateral malleolus. The talar articular surface makes an angle of $134^{\circ}$ with the talofibular surface, the former measuring $14 \mathrm{~mm}$ in length and $12 \mathrm{~mm}$ in breadth, while the latter is $14 \mathrm{~mm}$ in both anterior--posterior and transverse diameter. Moderate anterior flanging marks the anterior border of the tibial surface.

In all, the bone appears fairly gracile in appearance. Dimensions of the distal surface are quite small, even compared with Neandertal females (Table 12). It is likely that the Vindija fibula was smaller than either Tabun or $\mathrm{La}$ Ferrassie 2, and consequently that the body height was less than these diminutive individuals (estimated respectively as 155 and $154 \mathrm{~cm}$ by Genoves (1967) regression applied to femur length). The dimensions are markedly smaller than the Kiik Koba male. 
TABLE 12. Measurements of fibula length and of the distal articular surface (in millimeters) taken on the original specimens

\begin{tabular}{lccc}
\hline & & \multicolumn{2}{c}{ Distal surface } \\
\cline { 3 - 4 } & $\begin{array}{l}\text { Fibula } \\
\text { length }\end{array}$ & AP & ML \\
\hline Vindija 203 & & 19.6 & 14.5 \\
Tabun 1 & & & \\
La Ferrassie 2 & 294.4 & 22.3 & 13.7 \\
Kiik Koba & 343.0 & 29.1 & 16.4 \\
\hline
\end{tabular}

Vi 209 Glenoid region and scapular spine of left scapula (Fig. 12)

This specimen preserves the glenoid fossa, lateral scapular spine, and base of the coracoid process. The coracoid is broken immediately above the glenoid fossa, and the axillary margin only extends for some $30 \mathrm{~mm}$ below the fossa. In the vertebral direction, the maximum extension of the preserved bone is $48 \mathrm{~mm}$ from the center of the fossa.

The infraglenoid tuberosity is on the dorsal edge of the axillary border, and a shallow sulcus lies ventral to it. Descending inferiorly from the tubercle, the axillary crest angles sharply ventrally, terminating this shallow sulcus some $13 \mathrm{~mm}$ below the inferior glenoid fossa border. A second, more distinctive sulcus begins in almost this same position, but dorsal to the crest. By the most inferior point on the preserved axillary border, this dorsal sulcus has broadened to $6.4 \mathrm{~mm}$, and is $1.9 \mathrm{~mm}$ depth. Thus, the axillary crest forms the ventral border of the sulcus axillaris teretis, and the morphological complex is what Stewart (1962) calls the "Neandertal type."

The glenoid fossa is shallow and relatively narrow compared with its height. The breadth/height index (Table 13) of 70 lies within the human range of 65.7-91.4 reported by Smith (1976b), but at its low end is well below the mean of 78.6. The Vindija value is about a standard deviation above the average for eight Krapina specimens. The size of the fossa is $10 \%$ greater than the Krapina average, as estimated by the area. While it is also slightly larger than the La Ferrassie female, it is smaller than the La Ferrassie and Neandertal males.

Vi 228, Vi 253, and Vi 266 Right, left, and right distal humerus fragments (Fig. 12)

It seems very unusual that the only three humerus fragments preserved are broken exactly the same way. In this case, all three
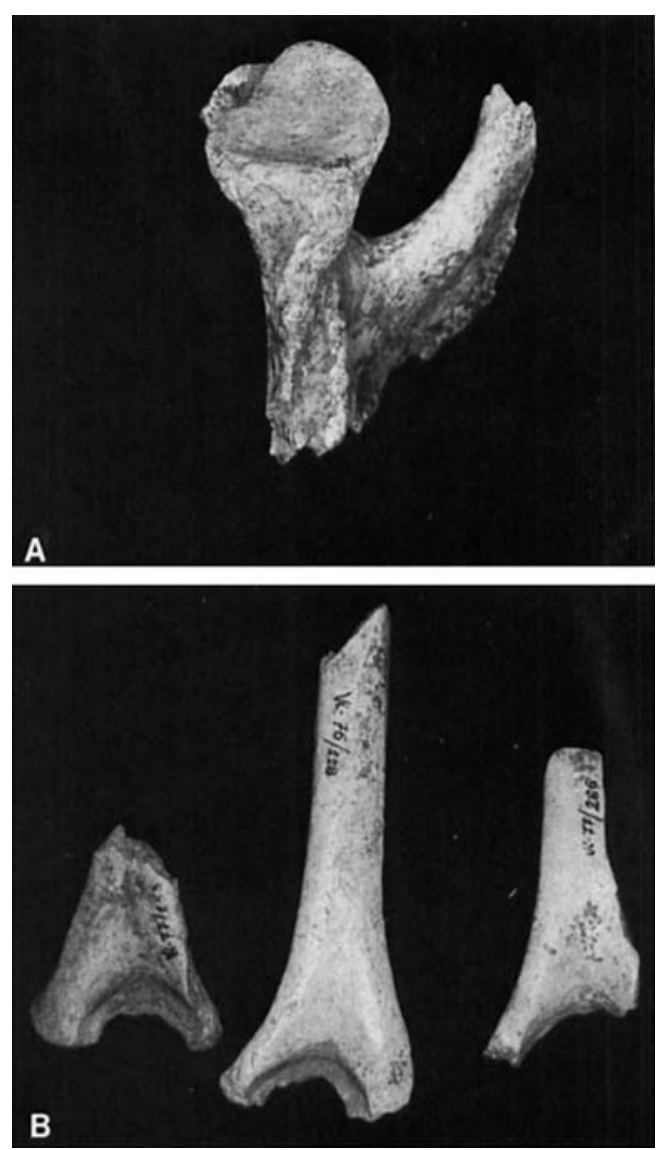

Fig. 12. Postcranial fragments from Vindija. Above is the scapular fragment Vi 209, and below are the three dista humeri Vi 253 (left), 228 (center), and 266 . Vi 228 and 253 may belong to the same individual.

retain the upper border of the olecranon fossa, while the lower border and the articular surface distal to it is lost. Because of the missing distal surface and medial epicondyle, we cannot be certain that all or any of the specimens are fully adult. The best-preserved fragment is $\mathrm{Vi}$ 228 , constituting approximately the distalmost $1 / 3$ of the bone. A low supinator ridge is preserved for some $56 \mathrm{~mm}$.

The three fragments are very similar in size, although Vi 266 is somewhat larger than the other two. For instance, the transverse breadth of the medial border of the olecranon fossa is 6.3 $\mathrm{mm}$ in Vi 228 and $7.7 \mathrm{~mm}$ in Vi 266 . The lateral border diameters for Vi 228 and Vi 253 are, respectively, 12.2 and $12.3 \mathrm{~mm}$. This pair of right and left fragments are similar in size and morphology, and might belong to the same in- 
TABLE 13. Dimensions and indices of the scapular glenoid (in millimeters) for Vindija, Krapina, and western European Neandertals ${ }^{t}$

\begin{tabular}{|c|c|c|c|c|}
\hline & \multicolumn{2}{|c|}{ Glenoid } & \multirow[b]{2}{*}{$\mathrm{B} / \mathrm{H}$ index } & \multirow{2}{*}{$\begin{array}{c}\text { Approximate } \\
\text { area }\end{array}$} \\
\hline & Height & Breadth & & \\
\hline Vindija 209 & 34.7 & 24.3 & 70.0 & 662 \\
\hline \multicolumn{5}{|l|}{ Krapina } \\
\hline 121 & 35.6 & & & \\
\hline 125 & 33.7 & 24.6 & 73.0 & 651 \\
\hline 127 & 31.4 & 21.4 & 68.2 & 528 \\
\hline 129 & 31.3 & 19.8 & 63.3 & 487 \\
\hline 130 & 38.8 & 28.4 & 73.2 & 865 \\
\hline 131 & 31.7 & 19.7 & 62.1 & 490 \\
\hline 132 & 31.4 & 21.1 & 67.2 & 520 \\
\hline 133 & 37.3 & 24.5 & 65.7 & 718 \\
\hline 134 & & 26.2 & & \\
\hline 139 & 35.1 & 21.3 & 60.7 & 587 \\
\hline Average & 34.0 & 23.0 & 66.7 & 606 \\
\hline$\sigma$ & 2.8 & 3.0 & 4.7 & 132 \\
\hline \multicolumn{5}{|l|}{ La Ferrassie } \\
\hline 1 & 42.5 & 29.8 & 70.1 & 995 \\
\hline 2 & 34.5 & 22.2 & 64.3 & 602 \\
\hline Neandertal & 37.5 & 24.4 & 65.1 & 719 \\
\hline
\end{tabular}

${ }^{1}$ All measurements taken on the original specimens.

dividual. The larger size of the bone length related measurements for the right fragment (Vi 228) conforms to the generally larger dimensions of the right distal humerus (Table 14) in Neandertal and modern people, reflecting right hand preference.

These bones indicate a rather small body size for the individuals represented. A comparison with six complete humeri of Neandertals (Table 14) indicates that the Vindija specimens are significantly smaller for both the breadth of the olecranon fossa (ofb) and the anterior-posterior diameter of the shaft just above it (for Student's t-test, the probability is .001). Indeed, the Vindija specimens are smaller than those from Krapina $(\mathbf{n}=13)$, in spite of the fact that the Krapina humeri are significantly smaller than the Würm Neandertal sample (Student's t-probability is .04).

Exactly how this reflects body size for the Vindija specimens is uncertain. However, attempts to correlate the two comparable dimensions (for the Vindija sample) with humerus length in the six Neandertals with complete humeri (Table 14) reveal that olecranon fossa breadth has a reasonable correlation $(\mathrm{r}=.724$; $\mathrm{p}(\mathrm{r}=0)=.02)$. Various regressions were attempted for this Neandertal sample in order to arrive at a formula for length estimation. Of these, the best fitting estimates (as judged by the average absolute error resulting from application of the regression to the Neandertal sample) were a power curve ( $L=8.87$ ofb $\left.^{1.05}\right)$ and a correlation surface linear regression $(\mathrm{L}=$ $12.74 *$ ofb -65.27$)$. The average absolute errors for the length estimate were, respectively, 7.4 and $7.6 \mathrm{~mm}$. Applied to the Vindija sample of two (assuming Vi 228 and Vi 253 are the same individual), these gave average estimated lengths of $245 \mathrm{~mm}$ and $255 \mathrm{~mm}$. This comes to about $80 \%$ of the average Neandertal humerus length. However, the average difference need not be this great. Five of the six $\mathrm{Ne}$ andertals with complete humeri are probably males. The Neandertal mid-sex average is $303 \mathrm{~mm}$ (virtually identical to the average humerus length for the 12 Krapina humeri as estimated by these regressions). Moreover, if the two Vindija humeri belong to the same individual, and if that individual is female, as suggested by the small humerus size, the Vindija female is about $87 \%$ the size of the La Ferrassie female. The Génoves (1967) regression for a female with a humerus of this length suggests a height of $135-138 \mathrm{~cm}$. There are too many estimates involved for this to be considered an accurate height determination, but it clearly suggests that this individual was very small.

Summary. Analysis of the postcranial remains is hampered by the small sample size and the uncertain stratigraphic position of the specimens. In our view, no taxonomically use- 
TABLE 14. Measurements of humerus length and of the olecranon fossa (in millimeters) for Vindija, Krapina, and western European Neandertal humeri, taken on the original specimens ${ }^{t}$

\begin{tabular}{|c|c|c|c|}
\hline & Length & $\begin{array}{l}\text { A-P above } \\
\text { olecranon } \\
\text { fossa }\end{array}$ & $\begin{array}{l}\text { Breadth of } \\
\text { olecranon } \\
\text { fossa }\end{array}$ \\
\hline \multicolumn{4}{|l|}{ Vindija } \\
\hline $228 \mathrm{R}$ & & 14.6 & 24.1 \\
\hline $253 \mathrm{~L}$ & & 14.0 & 24.7 \\
\hline \multicolumn{4}{|l|}{ Krapina } \\
\hline $165 \mathrm{~L}$ & & 13.8 & 26.8 \\
\hline $164 \mathrm{~L}$ & & 16.0 & \\
\hline $177 \mathrm{R}$ & & 12.0 & \\
\hline $163 \mathrm{~L}$ & & 15.3 & \\
\hline $173 \mathrm{R}$ & & 15.3 & \\
\hline $172 \mathrm{R}$ & & 14.1 & 26.7 \\
\hline $159 \mathrm{~L}$ & & 15.6 & 32.4 \\
\hline $160 \mathrm{~L}$ & & 15.7 & 31.0 \\
\hline $161 \mathrm{~L}$ & & 15.7 & 28.7 \\
\hline $162 \mathrm{~L}$ & & 16.9 & 25.2 \\
\hline $166 \mathrm{~L}$ & & 13.9 & 29.2 \\
\hline $169 \mathrm{R}$ & & 16.4 & 31.0 \\
\hline $170 \mathrm{R}$ & & 15.7 & 28.0 \\
\hline $171 \mathrm{R}$ & & 13.9 & 28.4 \\
\hline $174 \mathrm{R}$ & & & 29.3 \\
\hline $175 \mathrm{R}$ & & 14.9 & 30.5 \\
\hline $178 \mathrm{R}$ & & & 27.8 \\
\hline Neandertal R & 312 & 19.2 & 28.8 \\
\hline L & & 14.5 & 31.3 \\
\hline Regourdou R & 310 & 16.5 & 28.7 \\
\hline Lezetxiki R & 324 & 17.0 & 30.9 \\
\hline La Ferrassie $1 \mathrm{R}$ & 340 & 19.0 & 31.6 \\
\hline & & 16.2 & 33.3 \\
\hline La Ferrassie $2 \mathrm{R}$ & 287 & 16.3 & 28.3 \\
\hline La Chapelle R & 313 & 18.5 & 30.5 \\
\hline Tabun $1 \mathrm{~L}$ & 287 & 14.2 & 25.8 \\
\hline
\end{tabular}

'Note the marked side difference in Neandertal and La Ferrassie 1, reflecting right hand preference. Bone thickness (AP) just above the fossa is greater on the right side, while fossa breadth is greater on the left. The comparisons of Vi 228 and 253 reflect the same pattern, supporting the contention that these might represent the same individual.

ful features are preserved. Even the morphology of the scapular glenoid fossa and the region inferior to it reported for Vindija 209 has been observed in anatomically modern Homo sapiens samples (Smith, 1976b). Although the complex of features found in the Vindija specimens has a higher frequency in Neandertals, this complex is not unique to Neandertals, and it cannot be used as a sorting criterion.

One fact that emerges is that the (2-5) individuals represented by these remains were small. The fibula and two of the humeri are distinctly smaller than the La Ferrassie female (the distal fibula is about the size of the Tabun female). The third humerus fragment approximates the La Ferrassie female in size, and the scapular fragment is slightly larger. These comparisons only indirectly reflect height, since they are based on articular surface di- mensions of fragments. Nevertheless, even if all the individuals represented by postcranial remains at Vindija are females, and even if the humeri are not fully adult, the comparisons suggest that body size in this sample may have been smaller than in the western European Neandertals.

\section{DISCUSSION AND CONCLUSIONS}

We believe that both the Aurignacian-associated and the Mousterian-associated Vindija hominids provide important information regarding the evolution of European Neandertals and the origin of modern European populations in south central Europe. Our two main conclusions are that the Aurignacian-associated sample is not significantly different from the Mousterian-associated one, and that the Mousterian sample provides evidence of evolu- 
tionary trends within the Neandertals in the direction of the more modern populations that succeeded them.

We regard the first point with some degree of uncertainty, since there are only a few Aurignacian-associated specimens. These include the five isolated anterior teeth with provenience, the Vi 207 ramus and corpus fragment, and the Vi 208 parietal fragment. These anterior teeth are not diagnostic; their sizes fall between the Krapina average and the average for the European early Upper Paleolithic sample (Table 6), and they could be included within either range. Morphologically, the degree of lingual marginal ridge development and the marked, projecting double tubercle on the $I^{1}$ more closely resemble the $\mathrm{Ne}$ andertals, but again the difference between the Neandertal and the early modern European samples is in frequency rather than in type.

The Vi 207 mandibular fragment is a small specimen compared with Neandertals. Yet, the same can be said for the Mousterian-associated Vindija mandibles. Vi 207 shares a low posterior corpus, a relatively broad ramus, a horizontal-oval form in the mylohyoid sulcus/mandibular foramen, and a posterior position for the ramus relative to the $M_{3}$ with these other specimens. To the extent that these features are diagnostic, Vi 207 is like Neandertals. More specifically its small size, low posterior corpus, and relatively broad ramus are particularly characteristic of the Vindija Neandertals.

The juvenile parietal fragment, Vi 208, has only a few diagnostic features. Moreover, comparative material for the early Upper Paleolithic is virtually nonexistent. The distinct double-branched form of Breschet's sinus and the appearance of two Pacchioni's fossae resemble the condition reported for western European Neandertals (Heim, 1976).

At the least, we feel justified in concluding that no dramatic morphologic or metric distinctions separate the Aurignacian-associated sample from the earlier Mousterian-associated one.

Evidence for the evolutionary trends reflected in the Vindija Mousterian-associated sample and the generally intermediate position of this sample between the earlier Krapina $\mathrm{Ne}$ andertals and the sample associated with the early European Upper Paleolithic is much more firmly established. While there is somewhat more overlap, an intermediate position can also be established in comparison with the western European Neandertal sample.

It is clear from the foregoing descriptions that the hominid remains from level $\mathrm{G}_{3}$ at Vin- dija exhibit a total morphological pattern that we regard as unquestionably Neandertal. The major anatomical characteristics supporting this classification are detailed in the descriptive section and include (1) the dimensions and morphology of the supraorbital torus; (2) the relative size of the incisor sockets; (3) the morphology and overall configuration of the cranial vault; (4) the form of the axillary border of the scapula; and (5) the morphology of the mandible and anterior placement of the toothrow. No feature or combination of features for these Vindija hominids is inconsistent with their classification as Neandertals. They do, however, exhibit certain characteristics which, although still within the Neandertal range, give the impression of being nearer to the early modern European condition than are most other Neandertals. The Vindija specimens exhibit reduced midfacial prognathism, reduced facial size, thinner and less projecting supraorbital tori, a tendency toward smaller anterior teeth (especially in breadths), more pronounced mental eminences, smaller mental foramina, more acute symphyseal angles, posterior and basal vault thinning, possibly higher foreheads, and they seem to lack occipital bunning. All of these features strongly suggest that the Vindija Neandertals vary more in the direction of modern Europeans than any other series of European Neandertal finds. This is particularly evident in comparisons between the Krapina and Vindija samples, which very clearly indicate distinctive patterns of morphological change toward the modern condition from early to late Neandertal samples in south central Europe. Thus, we contend that the $\mathrm{Ne}$ andertals of this region express distinct evolutionary trends in the specific direction of more modern populations.

That some of the "advanced" characteristics of the Vindija remains might be due to a possible preponderance of females and juveniles in the sample is possible. Also, even though the fragmentary nature of the Vindija remains makes it impossible to be certain of body size, it appears that the Vindija hominids seem to be on the small end of the Neandertal size range. Thus, it is possible that smaller body size may have resulted in a less pronounced expression of certain Neandertal characteristics in the Vindija sample. We do not believe, however, that size or sex can fully account for the Vindija morphology. Known small female Neandertals-for example Gibraltar 1, Krapina C, Malarnaud, Tabun I, and others-are only slightly larger and often are smaller than comparable Vindija specimens, and yet they show 
no more indication of the early modern condition than do the larger Neandertals. For example, the index of thickness between the lateral and mid-orbital points on the supraorbital torus of Gibraltar 1 is 0.86 , which is above the Krapina mean and above the Vindija $\mathrm{G}_{3}$ mean of 0.81 (Table 3). Similarly, the Malarnaud mandible, one of the smallest western European Neandertal mandibles, has one of the highest symphyseal angles $\left(100^{\circ}\right)$ in the entire sample. None of the faces of skeletally small Neandertals (such as La Ferrassie 2 or Tabun I) have as narrow a nose or as small a lower face as the Vindija maxillae would indicate, though the Vindija specimens match them in certain other dimensions. Based on these examples, it appears unlikely that the modern-like aspects of the Vindija $G_{3}$ hominids can be purely attributed to allometric or other effects of size and/or sexual dimorphism. Furthermore, the reduced supraorbital torus, reduced facial size and prognathism, emergence of the mental eminence and of a more vertical symphysis, smaller anterior teeth, and alteration of the vault architecture make good sense as an evolving complex relating to reducing functional stress in the facial region. Thus, at this time, the most reasonable explanation for these characteristics in the Vindija hominids is simply that they reflect an evolutionary trend in the direction of modern Europeans, when compared with other known European Neandertal samples. We believe this contradicts the claim of a "relatively constant physical pattern" for the European Neandertals made recently by Trinkaus and Howells (1979).

Such an evolutionary trend might not be unexpected given the probable chronological position of the Vindija $\mathrm{G}_{3}$ sample, the late portion of the lower Würm stadial as defined by Musil and Valoch ('66), if one accepts the proposal that the late Neandertals of south central Europe were in the process of evolving into the early Upper Paleolithic-associated populations that followed them in time, such as those represented by Mladeč, Brno, and Předmostí. The generally archaic if not specifically Neandertal-like morphology common in these Upper Paleolithic samples does not argue against this proposal.

The alternative explanation for the observable sequence in south central Europe would regard the evolutionary trends as reflecting the influx of more modern populations from "somewhere in the east." This hypothesis has probably been best expressed recently by Trinkaus and Howells (1979), and Howells (1974, 1975), and has been consistently supported by Vandermeersch (1977). Theoreti- cally, we agree that peristent geneflow probably could not be distinguished from evolutionary change due to selection. However, we are troubled by the former explanation for several reasons, not the least of which is the absence of archaeological data suggesting the influx of populations from other regions during this timespan (Valoch, 1968), which is required by the migration model presented by Howells (1976).

In proposing that geneflow did not play an important role in the immediate origin of modern European populations, we do not wish to discount or discredit the importance of migration in human evolution (again contra Howells, 1976). The idea that this portion of the European sequence can be explained by the action of selection on existing populations does not result from an "antimigration assumption." Rather, it rests on archaeological and morphological grounds, and acts as a specific explanation for the case discussed. Howells proposes that the European Neandertals should be regarded as a test case in the general conflict between a migrational and local evolutionary explanation of Modern Homo sapiens origins. We believe this proposal is more eurocentric than is necessary and point to the evidence for regional continuity between archaic and modern Homo sapiens in other areas as supplementary support for our analysis of the European situation. The fact is that recognizable sequences in Sub-saharan Africa (Omo Kibish/ Laetolil $\rightarrow$ Border Cave/Florisbad), North Africa (Jebel Irhoud $\rightarrow$ Dar-eš-Soltane $\rightarrow$ Afalou/Singa), Mainland China (Choukoutein $\rightarrow$ Mapa/Dali $\rightarrow$ Liujiang/(Upper Cave), and Australasia (Sangiran Homo erectus $\rightarrow$ Sambungmachen $\rightarrow$ Solo $\rightarrow$ Kow Swamp/Mungo) show parallel, distinct developments reflecting local continuity and extend well before the appearance of modern Homo sapiens populations. A general migratory scheme must involve regions other than Europe and is required to account for the migrants taking on attributes of the local archaic sapiens populations they replace in a variety of different places. We find such a model to be unacceptable as a general explanation for the worldwide appearance of modern Homo sapiens populations; although it might apply to some local regional sequences, in our view, south central Europe is not one of these. Moreover, because of the geographic position of this region within Europe, we question whether migration was an important factor in the evolutionary changes taking place anywhere in Europe at this time $(50,000-30,000$ years ago). 
We recognize that geneflow need not require migration. However, it does require the presence of populations outside of Europe with distinctive European features. We believe that the hypothesis of significant genetic input from "somewhere to the east" can be rejected on purely morphological grounds, because the required populations cannot be found. "Somewhere to the east" has come to mean the Levant, since in this region early modern populations are known to be associated with Mousterian industries. These populations, best represented at Skhul and Qafzeh, are the presumed source of the more modern genetic material. What bothers us about this is our observation that these samples simply do not look particularly European in the sense that samples from Mladeč, Předmostí, Velika Pećina, and Brno do. We are also concerned by the fact that while neither of these important Near Eastern sites have been unambiguously dated, there are some indications that one or both may be later than the Vindija $\mathrm{G}_{3}$ hominids, if not actually contemporary with Mladeć, Brno, and Velika Pećina (Smith, 1977; Bada and Helfman, 1976; Trinkaus and Howells, 1979; Jelínek, 1969). Furthermore, we wonder how the more modern hominids of the Near East, associated with the Mousterian, could be ancestral to the Neandertal-like hominids from Vindija, associated with the early Upper Paleolithic, even if the relative dates allowed this potential relationship. Actually, comparing these different regions, we conclude that there need be no direct relation between hominids and industries. Just as it has become demonstrably unclear exactly who "Mousterian Man" refers to, a similar ambiguity may erode the utility of "Upper Paleolithic Man" (a point also raised by Stringer, '74). The newly discovered St. Césaire specimen establishes the presence of Neandertals associated with the European Upper Paleolithic; the resulting juxtapositions render a Near Eastern ancestry for the early modern Europeans (whenever they finally appear) even more improbable.

And in answer to the question of which earlier populations do appear European, we propose that the Neandertals themselves make the best candidates. This is especially clear in the facial features shared by early modern and late archaic Homo sapiens in the region, including the facial angle, the very marked nasal prominence and high nasal angle, and the anterior projection of the middle and upper face. These are features that are found persistently in the Würm populations from Europe and nowhere else in the world. Such a special relationship is also suggested by the presence of Neandertal characteristics in the vaults of numerous European early Upper Paleolithic specimens, as documented by Schwalbe (1906), Szombathy (1925), Matiegka (1934), and others. These include vault shape and proportions, the persistent appearance of bunning in many specimens, central supraorbital development, occipital elongation, and small mastoids. The females of this early sample, for instance, are robust enough to resemble the males of populations that followed them in time.

Finally, there is the question of why this relationship is not universally accepted. We believe that there are two main reasons for this; the choice of the early modern Homo sapiens sample that is usually compared with Neandertals, and the tendency to treat all European Neandertals as a single relatively invariant unit. We regret that some of the most important early modern European specimens such as the Mladeč males have consistently been ignored in most analyses proposing to examine the relationship between modern Europeans and $\mathrm{Ne}$ andertals [for instance, Corruccini (1976), most of Stringer's (1974) analyses, Howells' 1975 discussion, and Stringer's multivariate analysis presented by Trinkaus and Howells, 1979], while the females from this timespan are commonly included. We regard this problem, as well as the lack of appreciation of the variability and the evolutionary trends in the European Neandertals, as the main factors underlying the denials of a Neandertal ancestry for Europeans.

To the contrary, we are of the opinion that the Upper Pleistocene hominids of south central Europe represent an in situ evolutionary series, unbroken by the influx of fully developed modern types. We see the origin of modern Europeans, at least as documented in south central Europe, as a product of the evolutionary transition from Neandertals giving renewed support to Hrdlička's concept of "the Neanderthal phase of man" as it was originally applied in Europe.

\section{ACKNOWLEDGMENTS}

The authors would like to express their gratitude to the following persons and institutions for access to material utilized for comparison in this report: H. Bach, Schiller University (Jena); I. Crnolatac, Geological-Paleontological Museum (Zagreb); R. Feustel, Thüringen Museum for Early and Pre-history (Weimar); J.-L. Heim, Museum of Man (Paris); J. Jelíinek and K. Valoch, Moravian Museum (Brno); A. Leguebe, Royal Institute of Natural Sciences (Brussels); 
M.-A. and H. DeLumley, Laboratory of Human Paleontology and Prehistory (Marseille); C. Stringer, British Museum of Natural History (London); J. Szilvássy, Natural History Museum (Vienna); M. Thurzo, National Museum (Bratislava); T. Toth, Historical-Natural Museum of Hungary (Budapest); B. Vandermeersch, University of Paris; E. Vlček, National Museum (Prague); and U. Yakamov, Moscow State University. Sincere thanks are also extended to the following individuals for various forms of assistance: E. Trinkaus, J. Hinton, G.C. Ranyard, and M.O. Smith.

This work was supported by NSF grants BNS 75-21756 and BNS 76-87829, grants from the National Academy of Sciences, a Faculty Research grant from the University of Tennessee, and grants from the Council for Scientific Work of Socialist Republic Croatia, and the University of Zagreb.

\section{LITERATURE CITED}

Bada, JL, and Helfman, PM (1976) Application of amino acid racemization datings + in paleoanthropology and archaeology. In: Dations Absolutes et Analyses Isotopique en Prehistoire: Methods et Limites. (Colloque I. Union Int. Sei. Prehist. Protohist., 9th Congress). Paris, Centre Nationale de la Recherche Scientifique.

Brace, CL (1979) Krapina, "Classic" Neanderthals, and the evolution of the European face. J. Hum. Evol., 8:527-550.

Brose, DS and Wolpoff, MH (1971) Early Upper Paleolithic man and late Middle Paleolithic tools. Am. Anthropol., 73:1156-1194.

Corruccini, RS (1976) Calvarial shape relations between fossil hominids. Yearbook Phys. Anthropol., 18:89-109.

Cunningham, DJ (1908) The evolution of the eyebrow region of the forehead, with special reference to the excessive supraorbital development in the Neanderthal race. Trans. R. Soc. Edinb., 46:283-311.

Endo, B (1966) Experimental studies on the mechanical significance of the form of the human facial skeleton. J. Fac. Sci. Univ. Tokyo, sec. V (Anthropol.), 3:1-106.

Frayer, DW (1978) Evolution of the Dentition in Upper Paleolithic and Mesolithic Europe. U. Kansas Publ. Anthropol., 10.

Genoves, $\mathrm{S}$ (1967) Proportionality of the long bones and their relationship to stature among Mesoamericans. Am. J. Phys. Anthropol., 26:67-78.

Gorjanović-Kramberger, D (1906) Der Diluviale Mensch von Krapina in Kroatien. Wiesbaden, Kreidels.

Gorjanović-Kramberger, D (1913) Zivot i kultura diluvijalnoga čovjeka iz Krapine ur Hrvatskoj. Djela Jugosl. Akad. Znan. Umjetn., 23: 1-54.

Heim, J-L ( 1976) Les Hommes Fossiles de la Ferrassie. Tome I. Arch. Inst. Paleontol. Hum. Mem., 35.

Howells, WW (1974) Neander thals: names, hypotheses, and the scientific method. Am. Anthropol., 76:24-38.

Howells, WW (1975) Neanderthal man: facts and figures. Yearbook Phys. Anthropol., 18:7-16.

Howells, WW (1976) Explaining modern man: evolutionists versus migrationists. J. Hum. Evol, 5:477-496.

Jelinek, J (1969) Neanderthal man and Homo sapiens in Central and Eastern Europe. Current Anthropol., 10: 475-503.
Kallay, J (1970) Komparativne napomene o čljustima krapinskih praljudi s obzirom na položaj medu homonidima. In: Krapina: 1899-1969 M. Malez (ed), Jugoslavenska akademija znanosti i umjetnosti, Zagreb. pp. 153-164.

Klaatsch, H, and Hauser, O (1910) Homo Aurignacensis Hauseri. Praehist. Z., 1:273-338.

Lumley, MA de (1973) L'Homme de l'Hortus. In: Anténéandertaliens et Neándertaliens du bassin Méditerranéen occidental europeén. Et. Quatern, 2:311-550.

Malez, M (1975) Die Höhle Vindija-eine neue Fundstelle fossiler Hominiden in Kroatien. Bull, Sci. (Yugoslavie), 20:139-140.

Malez, M (ed) (1978a) Krapinski pračovjek i evolucija hominida. Jugoslavenska akademija znanosti i umjetnosti, Zagreb.

Malez, M (1978b) Novija instraživanja paleolitika u Hrvatskom Zagorju. Arheološka istraživanja u Sjeverozapadnoj Hrvatskoj, Zagreb, Hrvatsko arheološko društvo. pp. 9-69.

Malez, M (1978c) Populacije neandertalaca i neandertalcima sličnih ljudi u Hrvatskoj. In: Krapinski pračovjek i e volucija hominida. M. Malez, (ed). Jugoslavenska akad-emija znanosti i umjetnosti, Zagreb. pp. 331-371.

Malez, M (1978d) Fossile Menschen aus Norwestkroatien und ihre quarärgeologische, paläontologische und paläolithische Grundlage. Coll, Anthropol., 2:29-41.

Malez, M, and Rukavina, D (1975) Krioturbacijske pojave u gornjopleistocenskim naslagama pećine Vindije kod Donje Voće u sjeverozapadnoj Hrvatskoj. Rad Jugosl. Akad. Znan. Umjetn, 371:245-265.

Malez, M, and Rukavina, D (1979) Položaj naslaga spilje Vindije u sustau članjenja Kvartara šireg podurčja Alpa. Rad Jugosl. Akad. Znan. Umjetn. 383:187-218.

Malez, M, Smith, FH, Radovčić, J, and Rukavina, D (1980) Upper Pleistocene hominids from Vindija, Croatia, Yugoslavia. Current Anthropol., 21:365-367.

Matiegka, J (1934) Homo Předmostensis. Fosilni Clovek z Předmostí na Moravě. I. Lebky. Prague, Česká Akademie Věd a Umění.

Moss, ML, and Young, RW (1960) A functional approach to craniology. Am. J. Phys. Anthropol., 18:281-292.

Movius, H (1960) Radiocarbon dates and Upper Paleolithic archaeology in Central and Western Europe. Current Anthropol., 1:355-391.

Musil, R, and Valoch, K (1966) Beitrag zur Gliederung des Würms in Mitteleuropa. Eiszeitalter u. Gegenwart, 17:131-38.

Olivier, G (1969) Practical Anthropology. Charles C. Thomas, Springfield, Illinois.

Oyen, OJ, Rice, RW, and Cannon, MS (1979) Browridge structure and function in extant primates and Neanderthals. Am. J. Phys. Anthropol., 51:83-96.

Rukavina, D (1978) Paleoklimatološki i paleoekološki odnosi u gornjem pleistocenu Hrvatskog Zagorja. In: Krapinski pročovjek i evolucija hominida. M. Malez (ed). Jugoslavenska adademija zhanosti i umjetnosti. Zagreb. pp. $319-330$.

anderthal-like fossils. J. Hum. Evol., 7:619-636

Sehwalbe, G (1906) Studien zur Vorgeschichte des Menschen. Schweizerbartsche, Stuttgart.

Smith, FH (1976a) A fossil hominid frontal from velika Pećina (Croatia) and a consideration of Upper Pleistocene hominids from Yugoslavia. Am. J. Phys. Anthropol., 44:127-134.

Smith, FH (1976b) The Neandertal Remains from Krapina: A Descriptive and Comparative Study. University of Tennessee Department of Anthropology, Report of Investigations, 15

Smith, FH (1977) On the application of morphological "dating" to the hominid fossil record. J. Anthropol. Res., 33:302-316. 
Smith, FH (1978) Evolutionary significance of the mandibular foramen area in Neandertals. Am. J. Phys. Anthropol., 48:523-532.

Sokal, RR, and Rolf, FOJ (1969) Biometry. W.H. Freeman, San Francisco.

Stewart, TD (1962) Neanderthal scapulae with special attention to the Shanidar Neanderthals from Iraq. Anthropos, 57:779-800.

Stringer, CB (1974) Population relationships of later Pleist cene hominids: A multivariate study of available crania. $J$. Arch. Sci., 1:317-342.

Szombathy, J (1925) Die diluvialen Menschenreste aus der Fürst-Johanns-Höhle bei Lautsch in Mähren. Eiszeit, $2: 1-26,73-95$.

Tappen, NC (1978) The vermiculate surface pattern of brow ridges in Neandertal and modern crania. Am. J. Phys. Anthropol., 49:1-10.

Trinkaus, E, and Howells, WW (1979) The Neanderthals. Sci. Am., 241:118-133.

Valoch, K (1968) Evolution of the Paleolithic in Central and Eastern Europe. Current Anthropol., 9:351-390.
Vandermeersch, B (1977) Les Hommes Fossiles de Kafzeh (Israel). 2 Volumes Doctoral Thesis in Natural Sciences, Universitie Pierre dl et Marie Curie, Paris.

Vlček, E (1967) Die Sinus frontales bei europäischen Neandertalern. Anthropol. Anz., 30:166-189.

Vlček, E (1970) Étude Comparative onto-phylogénétique de l'enfant du Pech-del'Azé par rapport a d'autres enfants Néandertaliens. In: L'Enfant de Pech de l'Azé. Arch. Inst. Paléontol. Hum. Mem., 33:149-178.

Weidenreich, F (1936) The mandibles of Sinanthropus pekinensis: a comparative study. Paleontol. Sinica, ser. D, no. 7 .

Weidenreich, F (1951) Morphology of Solo man. Anth. Pap. Am. Mus Nat. Hist., 43:205-290.

Wolpoff, MH (1975) Some aspects of human mandibular evolution. In: Determinants of Mandibular Form and Growth. J.A. McNamara, Jr. (ed.) Ann Arbor, Center for Human Growth and Development, pp. 1-64.

Wolpoff, MH (1979) The Krapina dental remains. Am. J. Phys. Anthropol, 50:67-113.

Wolpoff, MH (1980) Paleoanthropology. Knopf, New York. 